CHAMBERLAIN CREEK ELK-LOGGING STUDY

Progress Report for the 1980 Field Season

\author{
School of Forestry \\ University of Montana \\ March 27, 1981
}

Submitted to the

Bureau of Land Management
By: C. Les Marcum
W. Daniel Edge

SD 538.2 . $\mathrm{M} 9$ M37 1981 

JOB II-D

CHAMBERLAIN CREEK STUDY

Progress Report for the Period January 1 - December 31, 1980

\section{INTRODUCTION}

Generally, the objectives of this study are to describe elk distribution and elk use of several available environmental factors before, during and after logging in Chamberlain Creek in western Montana. The study has been conducted by personnel of the School of Forestry, University of Montana since 1975, under contract to the Bureau of Land Management. Additional funding is provided through the McIntire-Stennis Federal Forestry Program administered through the Móntana Forest and Conservation Experiment Station, School of Forestry, University of Montana; and by the Timber and Land Department of the Burlington Northern Company.

During 1980, the Burlington Northern cutting units in and near the northeast part of the core study area (CSA) were logged. Because of poor lumber market conditions, work was not started on the BLM Chamberlain Creek Sale until early December, when spur road construction was initiated. Spur roads were also constructed on the west side of the CSA during the summer and fall of 1980. Road construction and logging will continue during 1981 .

Graduate student John F. Lehmkuhl left the project in April 1980 to take a position with the U.S. Forest Service in Albuquerque, New Mexico (Region III). His thesis, covering results obtained from 1977, 1978 and 1979 telemetry data, will be completed by April 1981. The telemetry work was continued by graduate student W. Daniel Edge, who began his studies in April 1980.

\section{STUDY AREA}

\section{Location and Physiography}

The study area is located in the northern Garnet Mountains of western Montana approximately 35 miles $(56 \mathrm{~km})$ east of Missqula (Fig, 1 ). Radio-collared elk have used an area of approximately $72 \mathrm{mi}^{2}\left(186 \mathrm{~km}^{2}\right)$. The core study area (CSA), where logging is planned, is 5800 acres (2350 ha) in size.

Elevations range from approximately 3800 feet $(1160 \mathrm{~m})$ along lower Elk Creek to 6860 feet $(2090 \mathrm{~m})$ at Chamberlain Mountain. Elevations within the CSA range from 4400 feet $(1340 \mathrm{~m})$ to 6800 feet $(2070 \mathrm{~m})$. 



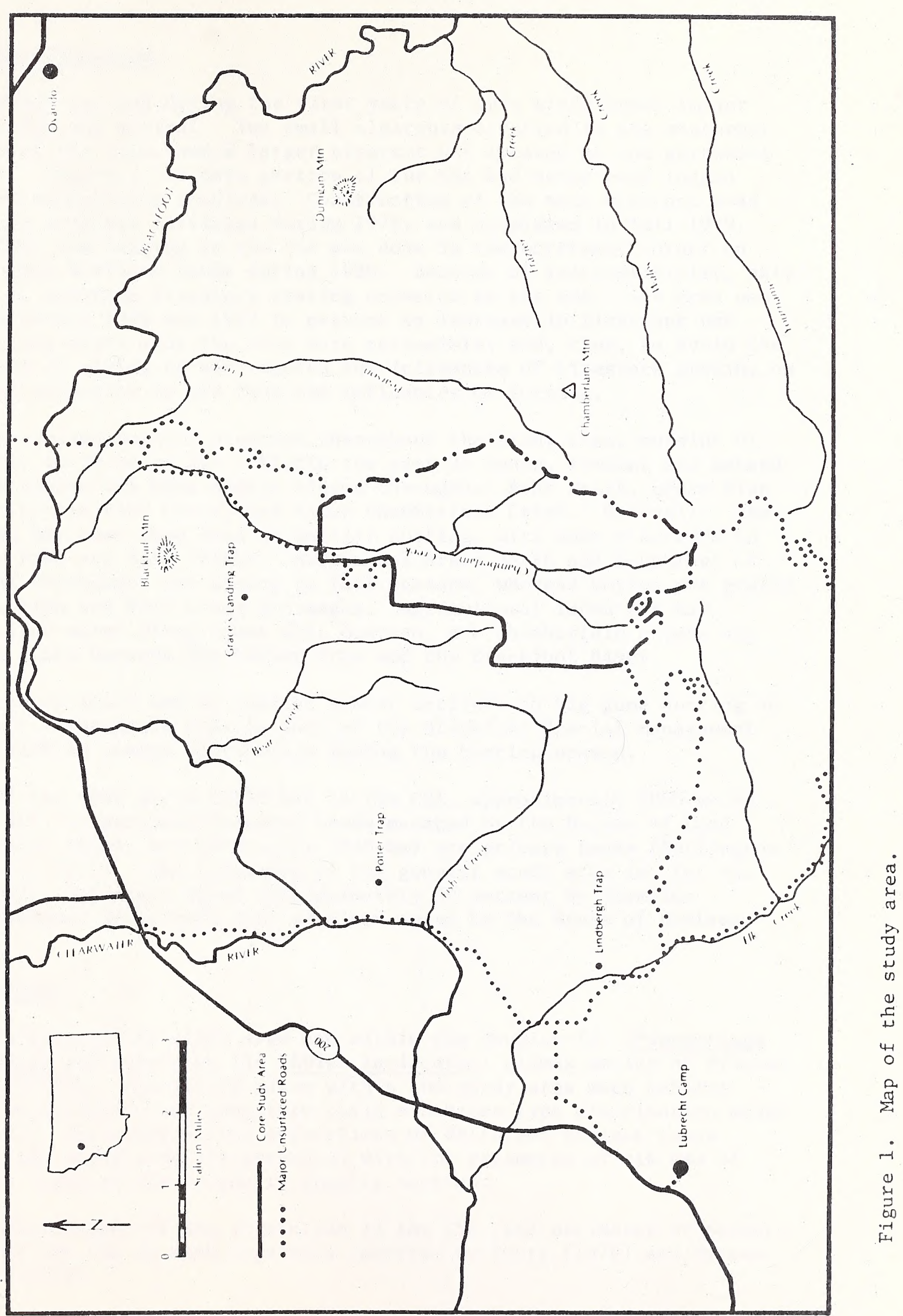



Land-Use Practices

Prior to, and during the first years of this study human impact on the CSA was minimal. Two small clearcuts occurred in the southwest corner of the area, and a larger clearcut was located at the northwest corner. However, the main portion of the CSA had never been logged and was essentially roadless. Construction of the main contract road into the area was initiated during 1978, and completed in fal1 1979. The first new logging in the CSA was done in the northeast corner on Burlington Northern lands during 1980. Because of inaccessibility, only light to moderate livestock grazing occurred in the CSA. The area was fenced during 1976 and 1977 to prevent an increase in livestock use as logging roads made the area more accessible; and, thus, to avoid the problems of trying to distinguish the influences of 1 ivestock grazing on habitat selection by elk from the influences of logging.

Extensive logging occurred throughout the study area, outside of the CSA, 40-50 years ago. Within the past 20 years, remnant and secondgrowth timber has been widely logged throughout Bear Creek, upper Fish Creek, Little Fish Creek, and Lower Chamberlain Creek. Generally, the logging has been some form of partial cutting, with some clearcuts in Little Fish and Bear creeks. Cattle use areas north and southwest of the CSA throughout the spring to fall seasons, whereas horses are grazed in the Fish and Bear creek drainages. Agricultural lands for hay production occur along lower Elk, Pearson, and Chamberlain creeks and on the flats between the Potter Trap and the Blackfoot River.

Recreational use is limited almost entirely to big game hunting in the fall. The study area is part of the Blackfoot Special Management Area which is closed to vehicles during the hunting season.

Of the 5800 acres ( 2350 ha) in the CSA, approximately 4000 acres (1620 ha) are National Resource Lands managed by the Bureau of Land Management (BLM), and 1800 acres ( 730 ha) are private lands (Burlington Northern, Inc.). The remainder of the general study area is, for the most part, privately owned (approximately 80 percent by Champion International Co.), with some sections owned by the State of Montana.

\section{Vegetation}

Forests of the study area are within the Douglas-fir (Pseudotsuga menziesii) and subalpine fir (Abies lasiocarpa) climax series of Pfister et a1. (1977). Almost 450 sites within the study area were habitat typed by elevation and aspect to build a habitat type distribution model (Fig. 2). Estimates of the proportions of different habitat types within the study area are presented with the estimates of elk use of habitat types in the telemetry results section.

Descriptions of the vegetation in the CSA, and estimates of proportions of the CSA in each type were reported by Scott (1978) and Marcum et al. (1979). 



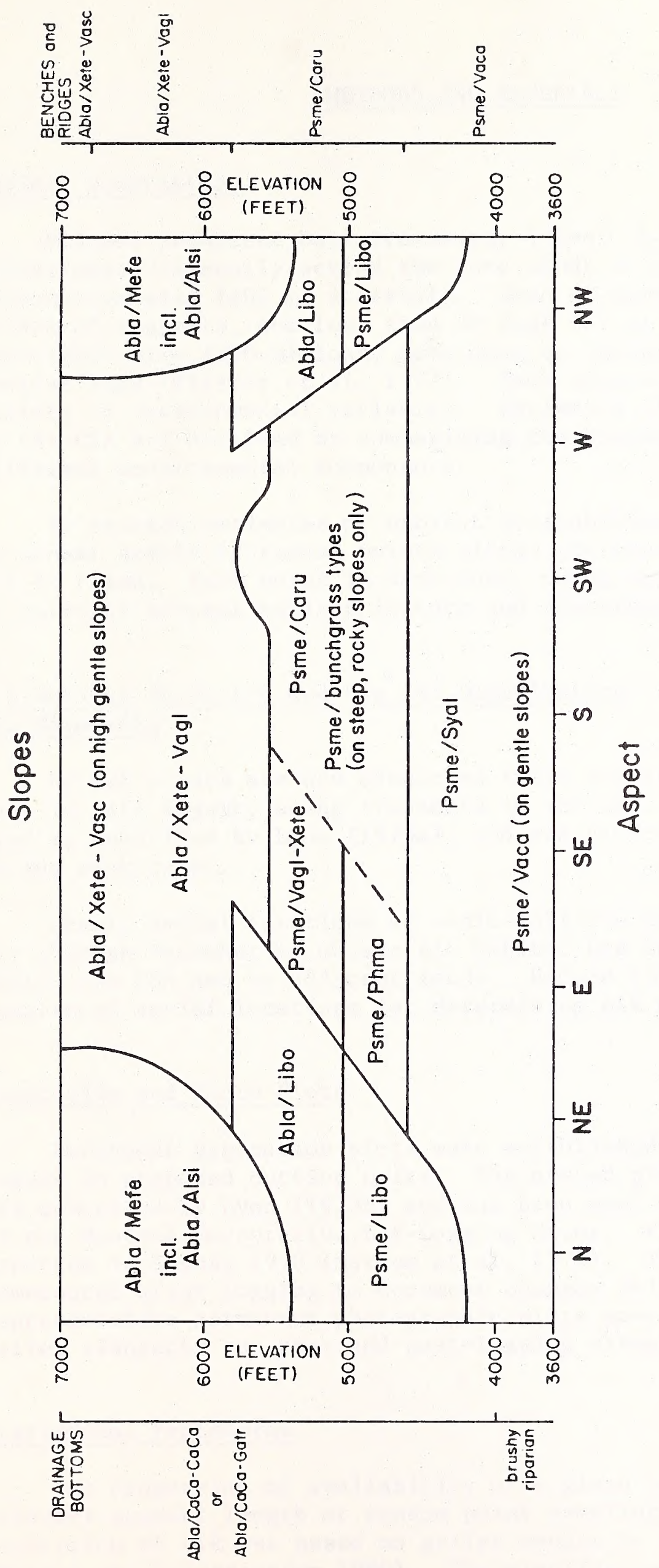

O 


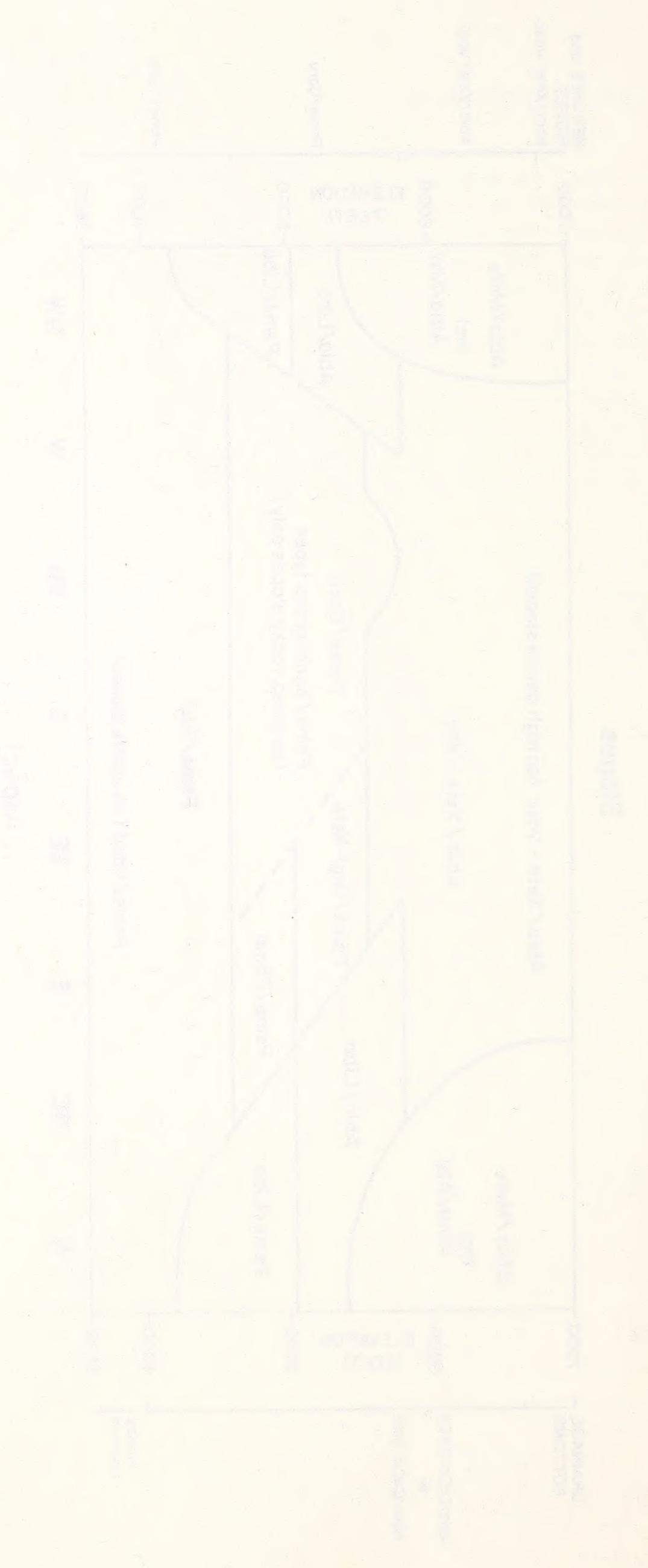


METHODS AND MATERIALS

Habitat Description

Fifteen permanent belt transects, 4 feet $(1.2 \mathrm{~m})$ wide, were established diagonally across the core study area (CSA) at approximately one-quarter mile $(400 \mathrm{~m})$ intervals. Each transect was divided into a series of segments, not less than 50 feet $(15 \mathrm{~m})$ and not greater than one-eighth mile $(200 \mathrm{~m})$ long, according to changes in cover and/or habitat type (Pfister et al. 1977). Each segment is categorized by a variety of environmental variables. Estimates of habitat availability in the CSA are obtained by summarizing the transect segments by the different environmental components.

To provide estimates of habitat availability for telemetry studies, an annual sample of random points within the area used by radio-collared elk is taken. Each point is described, using maps and aerial photographs, in terms of several habitat factors and disturbance relationships.

\section{Elk Habitat Selection and Use and Distribution} and Movements

Pellet counts are now conducted twice yearly, once in late June and once in late August, along transects in the CSA. Pellet groups are aged as described by Lyon (1973a), and are cleared from the transects during each count.

Weekly aerial locations of radio-collared elk are obtained from midMay through December to obtain elk habitat use and movements data, both inside the CSA and on adjacent lands. Ground telemetry is used to supplement aerial locations for determining elk movements and distribution.

\section{Vegetative and Photo Plots}

Permanent vegetation plots were established in eleven representative stands in proposed cutting units. The nested plot sampling system used was described by Lyon (1973b) and has been used in other investigations of the Montana Cooperative Elk-Logging Study. Pre-logging results were reported in August 1978 (Marcum et al. 1978). These plots will be remeasured after logging to document changes which occur. Also, representative permanent photographic plots have been established along pellet transects for pre- and post-logging visual reference.

\section{Statistical Procedures}

The proportion of availability of a given habitat factor, based on transect segment length or random point sampling, was compared to the proportion of elk use based on pellet counts or telemetry locations (Marcum and Loftsgaarden 1980). The significance of the difference 


\section{.}


between proportions was determined by a Z-test (Snedecor and Cochran 1967). 'Datum analysis was accomplished using the University of Montana DECSYSTEM-20 computer and a series of standard statistical programs, Statistical Package for the Social Sciences (SPSS, Nie et al. 1975).

The following convention was used to indicate the statistical significance of the difference between the proportion of availability of a habitat factor and the proportion of elk use of that factor: + or - indicates elk use significantly greater or less than availability, $\mathrm{p} \leq 0.05 ;$ H or -- indicates a significant difference with $\mathrm{p} \leq 0.01$; 1ack of a sign indicates no significant difference.

\section{RESULTS}

Results reported here are primarily from data collected during 1980. However, the results of the study to date will be considered in the discussion section. Data collected during previous years of this investigation are presented in previous annual reports, and in theses by Scott (1978) and Lehmkuh1 (1981). Pellet and telemetry results are treated separately because they are not strictly comparable due to differences in technique, area and time periods considered, and sampling intensity per unit area.

\section{Pellet Count Results}

Transects have been cleared of all elk pellets during each survey since the August count of 1978. Since then, old and very old (OvO) pellet groups counted during the spring have been used to provide an estimate of fall elk use for the preceding year. Sample sizes for fall 1978 and 1979 were 355 and 734 respectively. Only fresh and new (FN) pellet groups were used for spring and summer estimates of elk use. Sample sizes for spring counts were 77 during 1980, 118 during 1979, 82 during 1978, and 139 during 1977. The spring 1977 data were revised because of mistakes made in classifying pellet group ages on some transects. These data give fairly reliable estimates of spring distribution and habitat use by elk, but the total count will not be used to predict future spring use. Summer sample sizes were 193 during 1980, 420 during 1979, 380 during 1978, 600 during 1977, and 201 during 1976.

Because of these substantial differences in sample size between counts, care must be used in interpreting the tabular data which are reported here in terms of proportions of elk use for various environmental categories. Changes in proportions within a category from one count to another do not necessarily reflect changes in the actual number of pellet groups counted for that category. 

Elk distribution. The CSA was divided into 11 subunits based on topographic and vegetative homogeneity to identify yearly and seasonal shifts in elk distribution (Fig. 3). Percentages of elk use compared to availability for CSA subunits for fall 1979, and spring and sumer 1980 are shown in Table 1. Areas of actual elk use and non-use during the same seasons are shown in Figures 4 through 6 . Figures 7 and 8 are composite maps of the consistency of elk use in the CSA for 4 springs and 5 summers.

Table 1. Percentages of availability and elk use related to CSA subunits

\% Elk Use

\begin{tabular}{|c|c|c|c|c|}
\hline \multirow[b]{3}{*}{$\begin{array}{l}\text { Sub- } \\
\text { unit }\end{array}$} & \multirow[b]{3}{*}{$\begin{array}{c}\% \\
\text { Availability }\end{array}$} & \\
\hline & & (ovo Pellets) & \multicolumn{2}{|c|}{ (FN Pellets) } \\
\hline & & $\begin{array}{l}\text { Fa11 } \\
1979\end{array}$ & $\begin{array}{c}\text { Spring } \\
1980\end{array}$ & $\begin{array}{c}\text { Summer } \\
1980\end{array}$ \\
\hline 1 & 8.7 & 9.5 & ++27.3 & 7.8 \\
\hline 2 & 9.0 & 5.3 & 6.5 & 5.2 \\
\hline 3 & 9.0 & 8.2 & -0.0 & 10.4 \\
\hline 4 & 6.4 & 3.5 & -0.0 & 5.7 \\
\hline 5 & 2.5 & 1.4 & 0.0 & 4.1 \\
\hline 6 & 3.2 & 2.5 & 0.0 & 2.6 \\
\hline 7 & 1.2 & 0.1 & 0.0 & 0.0 \\
\hline 8 & 15.6 & +32.1 & +50.6 & 15.0 \\
\hline 9 & 14.9 & 16.9 & -5.2 & +29.0 \\
\hline 10 & 15.8 & --8.1 & 10.4 & 14.0 \\
\hline 11 & 13.7 & 12.4 & -0.0 & -6.2 \\
\hline
\end{tabular}

Most fall 1979 elk use of the CSA was in subunits 8 and 9. These two subunits made up $30.5 \%$ of the CSA, but received $49.0 \%$ of the fall elk use. Elk use was significantly greater than availability in subunit 8, and significantly less than availability in subunit 10 . Spring elk use occurred primarily on the lower elevation subunits 1 and 8 . Summer elk use was generally well distributed throughout the CSA, but use was significantly greater than availability in subunit 9, and significantly less in subunit 11. During summer months, relative elk use increased in mesic subunits $(3,4,5,9,10$, and 11) when compared to relative spring use. 



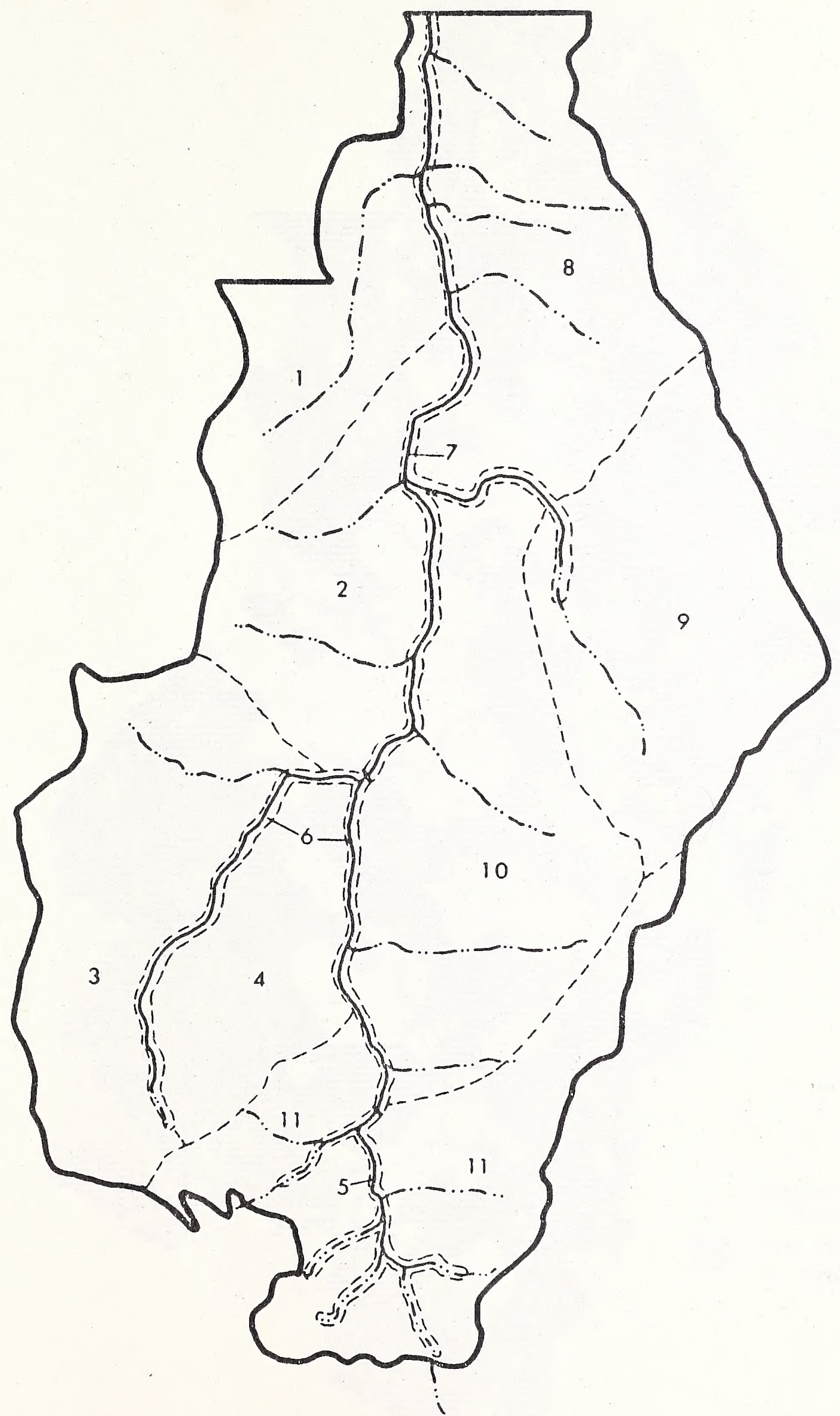

Figure 3. Map of subunits in the core study area. 


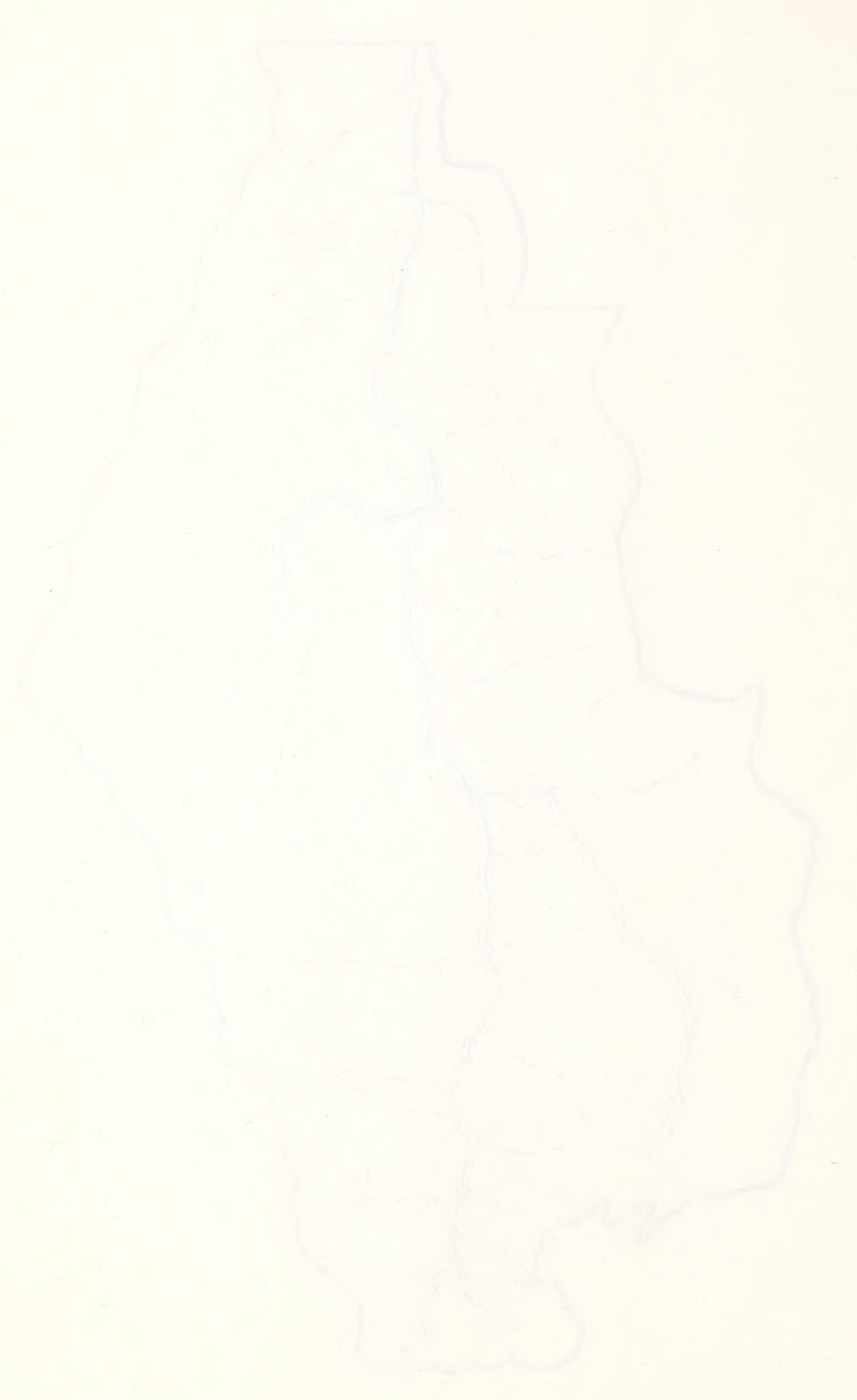




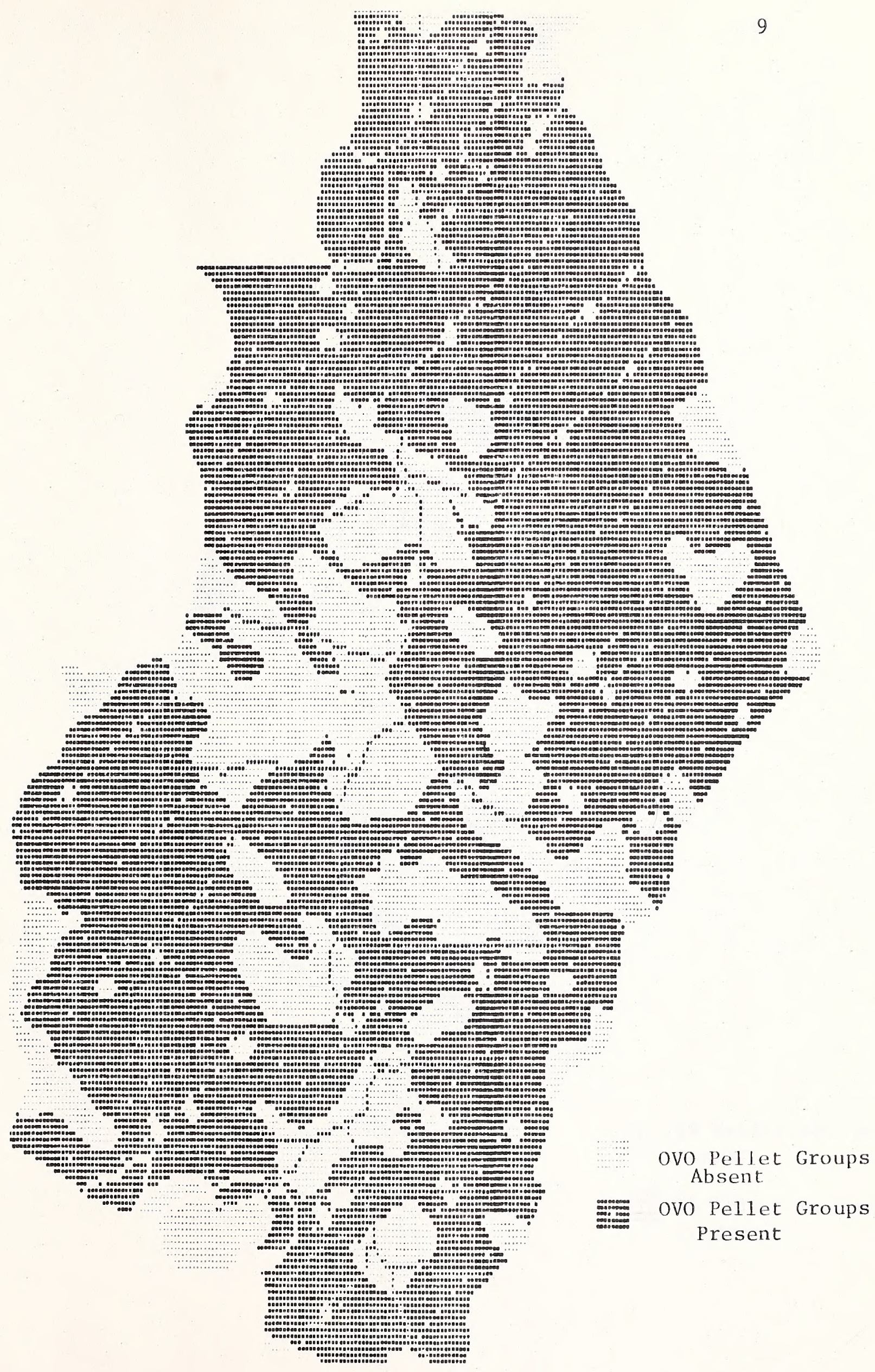

Figure 4. Areas of elk use and non-use in the CSA during fall 1979. 



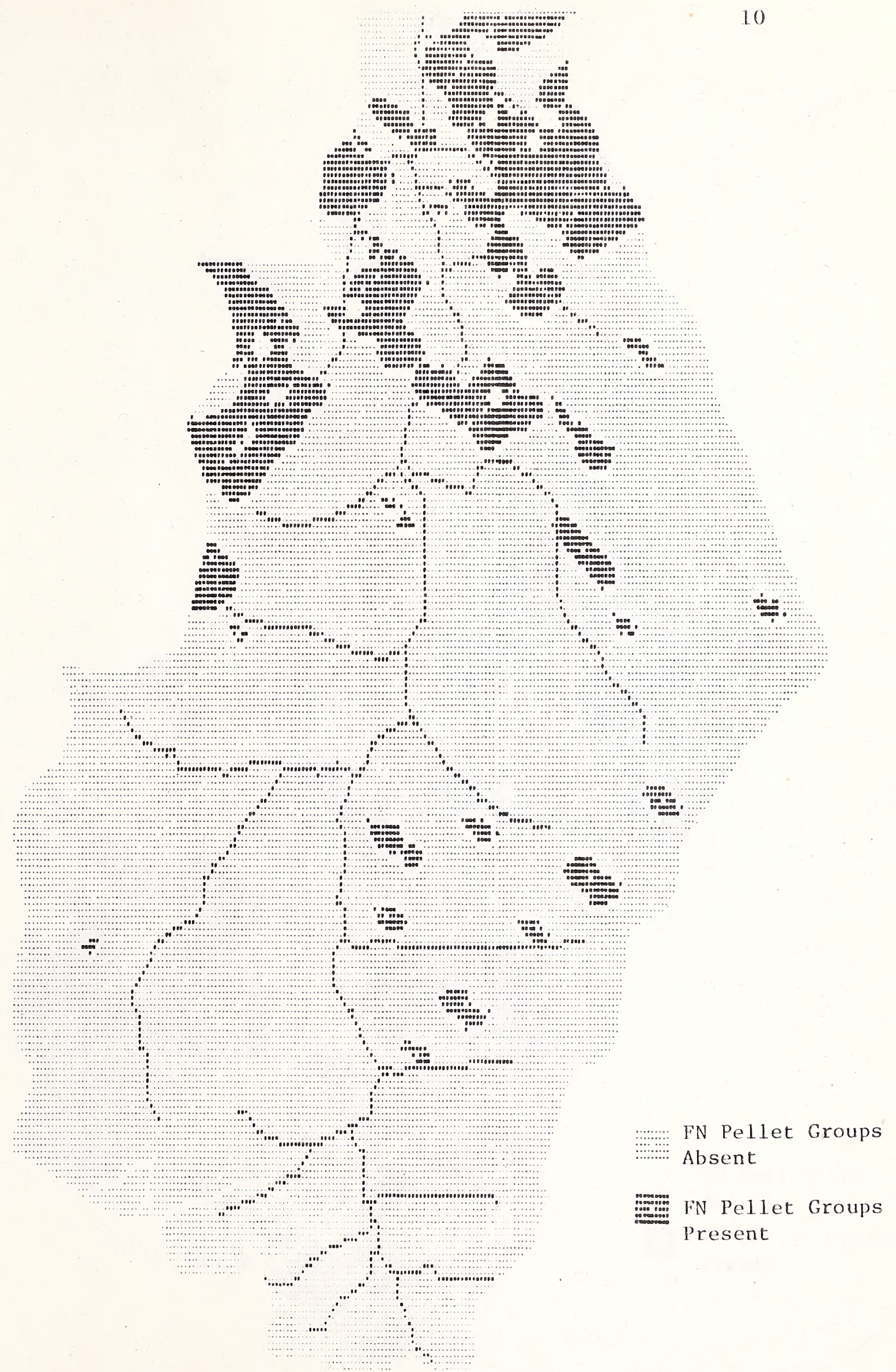

Figure 5. Areas of elk use and non-use in the CSA during spring 1980. 



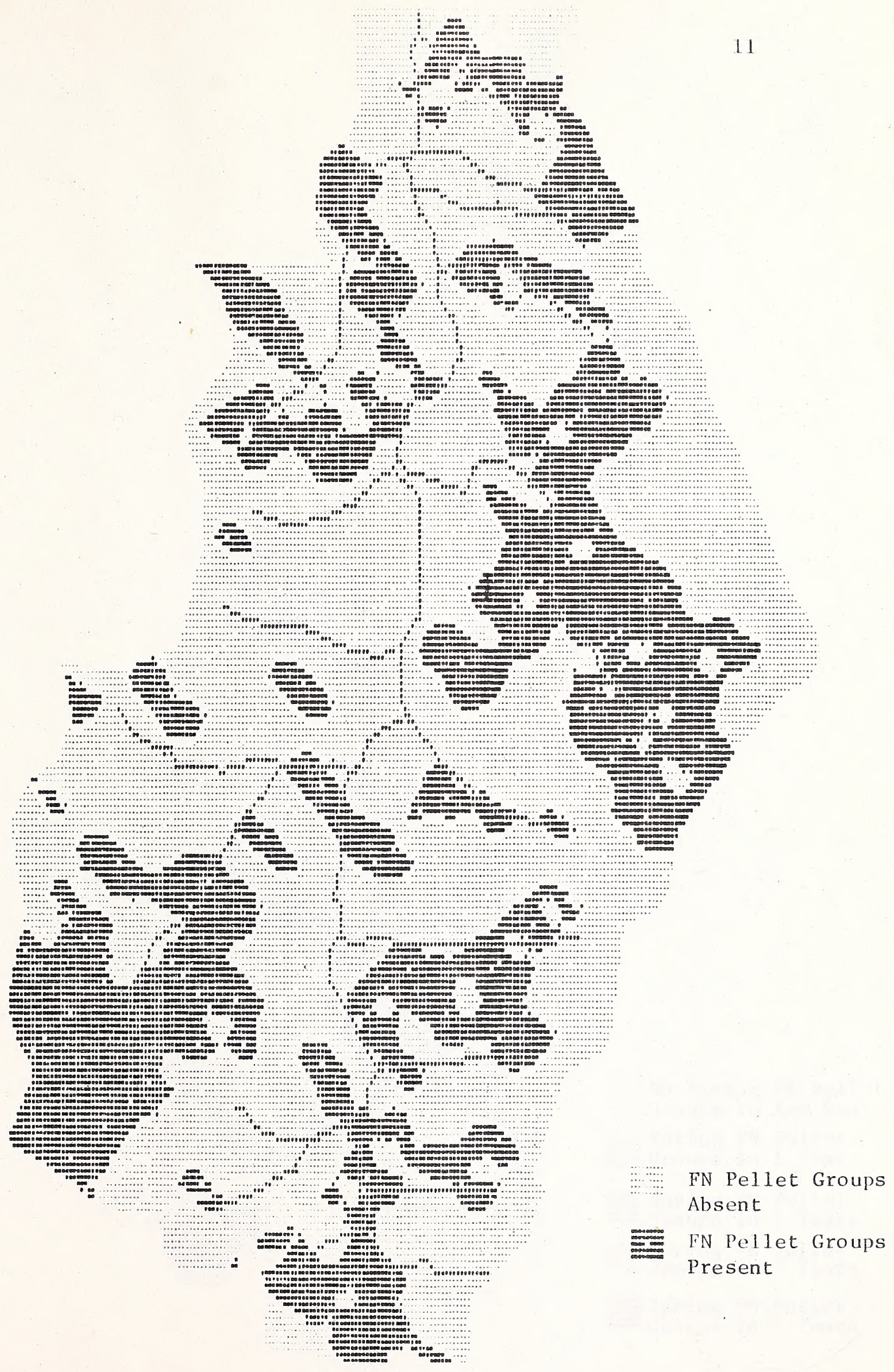

Figure 6. Areas of elk use and non-use in the CSA during summer 1980. 



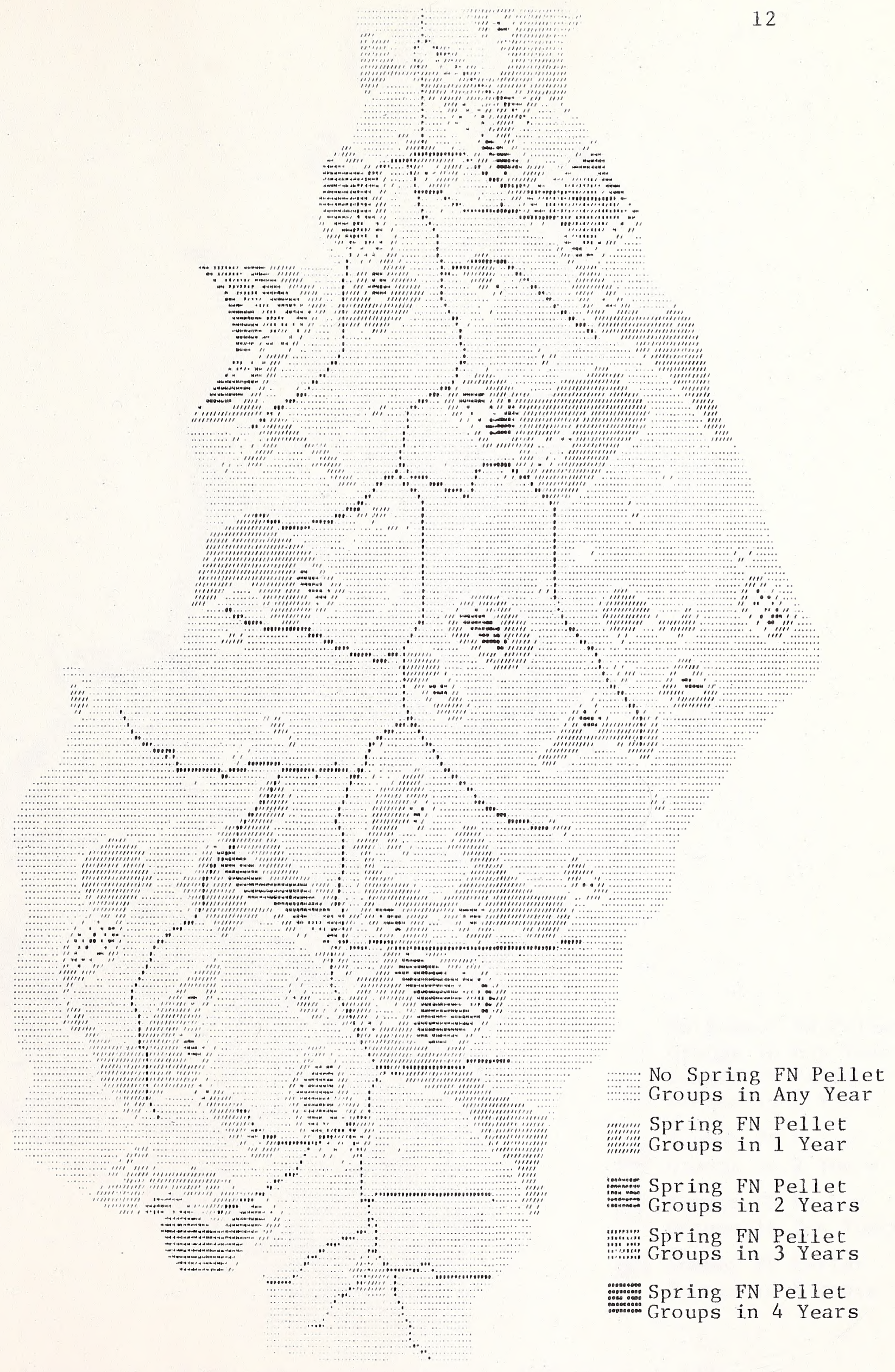

Figure 7. Consistency of CSA elk use for springs, 1977-1978-1979-1980. 


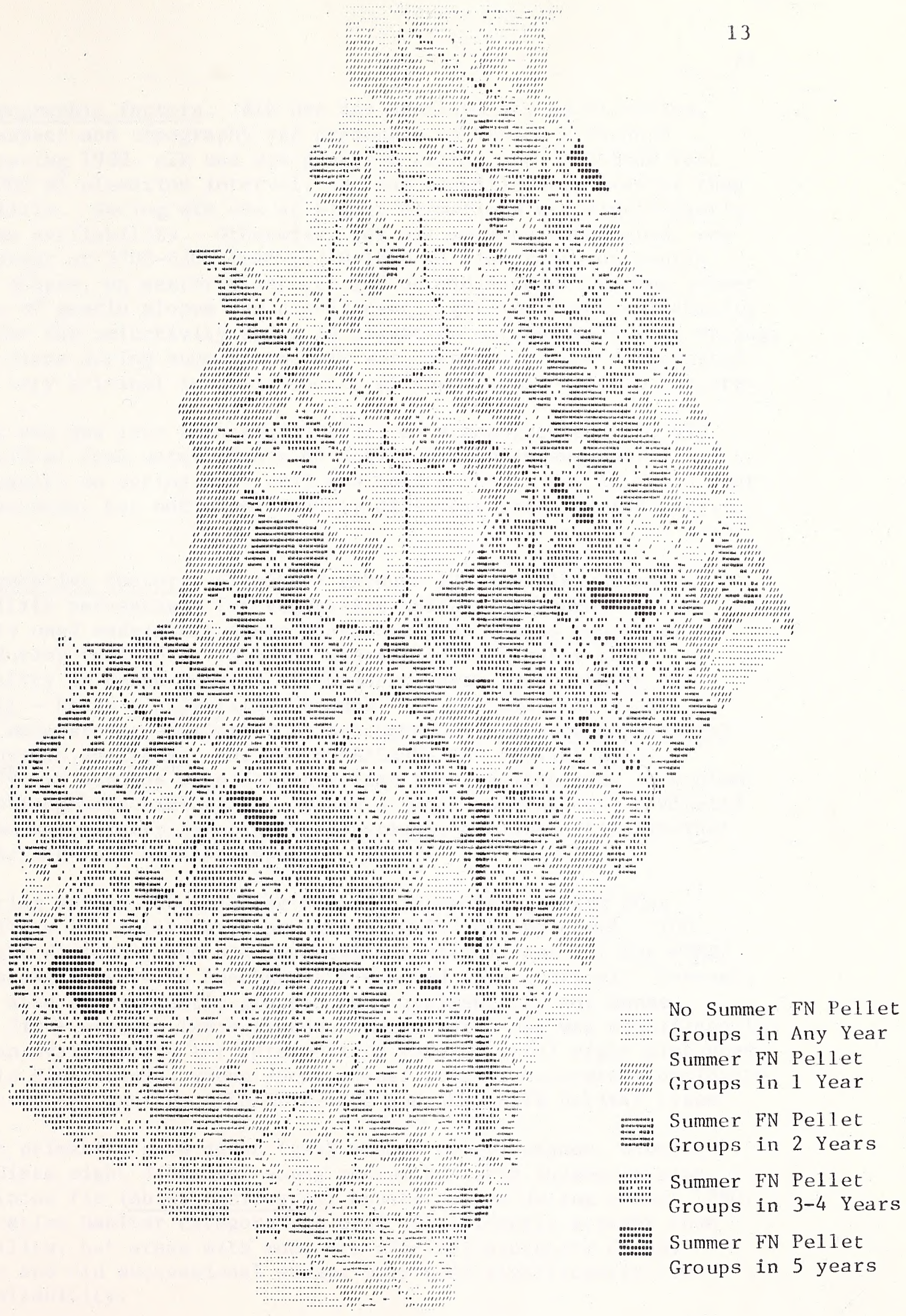

Figure 8. Consistency of CSA elk use for summers, 1976 through 1980. 
Topographic factors. Elk use and availability by elevation, slope, aspect and topography are presented in Tables 2 through 5. During spring 1980, elk use was greatest within the 5100-5600 feet (1550-1700 m) elevation interva1, and was significantly greater than availability. Spring elk use at higher elevations was significantly less than availability. Otherwise, for all seasons considered, use was greatest at 5700-6200 feet $(1740-1890 \mathrm{~m})$ elevation, on gentle $\left(0-15^{\circ}\right)$ slopes, on westerly aspects and on mid-slopes. During summer 1980 use of gentle slopes was significantly greater than availability. Except for the selectivity shown in elevation categories during spring, and for slope during summer, the elk were generally well distributed and not very critical in their choice of topographic habitat factors.

E1k use was less than availability on areas greater than 450 yards $(410 \mathrm{~m})$ from water (Table 6) during all three seasons, significantly so during fall 1979 and spring 1980. Use of areas near water was high, but not significantly different from availability.

Vegetative factors. Tables 7 through 12 show elk use and availability percentages for vegetative habitat components. Elk primarily used moderately dense lodgepole pine (Pinus contorta) stands during fall 1978. Use was significantly greater than availability in dense Douglas fir-western larch. (Pseudotsuga menziesii - Larix occidentalis) stands, old successional stage stands, understories dominated by bunchgrasses (Festuca idahoensis) and Agropyron spicatum), and the PSME/CARU-AGSP habitat type. Fa11 1979 elk use was significantly less than availability in medium to large lodgepole pine stands, young stands, understories dominated by grouse wortleberry (Vaccinium scoparium), and the ABLA/XETE-VAGL and ABLA/XETE-VASC habitat types.

During spring 1980 elk use was significantly greater than availability for relatively open areas ( $0-25 \%$ canopy cover, $>100$ yard sight distance, and old successional stage), and for the PSME/ FEID habitat type (with bunchgrass dominated understories). However, use was also significantly greater than availability for dense Douglas fir - western larch stands. Conversely, use was significantly less than availability for intermediate (50-100 yard) sight distances, lodgepole pine stands, young successional stages, understory dominants of mesic sites, and the ABLA/XETE-VAGL and ABLA/MEFE habitat types.

Elk primarily used dense ( $>75 \%$ canopy cover) stands, with intermediate sight distance, young medium to large lodgepole pine, in subalpine fir (Abies lasiocarpa) habitat types during summer 1980 . No vegetative habitat category was used significantly greater than availability, but areas with moderate (25-75\%) overstory canopy coverage and old successional stages were used significantly less than availability. 

Table 2. Percentages of availability and elk use related to CSA elevation.

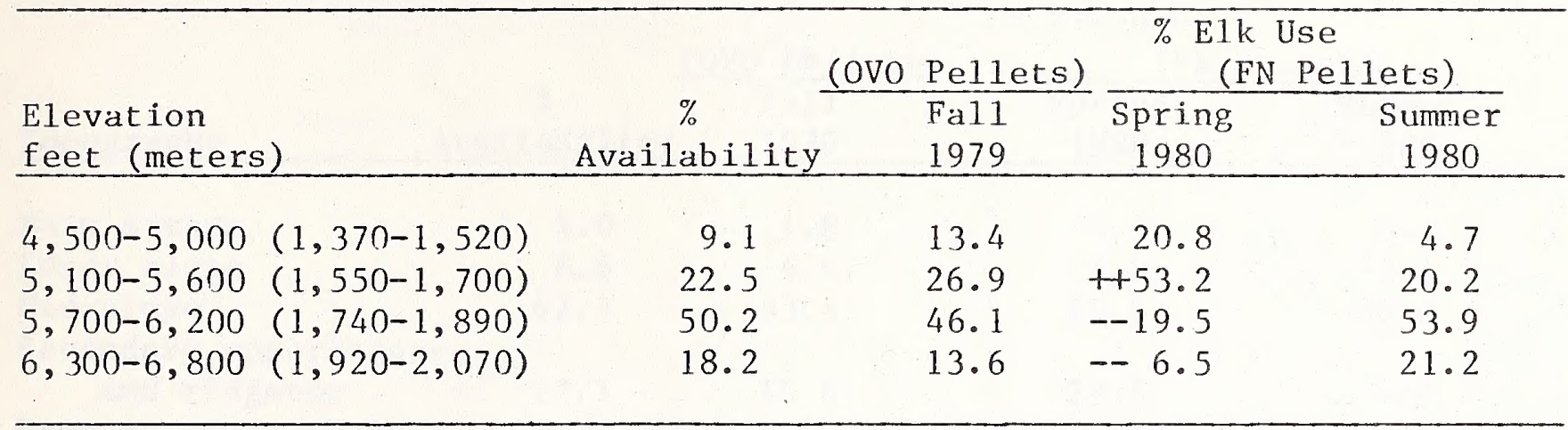

Table 3. Percentages of availability and elk use related to CSA slope.

\begin{tabular}{lcccc}
\hline & & (OVO Pellets) & $\%$ Elk Use & \multicolumn{2}{c}{ (FN Pellets) } \\
\cline { 3 - 5 } S1ope & Availability & 1979 & $\begin{array}{c}\text { Spring } \\
\text { Fall }\end{array}$ & $\begin{array}{c}\text { Summer } \\
1980\end{array}$ \\
\hline $0-15^{\circ}$ & 65.8 & 60.3 & 53.2 & +75.1 \\
$16-30^{\circ}$ & 30.3 & 35.3 & 41.6 & 22.3 \\
$31-38^{\circ}$ & 3.9 & 4.4 & 5.2 & 2.6 \\
\hline
\end{tabular}

Table 4. Percentages of availability and elk use related to CSA aspect.

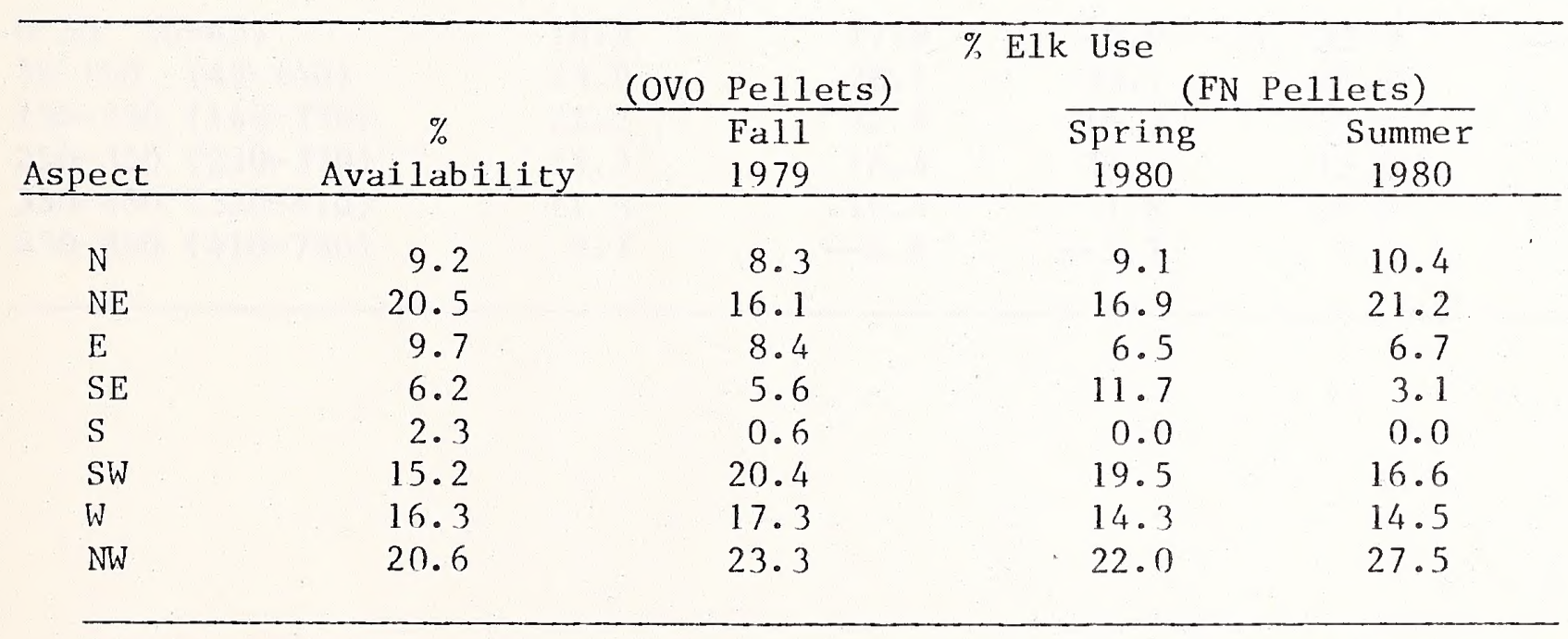



Table 5. Percentages of availability and elk use related to CSA topography.

\begin{tabular}{|c|c|c|c|c|}
\hline \multirow[b]{2}{*}{ Topography } & & (OVO Pellets) & \multicolumn{2}{|c|}{$\begin{array}{l}\text { Elk Use } \\
(\text { FN Pellets })\end{array}$} \\
\hline & $\begin{array}{c}\% \\
\text { Availability }\end{array}$ & $\begin{array}{l}\text { Fa11 } \\
1979 \\
\end{array}$ & $\begin{array}{c}\text { Spring } \\
1980 \\
\end{array}$ & $\begin{array}{c}\text { Summer } \\
1980\end{array}$ \\
\hline Main stream & $4 \cdot 0$ & 1.8 & 3.9 & 3.1 \\
\hline Lower slope & 6.6 & 4.6 & 2.6 & -2.1 \\
\hline Mid-slope & 47.3 & 53.5 & 50.6 & 58.0 \\
\hline $\begin{array}{l}\text { Secondary upper slope } \\
\text { and ridgetop } \\
\text { Primary upper slope }\end{array}$ & 12.7 & 16.6 & 23.4 & 8.8 \\
\hline $\begin{array}{l}\text { and ridgetop } \\
\text { Bench } \\
\text { Swale } \\
\text { Other }\end{array}$ & $\begin{array}{r}16.1 \\
5.0 \\
4.6 \\
3.7\end{array}$ & $\begin{array}{r}11.2 \\
5.6 \\
4.8 \\
1.9\end{array}$ & $\begin{array}{l}7.8 \\
3.9 \\
7.8 \\
0.0\end{array}$ & $\begin{array}{l}9.8 \\
5.2 \\
7.8 \\
5.2\end{array}$ \\
\hline
\end{tabular}

Table 6. Percentages of availability and elk use related to distance to water in the CSA.

\begin{tabular}{|c|c|c|c|c|}
\hline & & (ovo Pellets) & $\begin{array}{r}\text { E.1k Use } \\
\quad \text { (FN } \\
\end{array}$ & Pellets) \\
\hline Distance to water & $\%$ & $\mathrm{~F}$ a 11 & Spring & Summer \\
\hline yards (meters) & Availability & 1979 & 1980 & 1980 \\
\hline $0-50 \quad(0-45)$ & 18.3 & 17.9 & 16.9 & 23.3 \\
\hline $50-150 \quad(45-140)$ & 23.9 & 28.1 & 33.7 & 21.2 \\
\hline $150-250 \quad(140-230)$ & 21.2 & 22.6 & 18.2 & 23.9 \\
\hline $250-350(230-320)$ & 15.3 & 16.4 & 22.1 & 12.4 \\
\hline $350-450(320-410)$ & 11.6 & 10.4 & 7.8 & 11.9 \\
\hline $450-850(410-780)$ & 9.7 & --4.6 & --1.3 & 7.3 \\
\hline
\end{tabular}



Table 7. Percentages of availability and elk use related to CSA overstory canopy cover.

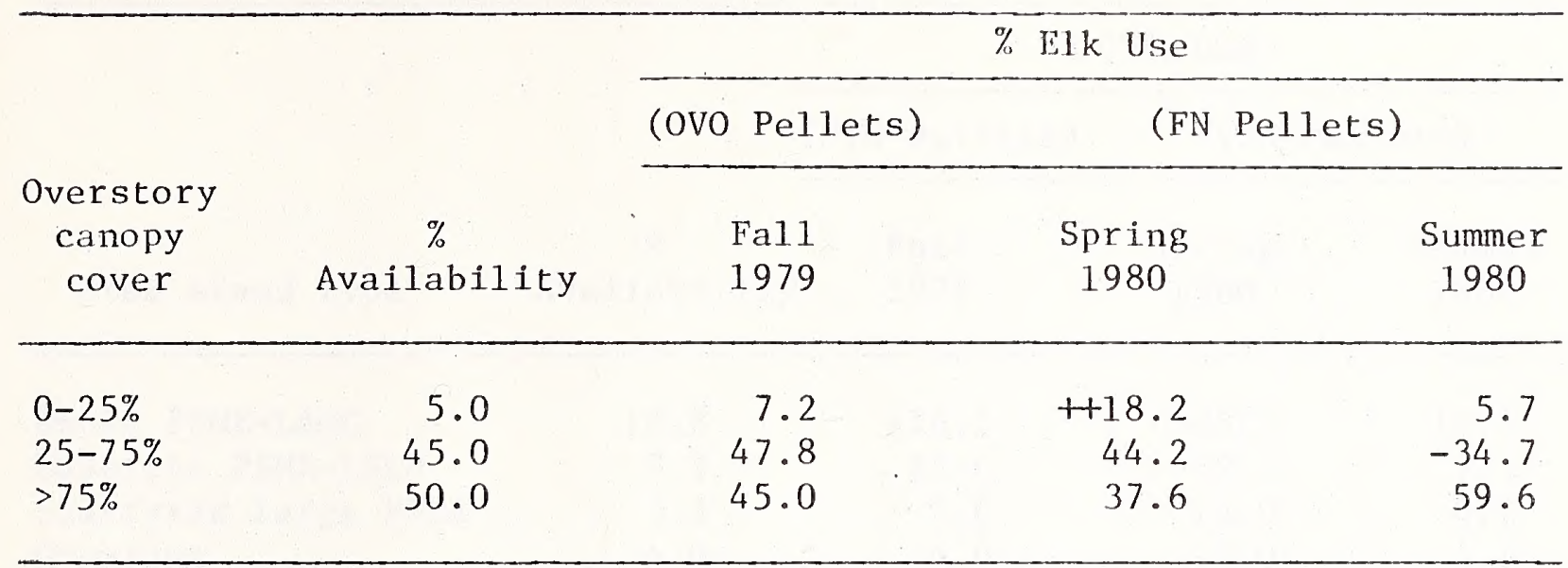

Table 8. Percentages of availability and elk use related to CSA sight distance.

\begin{tabular}{|c|c|c|c|c|}
\hline \multirow[b]{3}{*}{$\begin{array}{l}\text { Sight distance } \\
\text { yards (meters) }\end{array}$} & \multirow[b]{3}{*}{$\begin{array}{c}\% \\
\text { Availability }\end{array}$} & \multicolumn{3}{|c|}{$\%$ E1k Use } \\
\hline & & (ovo Pellets) & $(\mathrm{FN}$ & Pe11ets) \\
\hline & & $\begin{array}{l}\text { Fa11 } \\
1979\end{array}$ & $\begin{array}{l}\text { Spring } \\
1980\end{array}$ & $\begin{array}{c}\text { Summer } \\
1980\end{array}$ \\
\hline $\begin{array}{l}<50 \quad(<46) \\
50-100 \quad(46-91) \\
>100(>91)\end{array}$ & $\begin{array}{r}33.1 \\
58.3 \\
8.6\end{array}$ & $\begin{array}{r}31.8 \\
58.7 \\
9.5\end{array}$ & $\begin{array}{r}35.1 \\
--39.0 \\
++25.9\end{array}$ & $\begin{array}{r}26.9 \\
64.3 \\
8.8\end{array}$ \\
\hline
\end{tabular}



Table 9. Percentages of availability and elk use related to CSA tree stand type.

\begin{tabular}{|c|c|c|c|c|}
\hline \multirow[b]{3}{*}{ Tree stand type } & \multirow[b]{3}{*}{$\begin{array}{c}\% \\
\text { Availability }\end{array}$} & \multicolumn{3}{|c|}{$\%$ Elk Use } \\
\hline & & (ovo Pellets) & \multicolumn{2}{|c|}{ (FN Pellets) } \\
\hline & & $\begin{array}{l}\text { Fa11 } \\
1979\end{array}$ & $\begin{array}{c}\text { Spring } \\
1980\end{array}$ & $\begin{array}{c}\text { Summer } \\
1980\end{array}$ \\
\hline Dense PSME-LAOC & 10.8 & +16.5 & +25.9 & 10.4 \\
\hline Moderate PSME-LACO & 9.9 & 15.0 & 19.5 & 7.3 \\
\hline Scattered large PSME & 3.2 & 4.6 & 13.0 & 4.7 \\
\hline Clearing & 4.0 & 6.0 & 13.0 & 4.1 \\
\hline Dense ABLA-PIEN & 14.8 & 13.9 & 7.8 & 12.9 \\
\hline Moderate ABLA-PIEN & 5.6 & 5.6 & 3.9 & 7.3 \\
\hline Sma11 to medium PICO & 8.4 & 4.4 & -0.0 & 8.3 \\
\hline Medium to large PICO & 43.3 & --34.0 & --16.9 & 45.0 \\
\hline
\end{tabular}

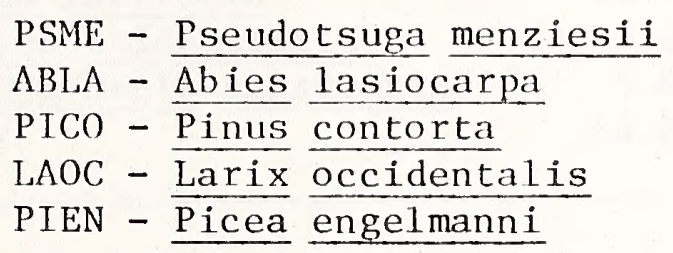

Table 10. Percentages of availability and elk use related to CSA successional stage.

\begin{tabular}{lcccr}
\hline & & \multicolumn{3}{c}{$\%$ E1k Use } \\
\cline { 3 - 5 } & & (Ovo Pellets) & (FN Pellets) \\
\cline { 3 - 5 } $\begin{array}{l}\text { Successional } \\
\text { stage }\end{array}$ & Availability & 1979 & Spring & Summer \\
& & & 1980 & 1980 \\
\hline $\begin{array}{l}\text { Brush-Seedling } \\
\text { Pole-Sapling }\end{array}$ & 1.8 & 1.1 & 3.9 & 1.6 \\
Young-Stand & 3.3 & 1.4 & 1.3 & 1.6 \\
$\begin{array}{l}\text { Mature Stand } \\
\text { Old Stand }\end{array}$ & 43.5 & --30.5 & --16.9 & 32.8 \\
& 27.6 & 33.8 & 31.2 & -14.0 \\
\hline
\end{tabular}



Table 11. Percentages of availability and elk use related to CSA. dominant understory species.

\begin{tabular}{|c|c|c|c|c|}
\hline \multirow{3}{*}{$\begin{array}{l}\text { Dominant } \\
\text { understory } \\
\text { species }\end{array}$} & \multirow[b]{3}{*}{$\frac{\%}{\text { Availability }}$} & \multicolumn{3}{|c|}{$\%$ Elk Use } \\
\hline & & (ovo Pellets) & (FN & Pellets) \\
\hline & & $\begin{array}{l}\text { Fal1 } \\
1979\end{array}$ & $\begin{array}{l}\text { Spring } \\
1980\end{array}$ & $\begin{array}{c}\text { Summer } \\
1980\end{array}$ \\
\hline \multicolumn{5}{|l|}{ Festuca idahoensis- } \\
\hline Agropyron spicatum & 5.8 & +11.4 & +26.0 & 3.6 \\
\hline Calamagrostis rubescens & 10.1 & 13.5 & 15.6 & 8.8 \\
\hline Arnica cordifolia & 6.6 & 7.8 & 10.4 & 3.6 \\
\hline Xerophyllum tenax & 35.1 & 35.6 & 31.2 & 35.8 \\
\hline Vaccinium scoparium & 17.1 & --7.8 & --5.2 & 9.8 \\
\hline Vaccinium globulare & 31.9 & 33.2 & 39.0 & 34.2 \\
\hline Menziesia ferruginea & 23.1 & 24.0 & --7.8 & 26.9 \\
\hline Alnus sinuata & 27.7 & 24.4 & --11.7 & 30.6 \\
\hline Arnica latifolia & 11.4 & 11.9 & -3.9 & 17.6 \\
\hline Senecio triangularis & 5.2 & 5.7 & -0.0 & 10.4 \\
\hline Calamagrostis canadensis & 5.0 & 3.4 & 1.3 & 6.7 \\
\hline Other & 16.6 & 17.4 & +39.0 & --7.8 \\
\hline
\end{tabular}

* Since the two dominant species on each segment were recorded, the percentages total to more than 100 percent.

Response to disturbance. During fall 1979, work on the main haul road was completed (Fig. 9), and the east side spur road was extended from BN cut number 3 into BN cut number 5. Work stopped prior to the opening of the general hunting season, and all roads were closed to vehicular access.

Logging was started on BN cuts 1 through 5 during winter 1980, and continued through the general hunting season. Spur road construction on the west side of the CSA began in late July. The first three weeks of this period were primarily used for equipment preparation. Road construction began in earnest on 12 August. From this time until midSeptember a three pronged spur road was constructed within subunit 2 . This road accesses BLM unit 1 and BN unit 7. A second spur road was constructed between mid-September and late october. This road begin in subunit 2 and continued into subunit 3 . This spur accesses BLM cutting unit 2 and BN cutting units 8 and 9 . The third spur road constructed within the CSA during 1980 began in early November. This 

Table 12. Percentages of availability and elk use related to CSA habitat types.

\begin{tabular}{|c|c|c|c|c|}
\hline \multirow[b]{3}{*}{ Habitat Type } & \multirow[b]{3}{*}{$\begin{array}{c}\% \\
\text { Availability }\end{array}$} & \multicolumn{3}{|c|}{$\%$ E1k Use } \\
\hline & & (ovo Pellet) & \multicolumn{2}{|c|}{ (FN Pellet) } \\
\hline & & $\begin{array}{l}\text { Fa11 } \\
1979\end{array}$ & $\begin{array}{c}\text { Spring } \\
1980\end{array}$ & $\begin{array}{c}\text { Summer } \\
1980\end{array}$ \\
\hline PSME/FEID & 2.5 & 5.5 & +15.6 & 0.5 \\
\hline PSME/CARU,AGSP & 1.6 & +4.5 & 7.8 & 1.6 \\
\hline PSME/CARU ${ }^{1}$ & 4.7 & 4.2 & 5.2 & 3.1 \\
\hline PSME/PHMA ${ }^{2}$ & 0.6 & 1.4 & 2.6 & 0.0 \\
\hline PSME/VAGL-XETE ${ }^{3}$ & 1.3 & 2.5 & 0.0 & 0.5 \\
\hline PSME/LIBO 4 & 1.1 & 1.8 & 5.2 & 0.0 \\
\hline $\mathrm{PSME}$ SYAL $^{5}$ & 0.9 & 1.9 & 1.3 & 1.6 \\
\hline ABLA/LIBO & 1.9 & 2.5 & 3.9 & 1.6 \\
\hline ABLA/LIBO-XETE & 14.6 & 20.4 & 29.8 & 17.1 \\
\hline ABLA/XETE-VAGL ${ }^{6}$ & 26.0 & --17.2 & --6.5 & 19.6 \\
\hline ABLA/XETE-VASC & 5.0 & --1.2 & 2.6 & 3.1 \\
\hline ABLA/MEFE & 24.8 & 24.8 & --6.5 & 31.5 \\
\hline ABLA/ALSI & 4.0 & 2.9 & 1.3 & 3.1 \\
\hline ABLA/CLUN ${ }^{7}$ & 1.3 & 1.9 & 3.9 & 2.6 \\
\hline ABLA/CACA-CACA & 3.6 & 4.1 & 0.0 & 9.3 \\
\hline ABLA/CACA-GATR ${ }^{8}$ & 2.5 & 1.8 & 3.9 & 1.6 \\
\hline ABLA/CACA-VACA ${ }^{9}$ & 1.4 & 0.0 & 0.0 & 1.6 \\
\hline Clearcut & 2.0 & 1.1 & 3.9 & 1.6 \\
\hline Rock & 0.2 & 0.3 & 0.0 & 0.0 \\
\hline
\end{tabular}

${ }^{1}$ Includes ABLA/CARU

${ }^{2}$ Includes PSME/PHMA-CARU

${ }^{3}$ Includes PSME/VAGL

${ }^{4}$ Includes PSME/LIBO-SYAL, PSME/LIBO-VAGL, and PSME/LIBO-CARU

${ }^{5}$ Includes PSME/SYAL-CARU and PSME/SYAL-AGSP

${ }^{6}$ Includes $A B L A / V A G L$

${ }^{7}$ Includes ABLA/CLUN-ARNU and ABLA/CLUN-MEFE

${ }^{8}$ Includes ABLA/GATR

Includes ABLA/VACA and wet meadows 



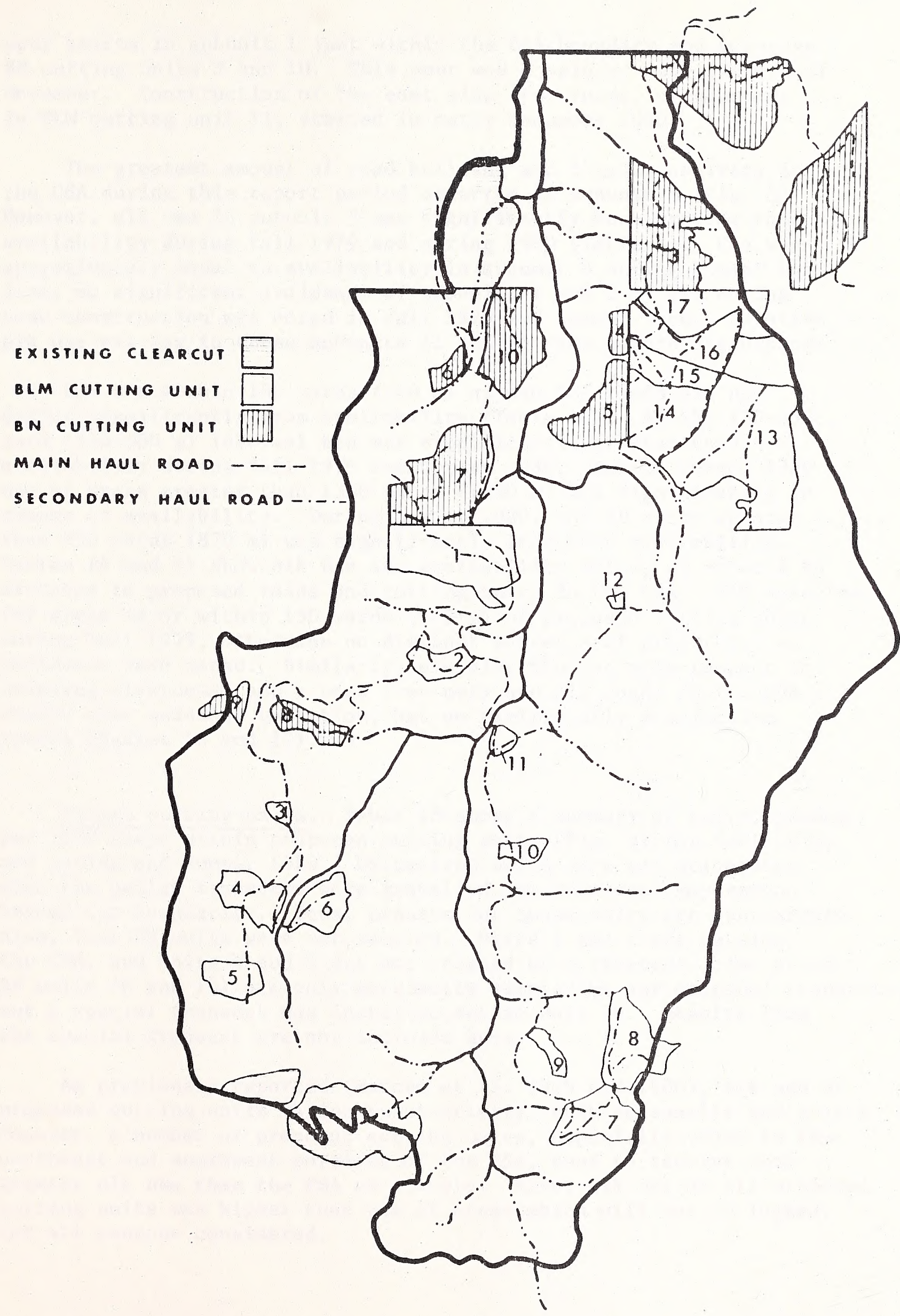

Figure 9. Map of existing clearcuts, planned cutting units, and planned roads in the CSA. 

spur starts in subunit 1 just within the CSA boundary and accesses BN cutting units 9 and 10 . This spur was completed near the end of November. Construction of the east side spur roads, originating in BLM cutting unit 11, started in early December 1980.

The greatest amount of road building and logging activity in the CSA during this report period occurred in subunit 8 (Fig. 3 ). However, elk use in subunit 8 was significantly much greater than availability during fall 1979 and spring 1980 (Table 1). Use was approximately equal to availability in subunit 8 during summer 1980 . Also, no significant avoidance of subunits 1 and 2 by elk during road construction was noted in fall 1979 and summer 1980. Relative elk use was low in these subunits ( 1 and 2 ) even before disturbance

E1k use within 150 yards $(140 \mathrm{~m})$ of new CSA roads did not differ significantly from availability (Table 13). At the 150-550 yard (140-500 $\mathrm{m}$ ) interval use was significantly greater than availability during fall 1979 and spring 1980. During summer 1980 use of areas greater than 1350 yards $(1230 \mathrm{~m})$ was significantly in excess of availability. During spring 1980, use of areas greater than 950 yards $(870 \mathrm{~m})$ was significantly less than availability. Tables 14 and 15 show elk use and availability values as related to distance to proposed roads and cutting units in the CSA. Elk selected for areas in or within 150 yards $(140 \mathrm{~m})$ of proposed cutting units during fall 1979, otherwise no distinct patterns of preference or avoidance were noted. Similarly, elk distribution with respect to existing clearcuts (and a seed tree cut) and old roads in the CSA showed some seasonal variation, but no sigificantly distinctive trends (Tables 16 and 17).

Future cutting units. Table 18 shows a summary of pellet groups

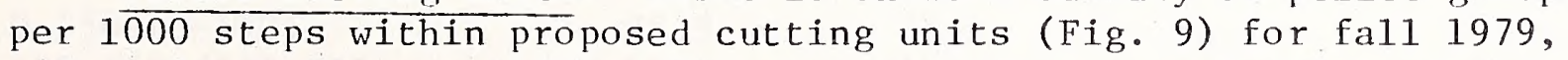
and spring and summer 1980. BN cutting units were not delineated when the pellet transects were installed, so transects may extend beyond cut boundaries. Thus, results for those units are approximate. Also, four $B N$ units were not sampled. Units 1 and 2 are outside the CSA, and units 4 and 9 are not crossed by a transect. Two other BN units ( 8 and 10 ) are only marginally sampled by our original transects, but a special transect was installed across unit 10. Results from the special transect are not included here.

As previously reported (Marcum et al. 1979 and 1980), elk use of proposed cutting units varies substantially, both seasonally and yearly. However, a number of proposed cutting units, especially those in the northeast and southwest portions of the CSA, tend to receive much greater elk use than the CSA as a whole. Also, elk use on all proposed cutting units was higher than use of areas which will not be logged, for all seasons considered. 

Table 13. Percentages of availability and elk use related to distance to new roads constructed within the CSA since spring 1978.

\begin{tabular}{lrrrr}
\hline & & \multicolumn{3}{c}{$\%$ E1k Use } \\
\cline { 3 - 5 } & & (OVo Pe11ets) & (FN Pellets) \\
\cline { 3 - 5 } $\begin{array}{c}\text { Distance } \\
\text { yards (meters) }\end{array}$ & Availability & 1979 & Spring & \multicolumn{1}{c}{ Summer } \\
& & & 1980 & 1980 \\
\hline $0-150(0-140)$ & 9.2 & 6.4 & 11.7 & 5.2 \\
$150-550(140-500)$ & 22.4 & ++32.2 & ++54.5 & 21.2 \\
$550-950(500-870)$ & 14.0 & 13.9 & 22.1 & 8.8 \\
$950-1350(870-1230)$ & 11.3 & 9.7 & --1.3 & 10.4 \\
$>1350 \quad(>1230)$ & 43.1 & 37.8 & --10.4 & +54.4 \\
\hline
\end{tabular}

Table 14. Percentages of availability and elk use related to distance to proposed roads within the CSA.

\begin{tabular}{lcccc}
\hline & & \multicolumn{3}{c}{$\%$ E1k Use } \\
\cline { 3 - 5 } & & (OVO Pellets) & (FN Pellets) \\
\cline { 3 - 5 } Distance & $\%$ & Fal1 & Spring & Summer \\
yards (meters) & Availability & 1979 & 1980 & 1980 \\
\hline $0-150 \quad(0-140)$ & 28.9 & 31.1 & 31.2 & 25.9 \\
$150-550(140-500)$ & 45.4 & 49.4 & 57.0 & 47.2 \\
$550-950(500-870)$ & 18.2 & 15.7 & -7.8 & 21.2 \\
$950-1350(870-1230)$ & 6.3 & 3.3 & 3.9 & 4.7 \\
$>1350 \quad(>1230)$ & 1.2 & 0.5 & 0.0 & 1.0 \\
\hline
\end{tabular}



Table 15. Percentages of availability and elk use related to distance to proposed cutting units within the CSA.

\begin{tabular}{lrrrr}
\hline & & \multicolumn{3}{c}{$\%$ Elk Use } \\
\cline { 3 - 5 } & & (Ovo Pellets) & (FN Pellets) \\
\cline { 3 - 5 } Distance & $\%$ & Fal1 & Spring & Summer \\
yards (meters) & Availability & 1979 & 1980 & 1980 \\
\hline $0-150 \quad(0-140)$ & 34.1 & +14.6 & 46.7 & 26.4 \\
$150-550(140-500)$ & 37.5 & 32.5 & 41.6 & 37.9 \\
$550-950(500-870)$ & 19.3 & 16.4 & --7.8 & 27.5 \\
$950-1350(870-1230)$ & 7.5 & 5.3 & 2.6 & 4.1 \\
$>1350 \quad(>1230)$ & 1.6 & 1.2 & 1.3 & 4.1 \\
\hline
\end{tabular}

Table 16. Percentages of availability and elk use related to distance to existing clearcuts.

\begin{tabular}{lccrc}
\hline & & \multicolumn{3}{c}{$\%$ Elk Use } \\
\cline { 3 - 5 } & & (Ovo Pellets) & (FN Pellets) \\
\cline { 3 - 5 } $\begin{array}{c}\text { Distance to existing } \\
\text { clearcuts } \\
\text { yards (meters) }\end{array}$ & Availability & 1979 & Spring & Summer \\
& & & 1980 & 1980 \\
\hline $0-150 \quad(0-140)$ & 6.3 & 4.5 & 6.5 & 4.2 \\
$150-550 \quad(140-500)$ & 11.6 & 12.3 & 9.1 & 8.8 \\
$550-950 \quad(500-870)$ & 15.5 & 18.0 & 28.6 & 15.5 \\
$950-1350(870-1230)$ & 15.5 & 18.3 & 27.2 & 16.1 \\
$>1350 \quad(>1230)$ & 51.3 & 46.9 & --28.6 & 55.4 \\
\hline
\end{tabular}



Table 17. Percentages of availability and elk use related to old roads in the CSA, constructed prior to spring 1978.

\begin{tabular}{|c|c|c|c|c|}
\hline \multirow[b]{3}{*}{$\begin{array}{l}\text { Distance to } \\
\text { road } \\
\text { yards (meters) }\end{array}$} & \multirow[b]{3}{*}{$\frac{\%}{\text { Availability }}$} & \multicolumn{3}{|c|}{$\%$ Elk Use } \\
\hline & & (ovo Pellets) & $(\mathrm{FN}$ & Pellets) \\
\hline & & $\begin{array}{l}\text { Fa } 11 \\
1979\end{array}$ & $\begin{array}{c}\text { Spring } \\
1980\end{array}$ & $\begin{array}{c}\text { Summer } \\
1980\end{array}$ \\
\hline $0-150 \quad(0-140)$ & 12.4 & 8.6 & 10.4 & 7.3 \\
\hline $150-550(140-500)$ & 27.4 & 27.5 & 36.3 & 25.4 \\
\hline $550-950(500-870)$ & 27.7 & 33.1 & 24.7 & 33.1 \\
\hline $950-1350(870-1230)$ & 21.6 & 24.4 & 20.8 & 24.9 \\
\hline$>1350 \quad(>1230)$ & 10.9 & -6.4 & 7.8 & 9.3 \\
\hline
\end{tabular}

Table 18. Pellet groups per 1,000 steps in proposed CSA cutting units.

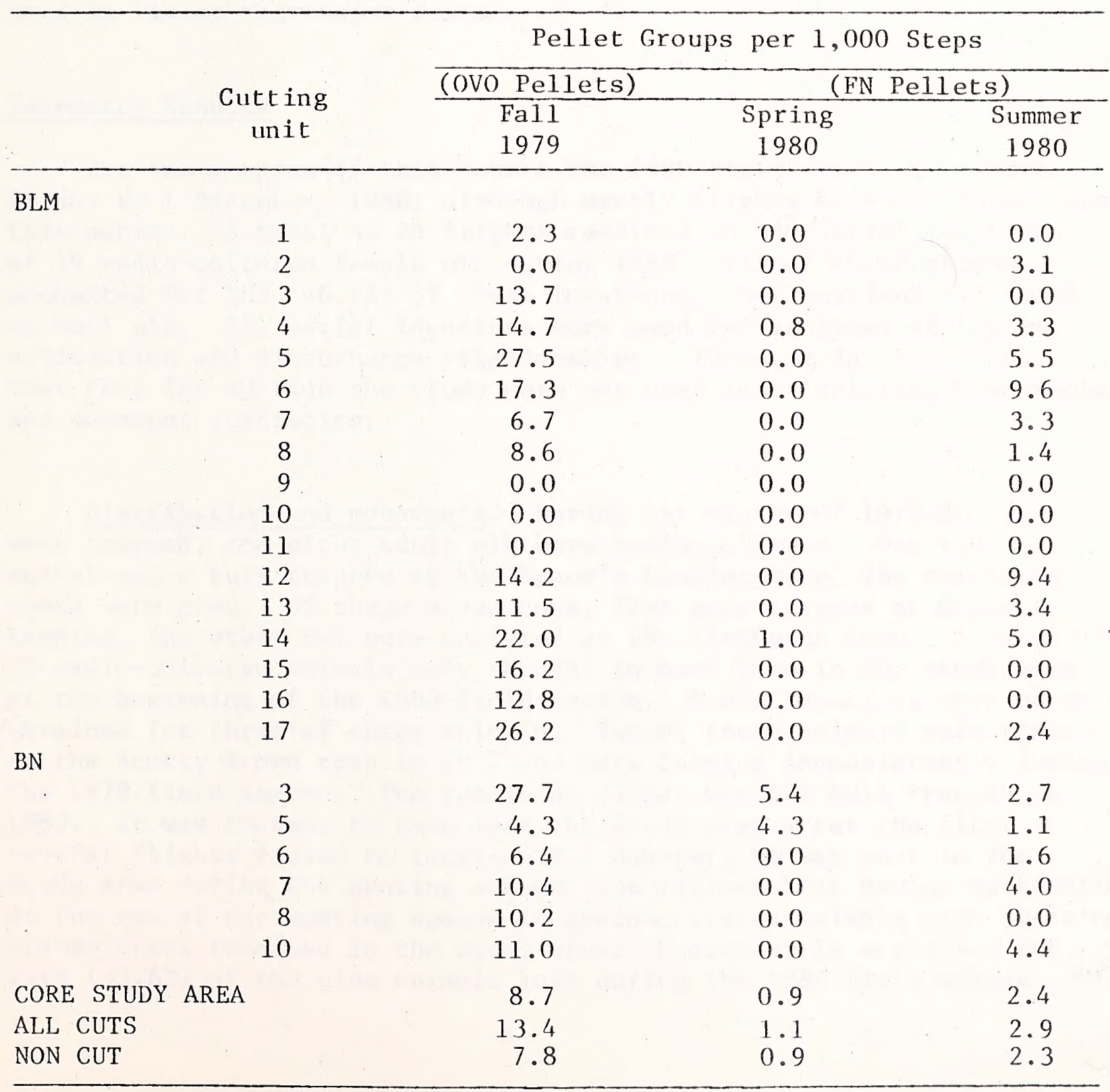



Elk use in the CSA related to precipitation. Figure 10 shows cummulative precipitation from October through the following September for 1979-80, as compared to that for a 20 year mean and several previous years. Precipitation data are from the Lubrecht Experimental Forest of the University of Montana School of Forestry, located approximately 7 miles west of the CSA (Steele 1980). During 1979-80, precipitation was less than normal through April, but record rainfall during May resulted in higher than normal cumulative moisture for the year.

As reported previously (Marcum et al. 1979 and 1980), we have shown a significant inverse relationship between precipitation and summer elk use of the CSA during years of little or no disturbance. After adding the precipitation and pellet count data for 1980, we still show a high correlation. The best result $(r=-0.98)$ is obtained by using data from even numbered transects only (Fig. 11), for which we now have 6 years of data. The correlation between precipitation and summer pellet counts on al1 transects from 1976 through 1980 remained at $r=-0.95$. A similar correlation $(r=-0.99)$ has been shown for October through May or June precipitation with the spring pellet counts for 1977 through 1979. The spring 1980 pellet count data were revised, so the total count was not used in linear regression tests.

\section{Telemetry Results}

For the purpose of this report the 1980 field season runs from 13 May to 1 December, 1980, although weekly flights have continued since this period. A total of $29 \mathrm{flights}$ resulted in 438 aerial locations of 19 radio-collared female elk during 1980. Visual observations accounted for $202(46.1 \%)$ of these locations. No locations were made on bull elk. All aerial locations were used for analyses of habitat utilization and disturbance relationships. Three aerial locations that fell far outside the study were not used in calculating home range and movement statistics.

Distribution and movements. During the winter of 1979-80, 24 elk were trapped, and eight adult elk were radio-collared. One radioed animal was a bull trapped at the Grace's Landing trap, the remaining seven were cows. Of these seven cows, five were trapped at Grace's Landing, the other two were captured at the Lindbergh trap. A total of 22 radio-collared animals were thought to have been in the study area at the beginning of the 1980 field season. Radio locations were never obtained for three of these animals. Two of these animals were trapped at the Scotty Brown trap in 1977 and were located inconsistently during the 1979 field season. The remaining animal was the bull trapped in 1980. It was thought to have left the study area after the first several flights failed to locate him. However, he was shot in the study area during the hunting season, the radio-collar having malfunctioned. At the end of the hunting season 10 radio-collared animals with functional transmitters remained in the study area. Hunter kills accounted for five (55.6\%) of the nine animals lost during the 1980 field season. Of 



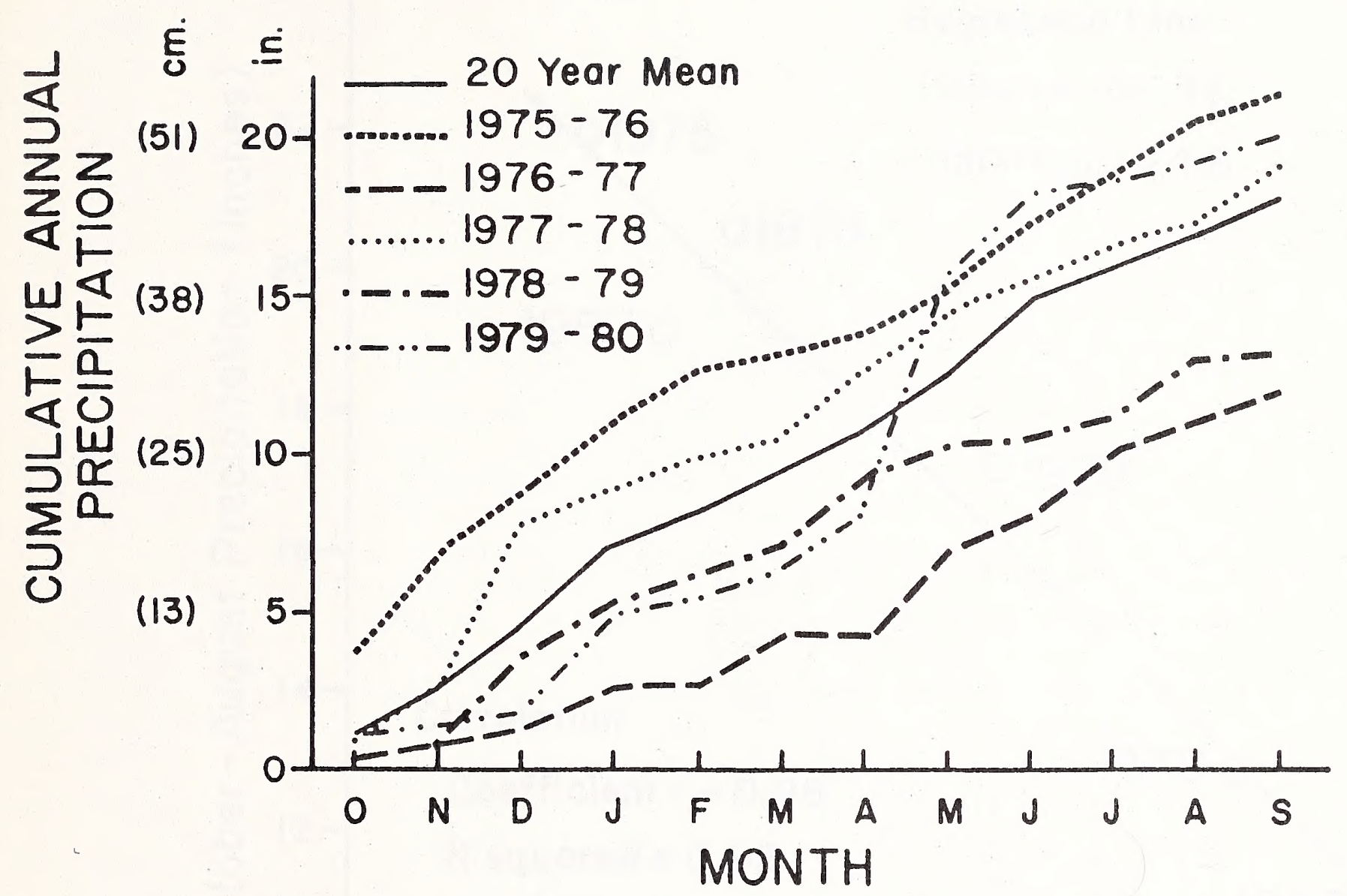

Figure 10. Cumulative annual precipitation at Lubrecht Experimental Forest (Steele 1981). 



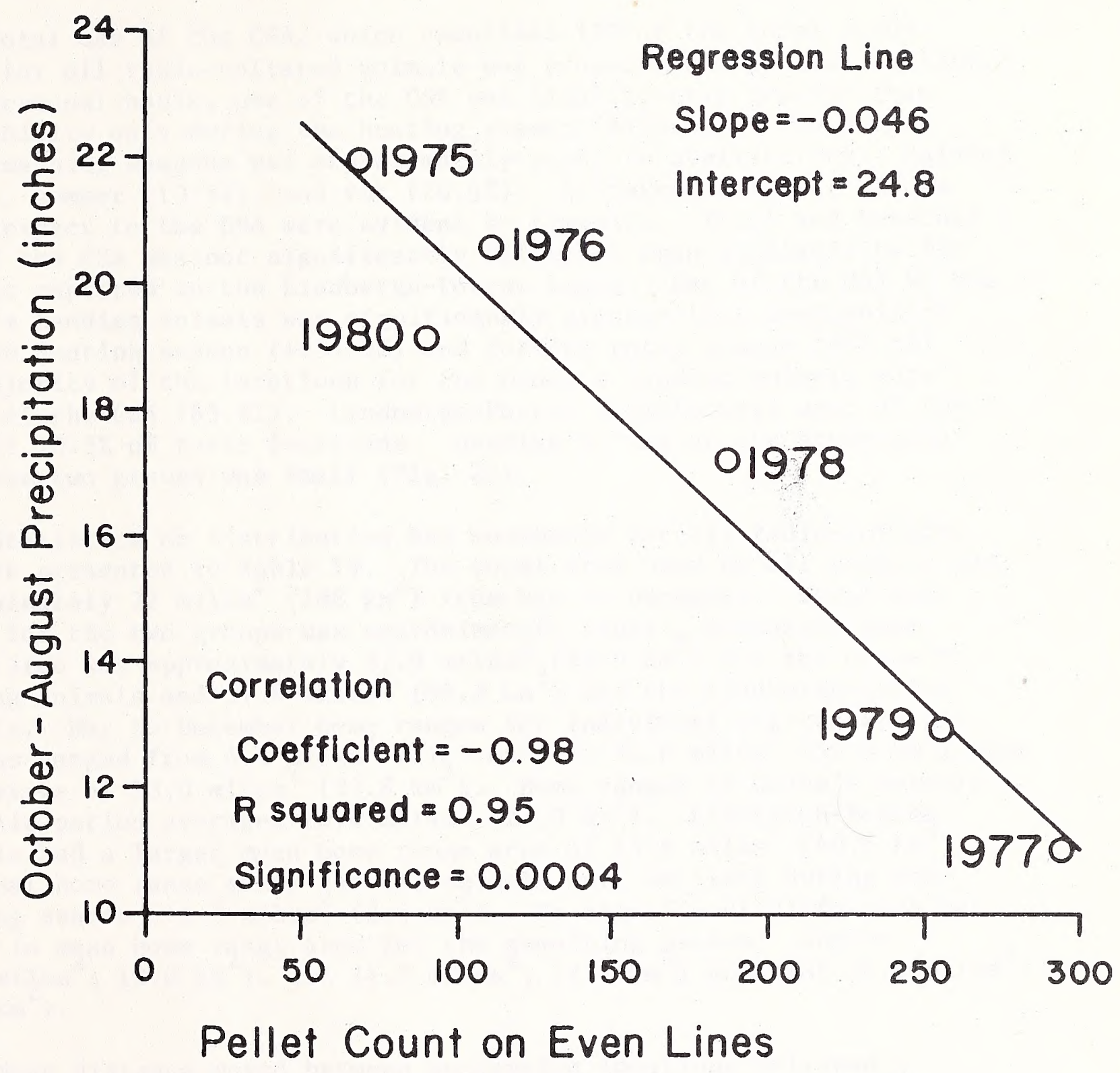

Figure 11. Linear regression of yearly summer pellet counts in the CSA against annual precipitation. 


$$
\text { . }
$$


the remaining four, one radio-collar broke off in early December, and the other three stopped transmitting. Home range polygons and seasonal and total geographic centers of activity for each radioed animal are shown in Figures 12 through 21.

Total use of the CSA, which comprises $15 \%$ of the total study area, for all radio-collared animals was proportional to availability. On a seasonal basis, use of the CSA was significantly greater than availability only during the hunting season $(+36.4 \%)$. Use during the remaining seasons was approximately equal to availability: calving $(8.1 \%)$, summer $(13.5 \%)$, and rut $(20.4 \%)$. Different patterns of use with respect to the CSA were evident by trapsite. Total and seasonal use of the CSA was not significantly different than availability for animals captured in the Lindbergh-Potter traps. Use of the CSA by the Grace's Landing animals was significantly greater than availability for the hunting season $(++54.9 \%)$ and for the total season $(+24.1 \%)$. The majority of the locations for the Grace's Landing animals were north of the CSA (65.8\%). Lindbergh-Potter animals were west of the CSA for $70.8 \%$ of their locations. Overlap in use of the study area by these two groups was small (Fig. 22).

Statistics on distribution and movements for all radio-collared elk are presented in Table 19.2 The total area used by all animals was approximately 72 miles $\left(188 \mathrm{~km}^{2}\right)$ from May to December. Total home range for the two groups was approximately equal. 2 Composite home range area was approximately 37.9 miles $2\left(98.5 \mathrm{~km}^{2}\right)$ for the Grace's Landing animals and $37.8 \mathrm{miles}^{2}\left(99.3 \mathrm{~km}^{2}\right.$ ) for the Lindbergh-Potter animals. May to December home ranges $\mathrm{f}_{\mathcal{Q}} \mathrm{r}$ individual elk tracked 211 seasons ranged from 6.8 miles $\left(17,7 \mathrm{~km}^{2}\right)$ to 23.0 miles $\left(59.9 \mathrm{~km}^{2}\right)$ with an average of 13.0 miles $\left(33.8 \mathrm{~km}^{2}\right.$. Home ranges of Grace's animals for this period averaged 10.4 miles $^{2}(27.0 \mathrm{~km})$. Lindbgrgh-Potter animals had a larger mean home range area of 15.6 miles $\left(40.6 \mathrm{~km}^{2}\right)$. Seasonal home range areas for all ayimals were smallest during the calving season - 1.3 miles $\left(3.4 \mathrm{~km}^{2}\right)$. No significant difference was noted in mean home range area for the remaining geason: summer ${ }^{2}(4.6$ mizes $; 12.0 \mathrm{~km})$, rut $\left(4.7\right.$ miles $\left.; 12.2 \mathrm{~km}^{2}\right)$ and hunt $(4.4$ miles; $\left.11.4 \mathrm{~km}^{2}\right)$.

Mean distance moved between successive locations followed a pattern similar to that for home range areas. Calving season showed the smallest grand mean of 1.2 miles $(1.9 \mathrm{~km})$ as well as the smallest mean movement for individual elk $(0.5$ miles; $0.8 \mathrm{~km})$. The other grand mean values were 1.9 miles $(2.7 \mathrm{~km})$ for the summer and total seasons and 2.0 miles $(3.2 \mathrm{~km})$ for the rut and hunt. Grand means were smaller for the Grace's Landing versus Lindbergh-Potter groups during calving (1.0 miles; $2.6 \mathrm{~km}$ versus 1.6 miles, $4.2 \mathrm{~km})$, summer $(1.5$ miles; $3.9 \mathrm{~km}$ versus 2.2 miles; $5.7 \mathrm{~km}$ ), hunt $(1.6$ miles; $4.2 \mathrm{~km}$ versus 2.6 miles; $6.8 \mathrm{~km}$ ) and total ( 1.5 miles; $3.9 \mathrm{~km}$ versus 2.1 miles; $5.5 \mathrm{~km})$.

Maximum distance moved between successive locations followed the same pattern as mean distance for the two groups of animals. The 



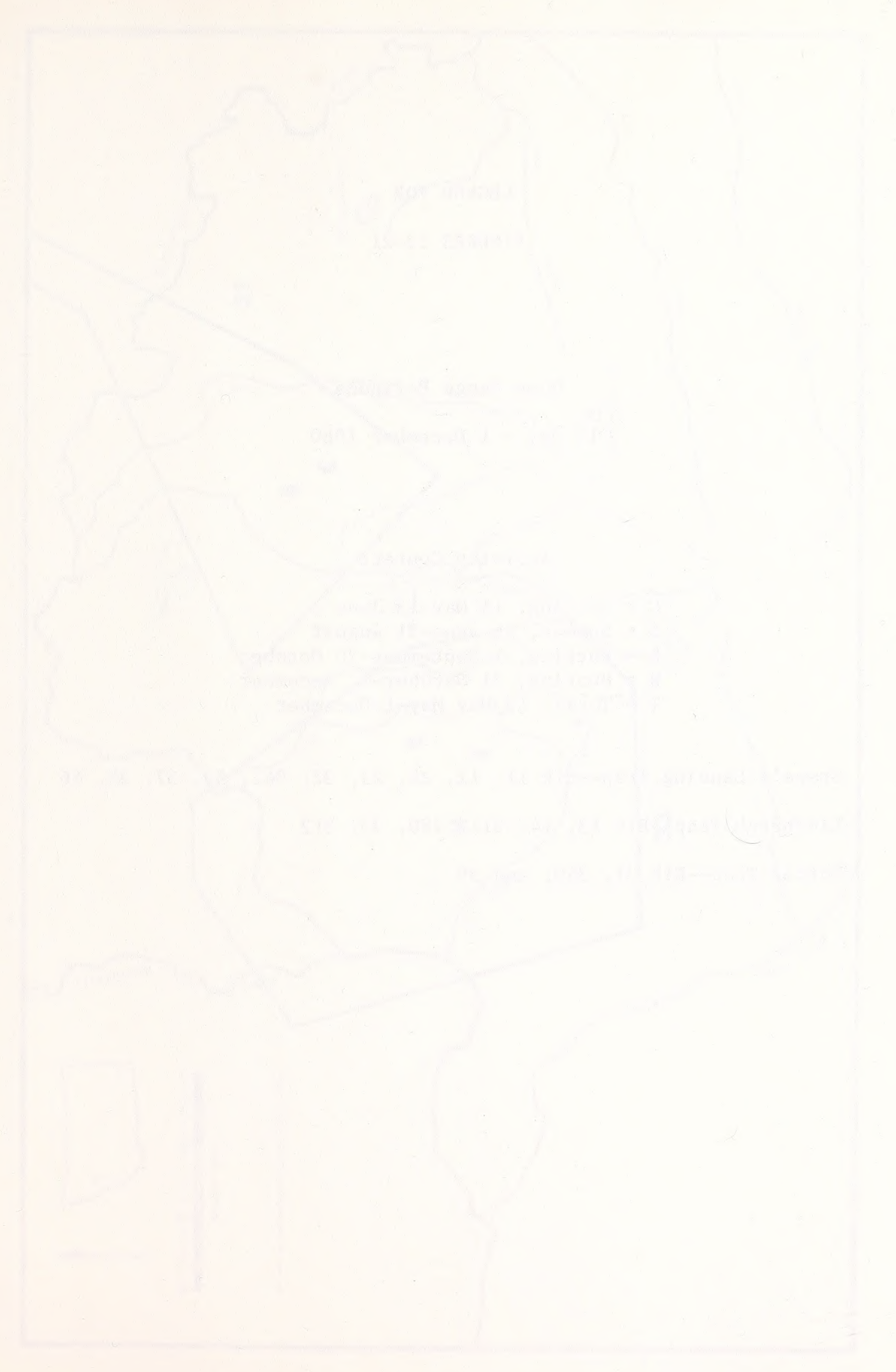




\title{
LEGEND FOR
}

FIGURES 12-21

\author{
Home Range Polygons
}

15 May - 1 December 1980

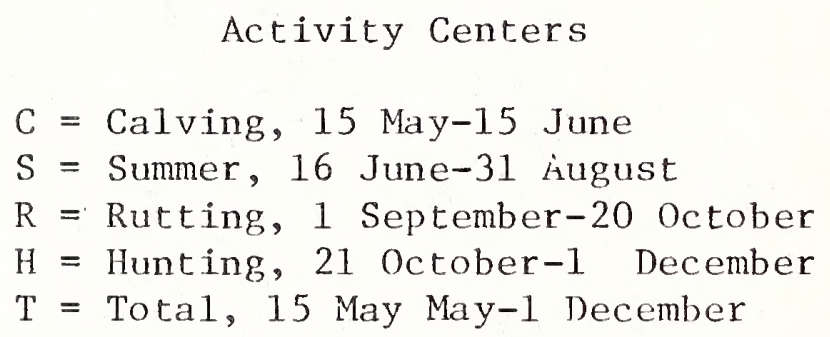

Grace's Landing Trap--Elk 11, 12, 22, 25, 32, 341, 35, 37, 38, 46 Lindbergh Trap--E1k 13, 14, 211, 280, 33, 312

Potter Trap--E1k 31, 340, and 39 


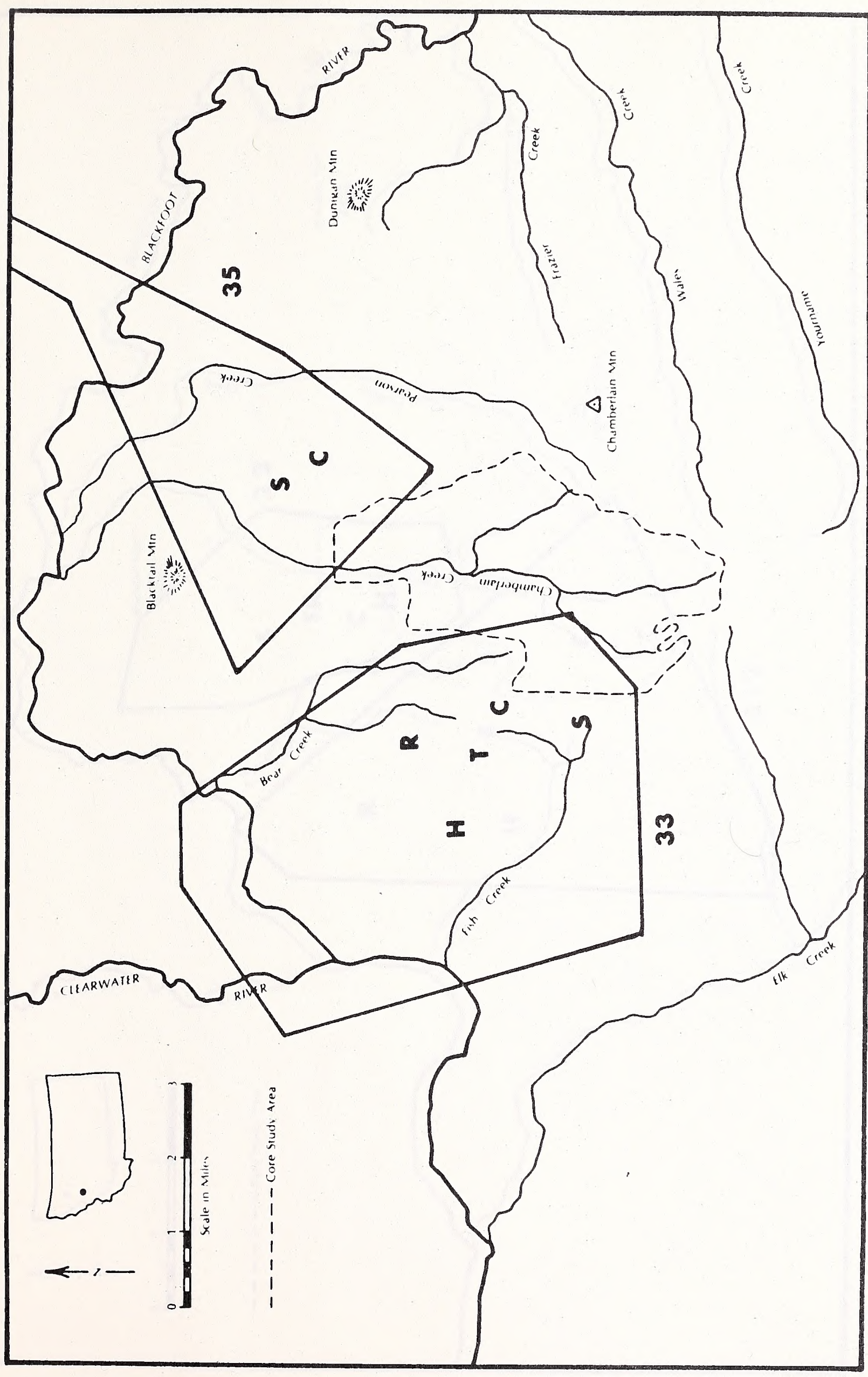

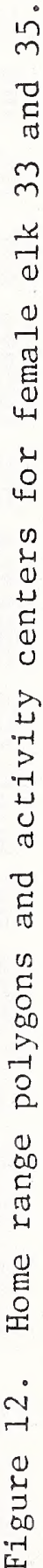





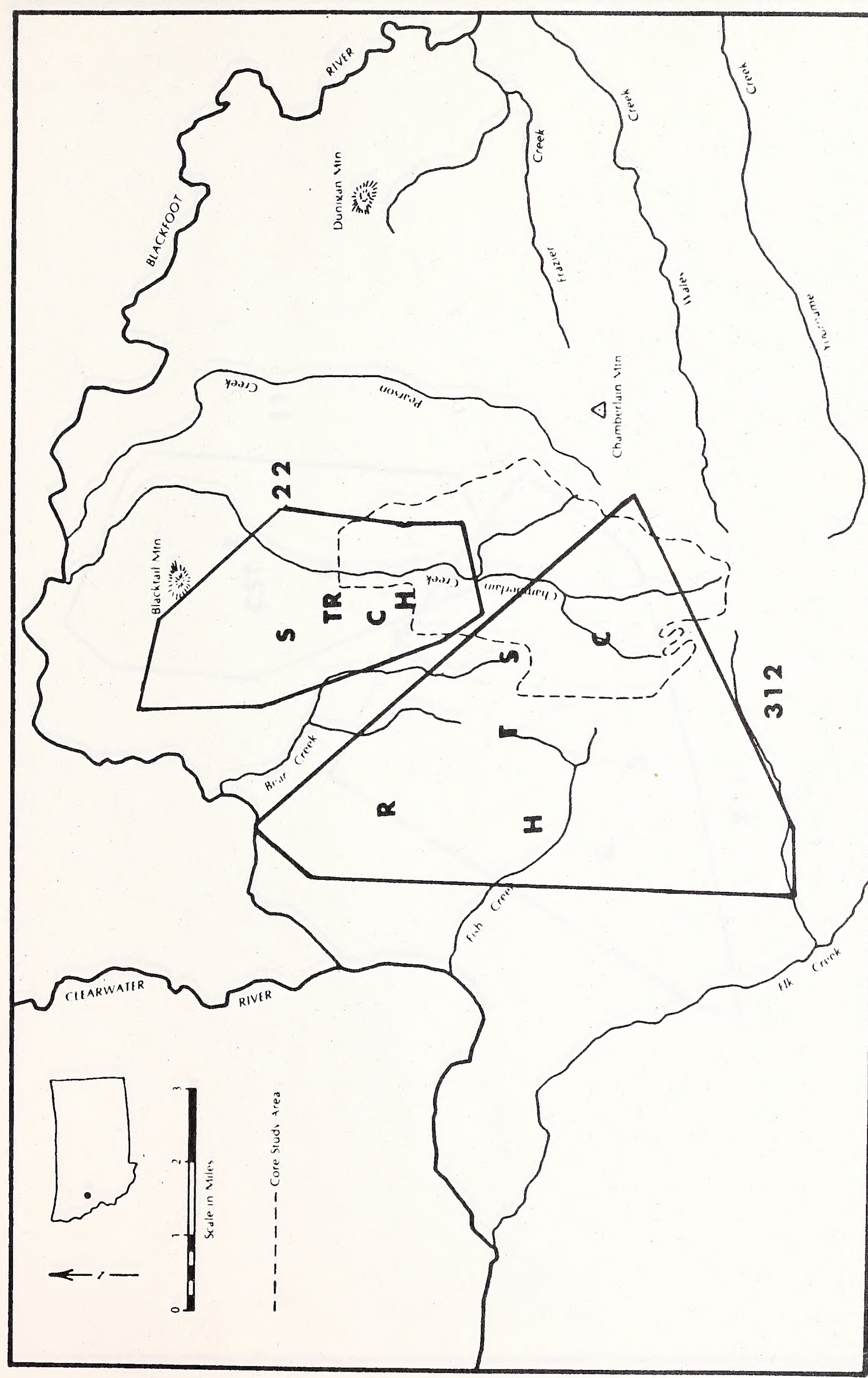

ป 



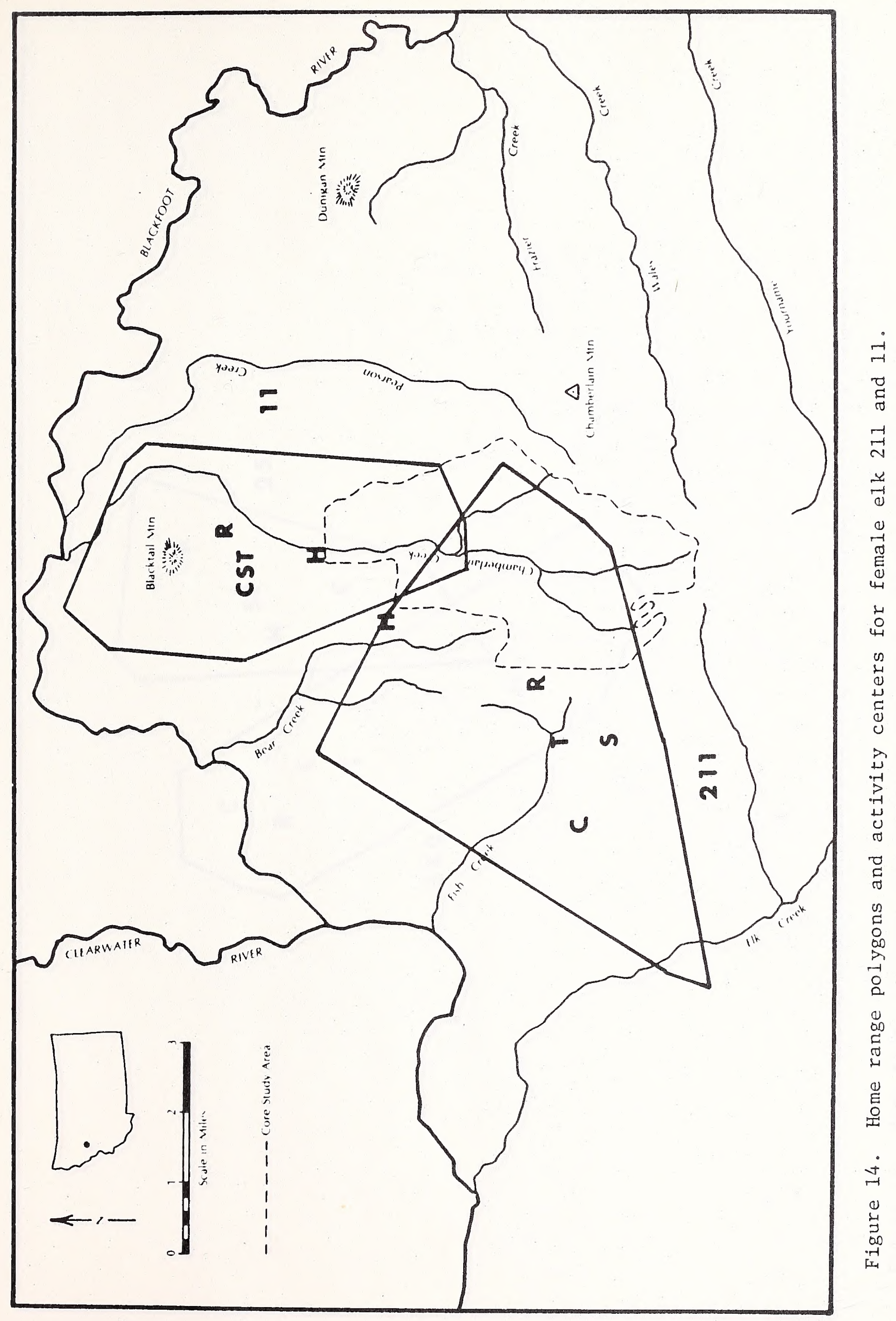





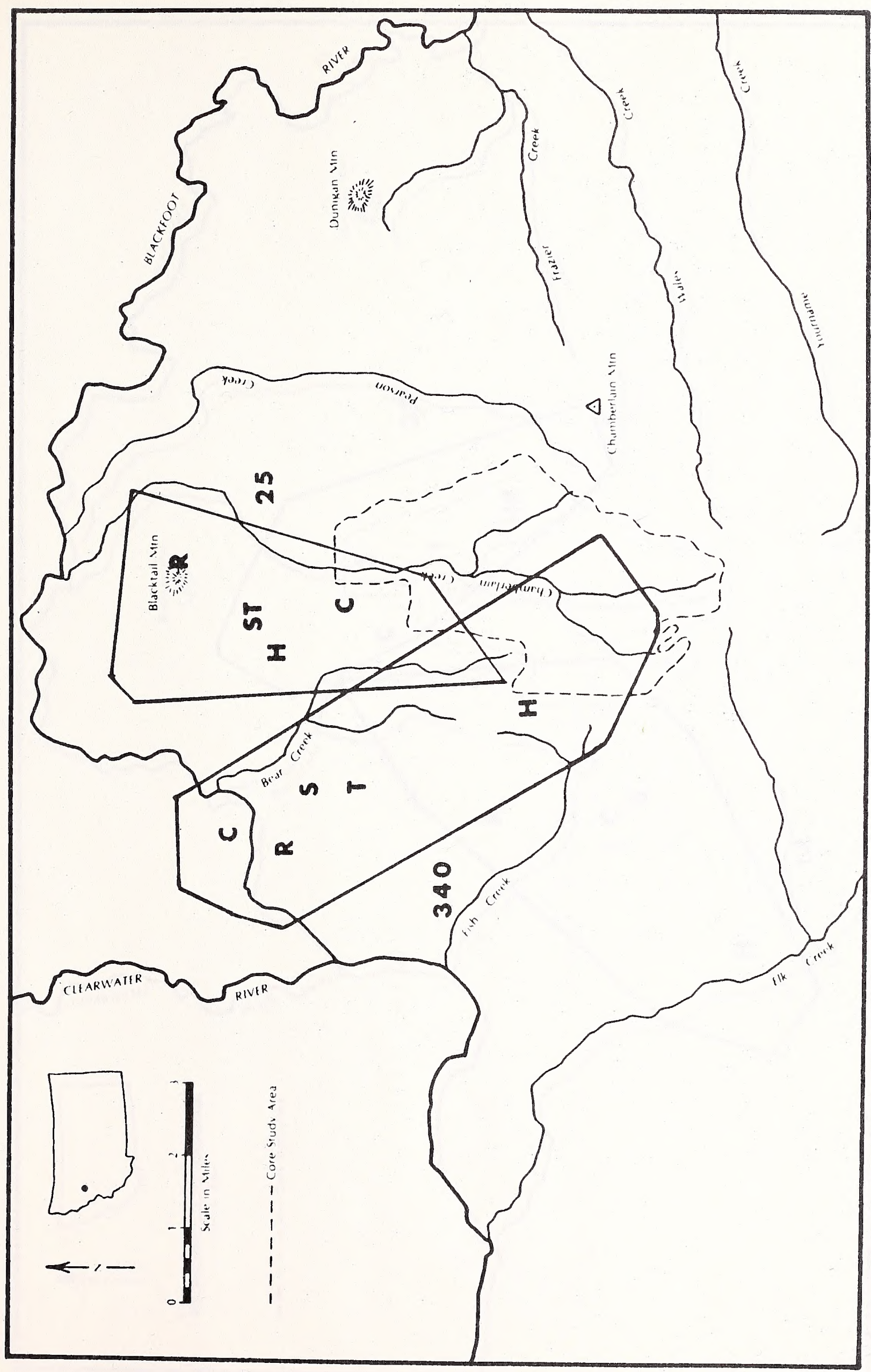

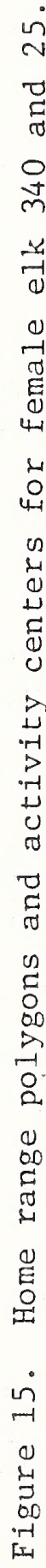




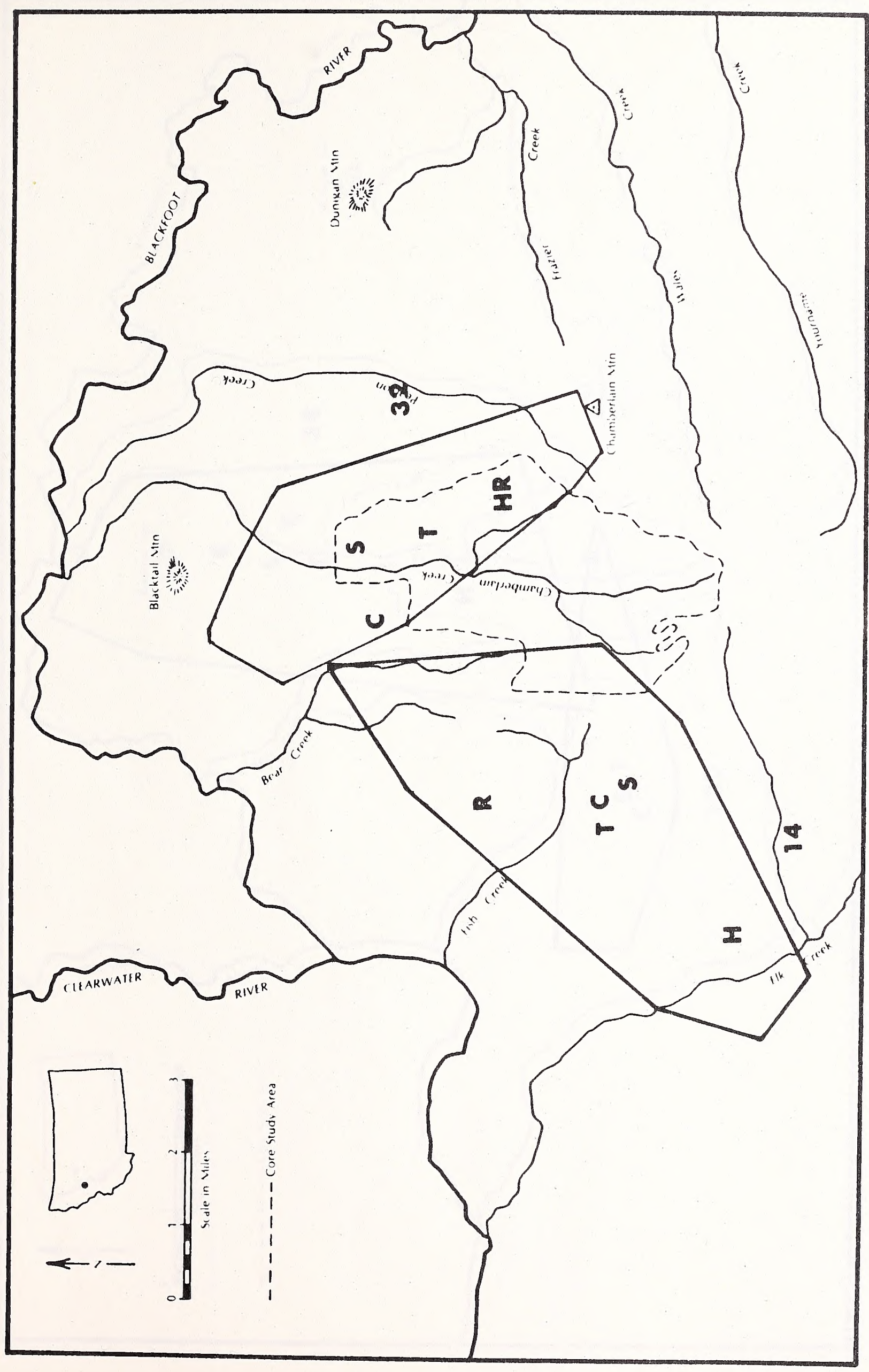

Oت 



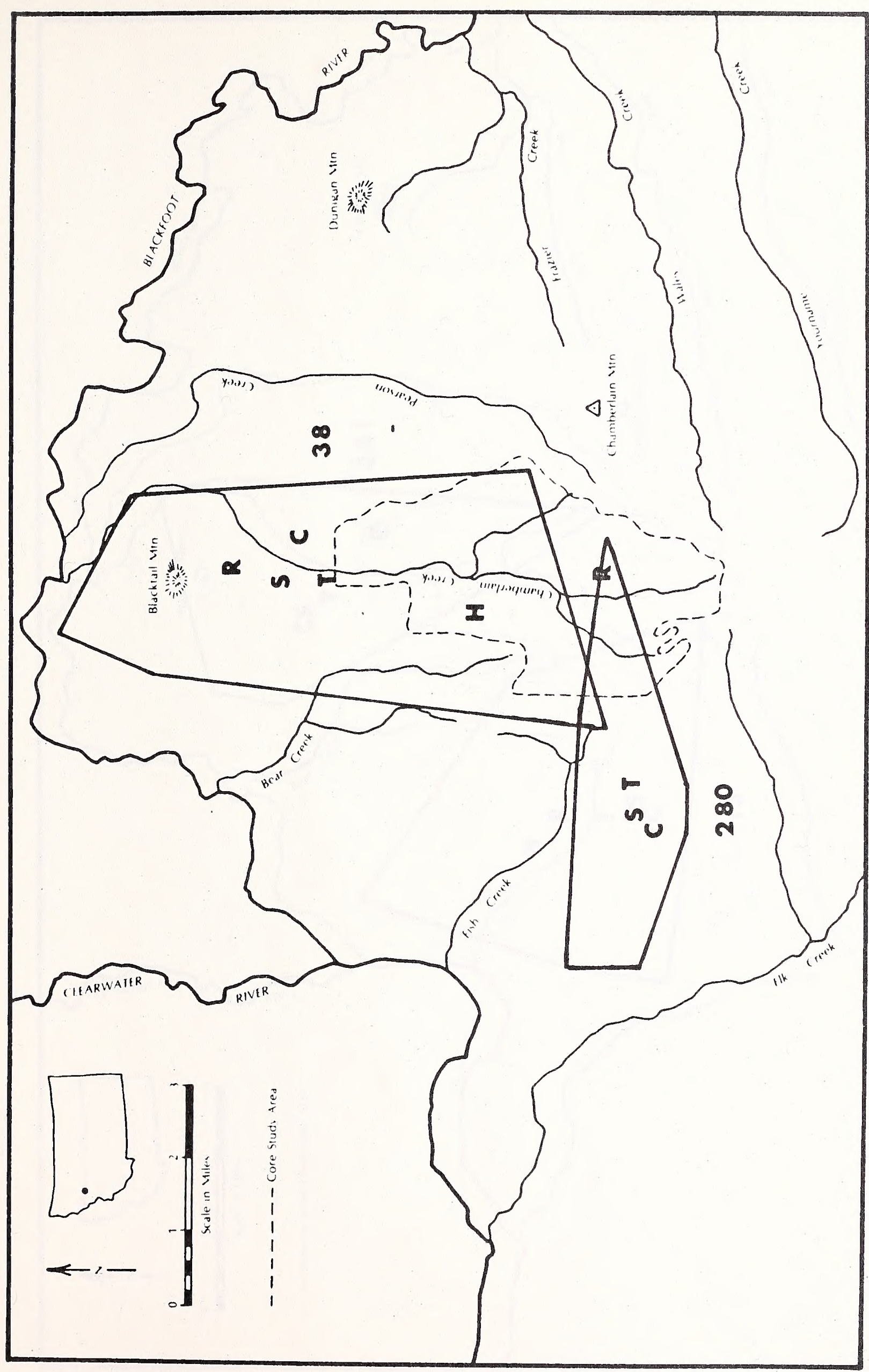

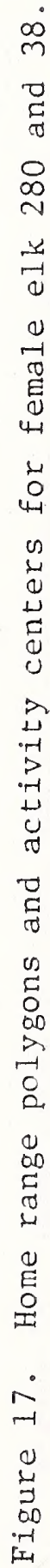





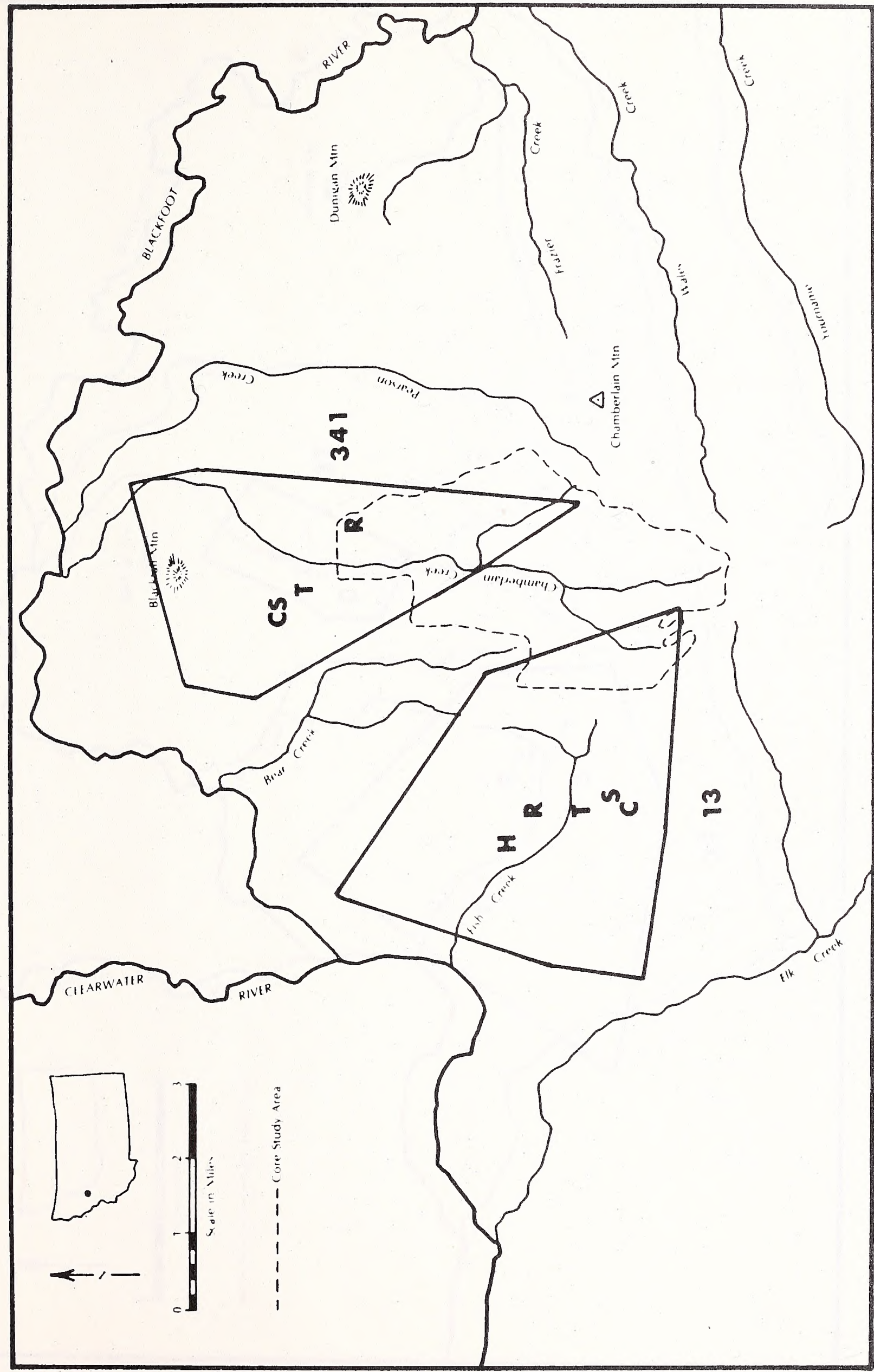

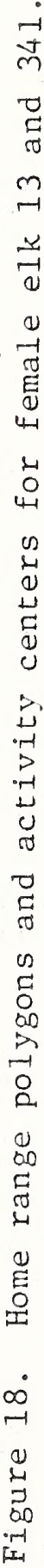





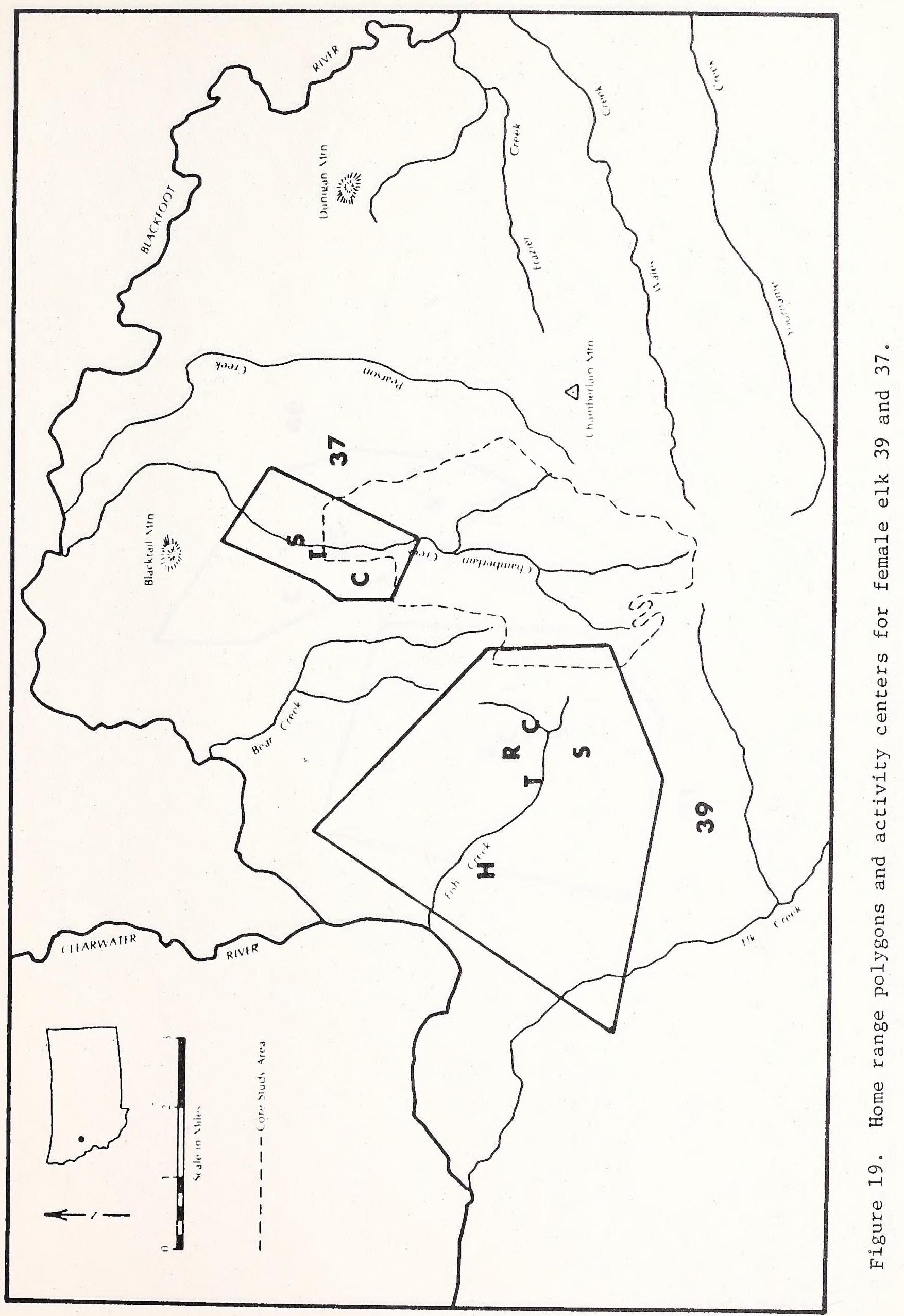




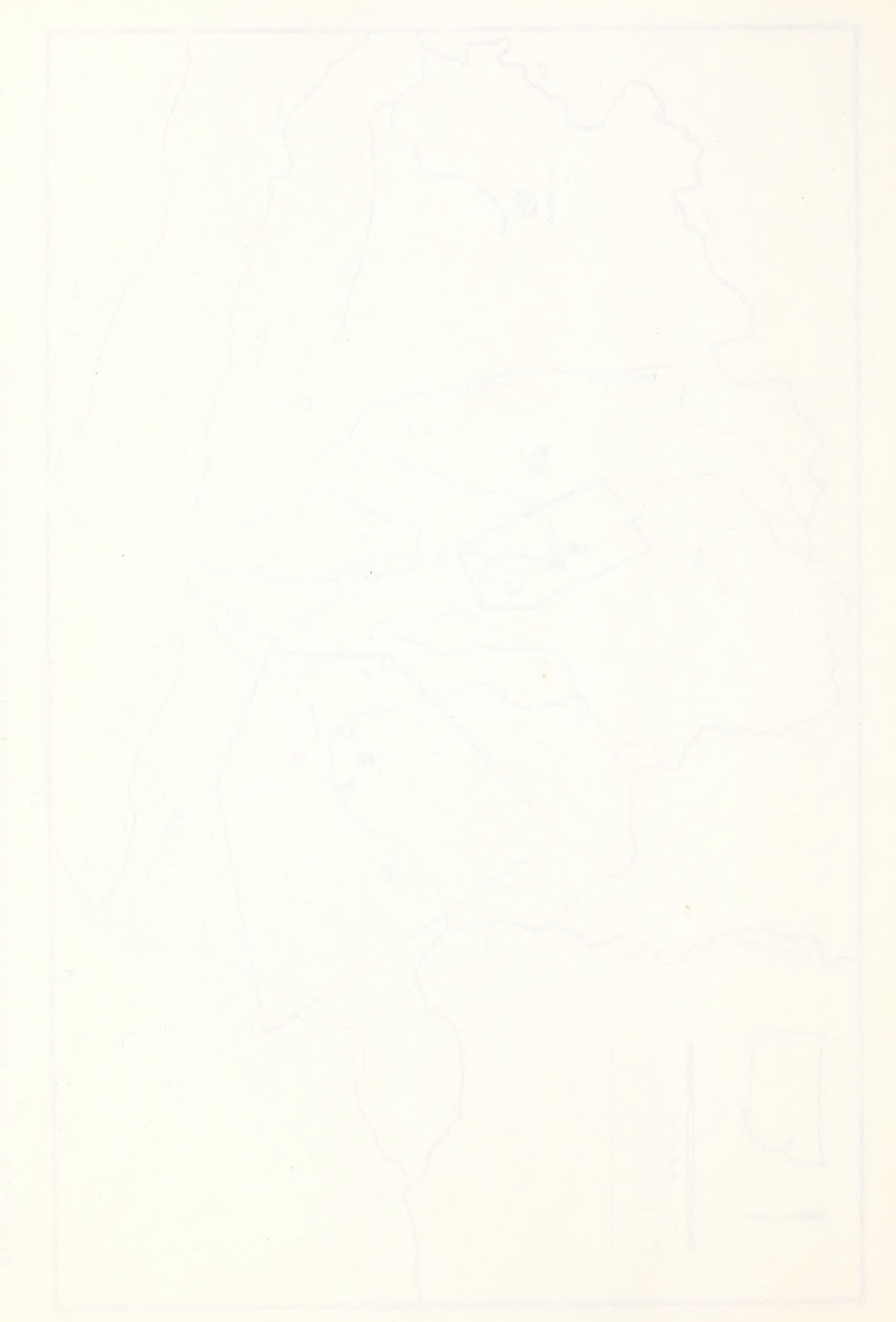




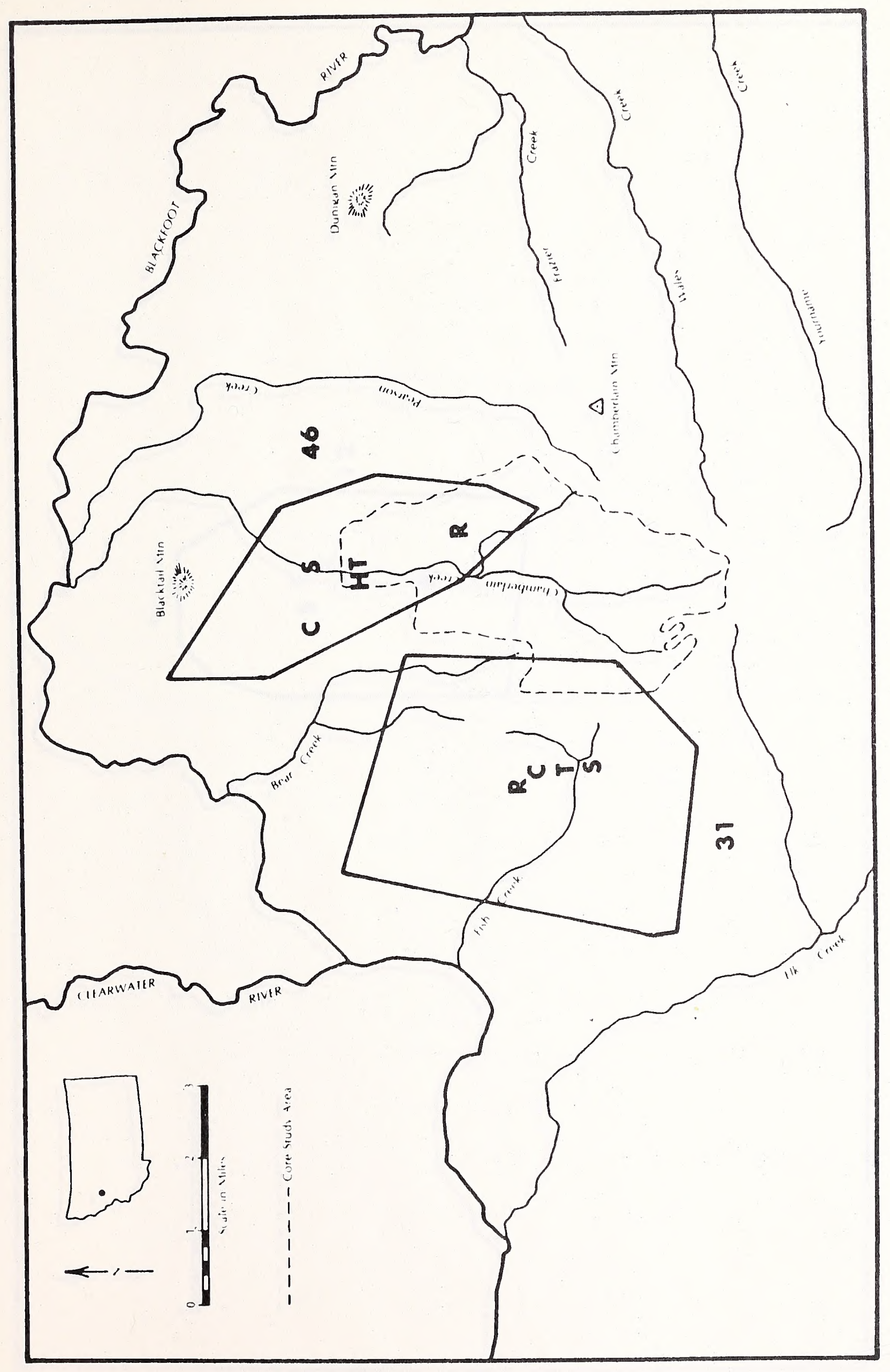

O 



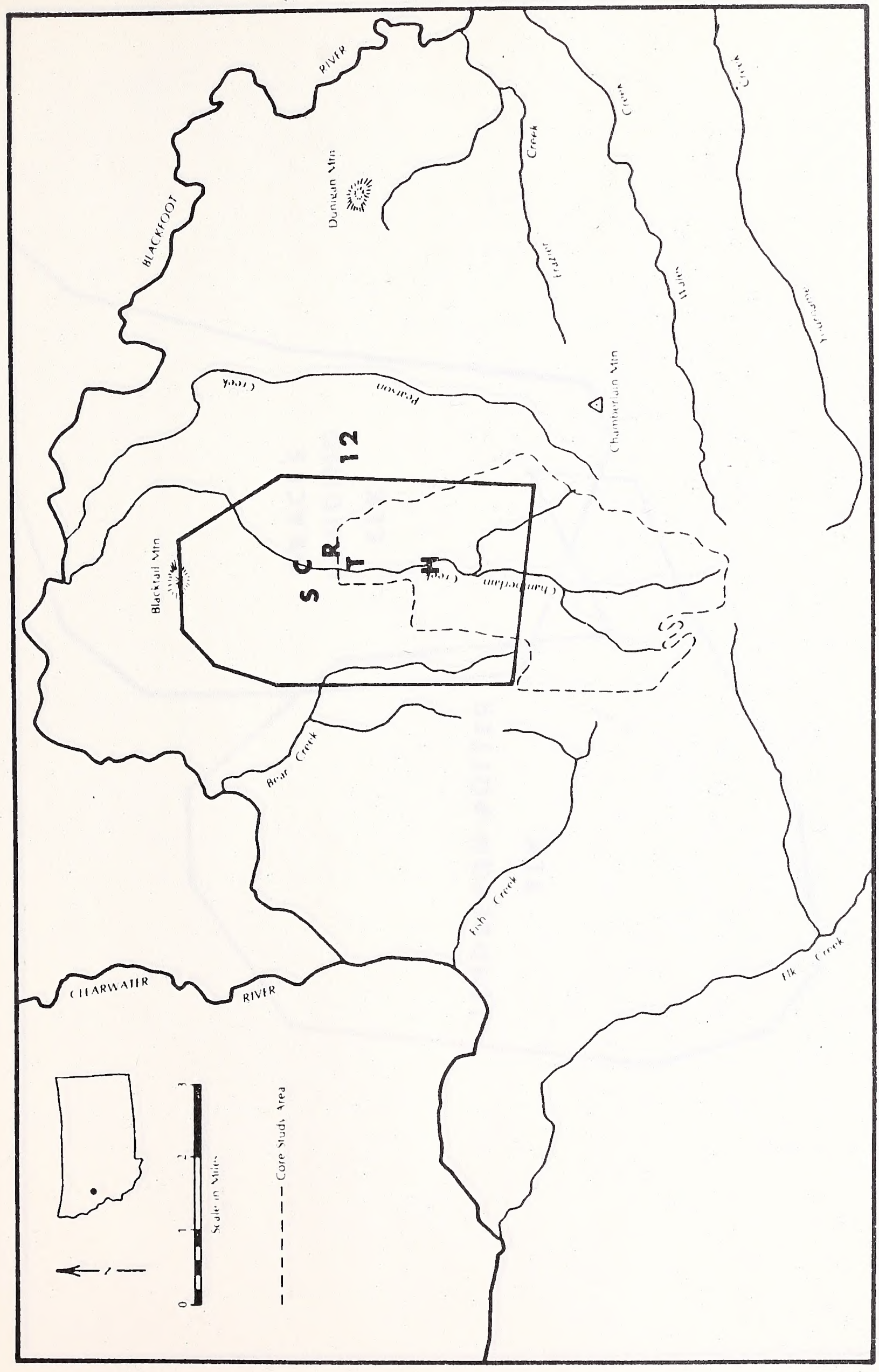

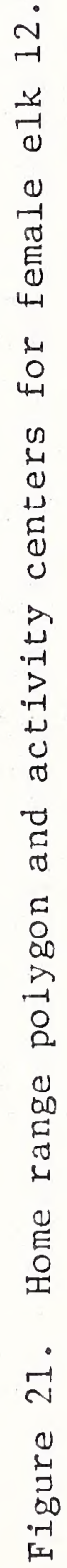





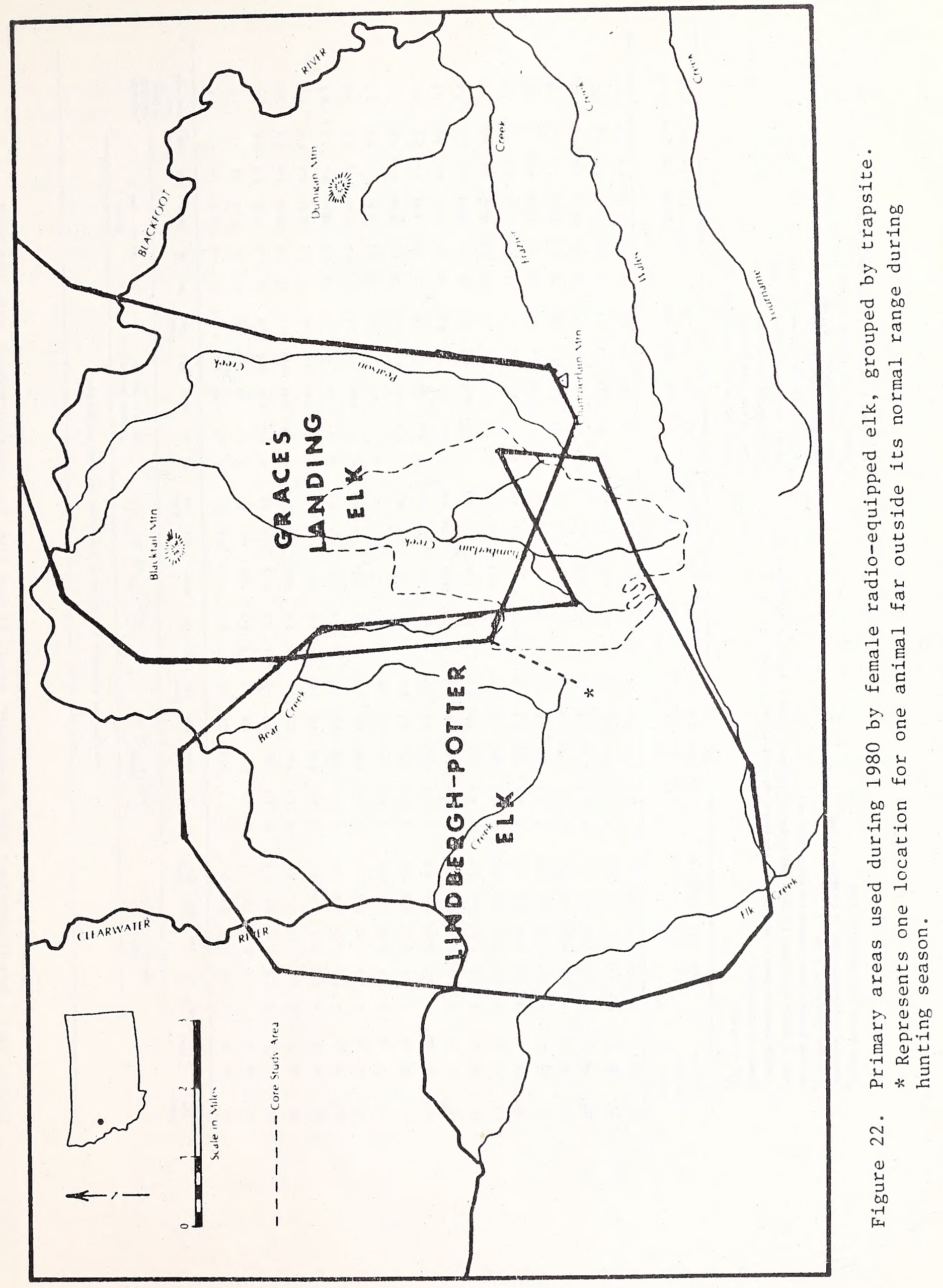




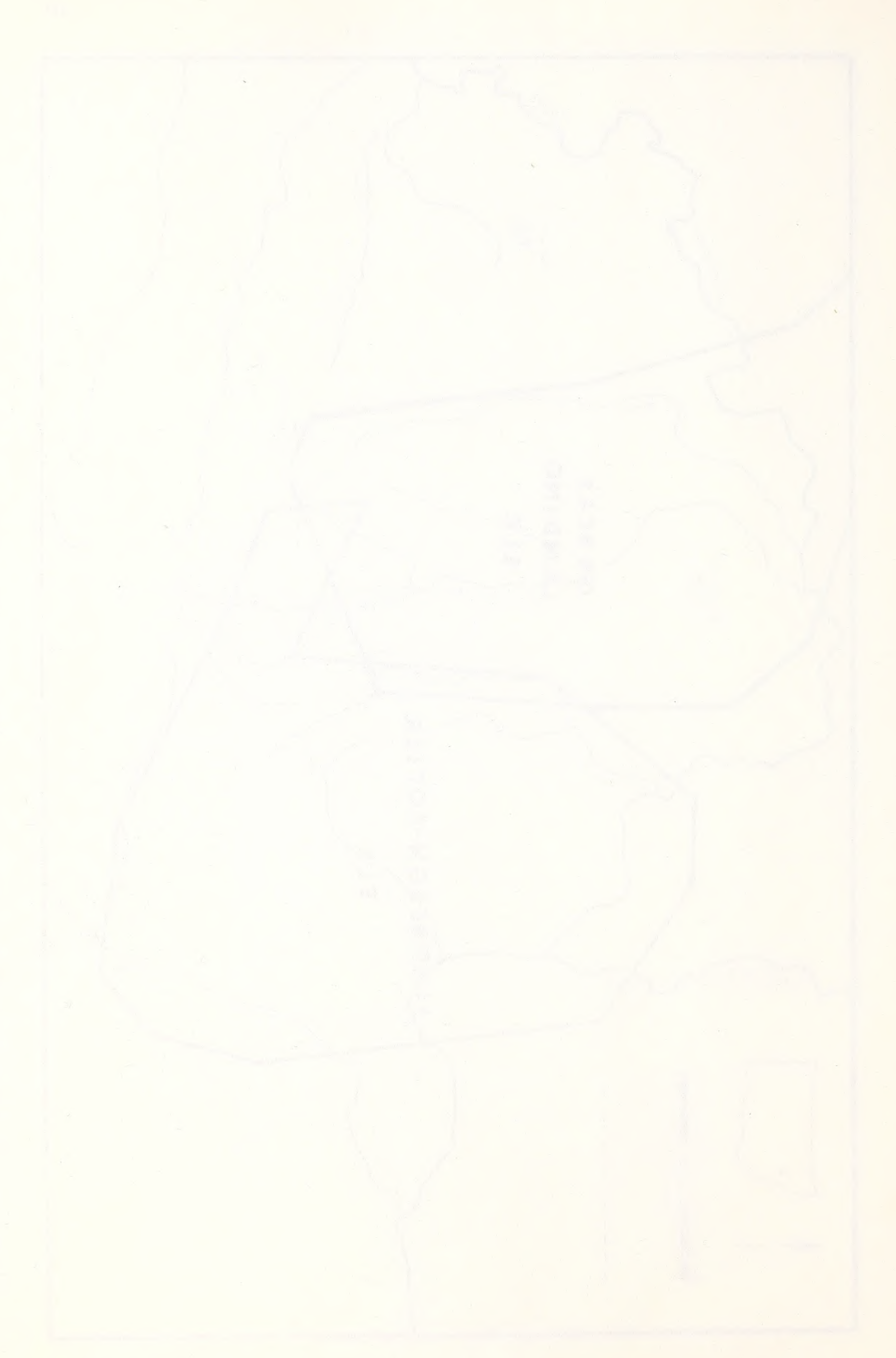




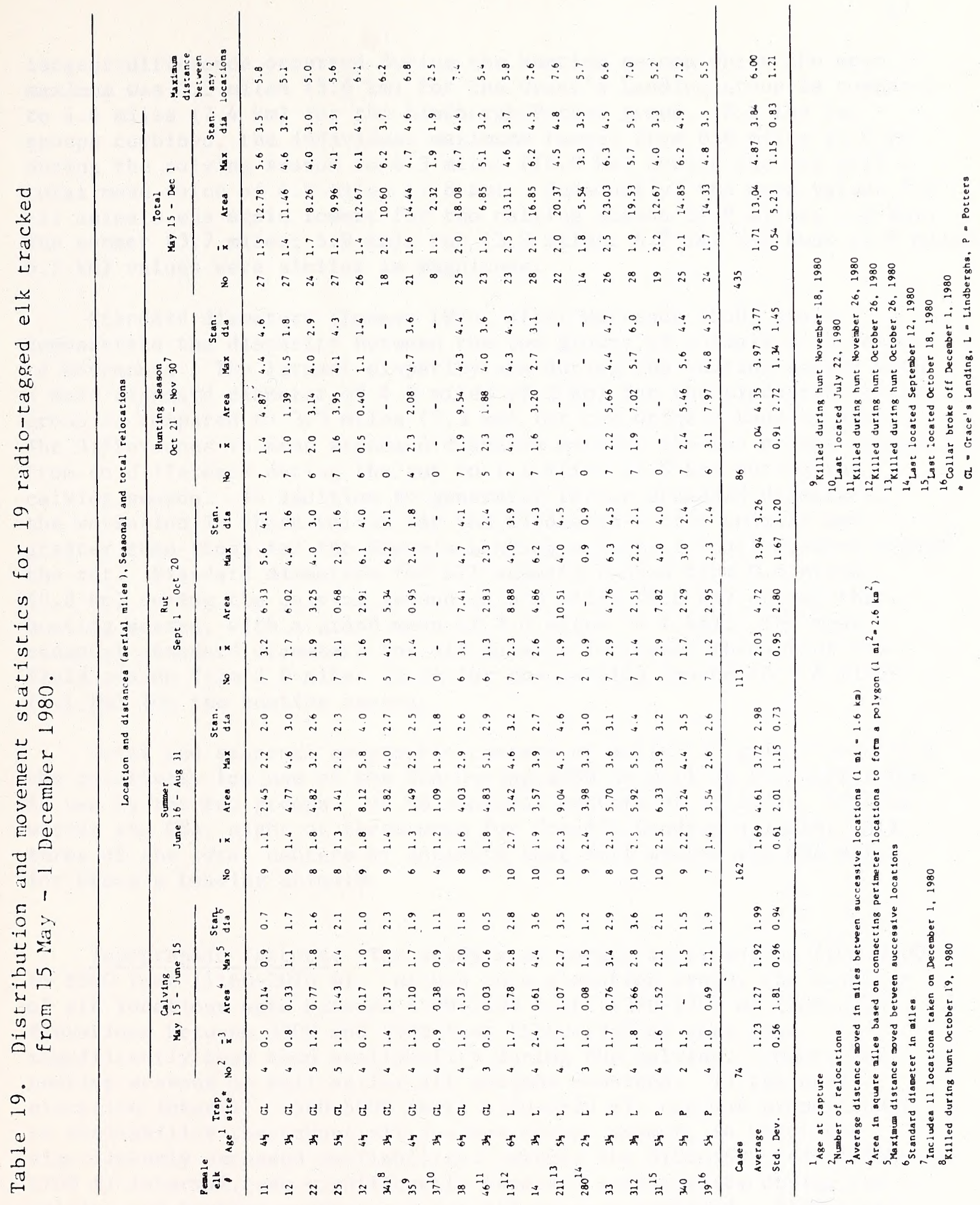



largest difference occurred during the hunting season where the mean maximum was 3.5 miles $(5.6 \mathrm{~km})$ for the Grace's Landing group as compared to 4.6 miles $(7.4 \mathrm{~km})$ for the Lindbergh-Potter group. For the two groups combined, the individual maximums ranged from 0.6 miles $(1.0 \mathrm{~km})$ during the calving season to 6.3 miles $(10.0 \mathrm{~km})$ during the rut with a total mean value of 4.9 miles $(7.8 \mathrm{~km})$. Seasonally, the mean values for all animals was again lowest for the calving season $(1.9$ miles; $3.0 \mathrm{~km})$. The summer $(3.7$ miles; $5.9 \mathrm{~km})$, rut $(3.9$ miles; $6.2 \mathrm{~km})$ and hunt $(3.9$ miles; $6.2 \mathrm{~km}$ ) values were similar in magnitude.

Standard diameters (Lonner 1976, after Harrison 1958) again demonstrate the disparity between the two groups of animals with respect to movements. The largest disparity was during the hunting season with a mean standard diameter of 4.5 miles $(7.2 \mathrm{~km})$ for the Lindbergh-Potter group as compared to 3.3 miles $(5.3 \mathrm{~km})$ for the Grace's Landing group. The differences in mean standard diameter between the two groups ranged from no difference during the rut to 1.1 miles $(1.8 \mathrm{~km})$ during the calving season. In addition to generally larger standard diameters, the variation in these values for the Lindbergh-Potter animals was greater than those for the Grace's Landing animals for all seasons except the rut. Standard diameters for all animals ranged from 0.5 miles $(0.8 \mathrm{~km})$ during the calving season to 6.0 miles $(9.6 \mathrm{~km})$ during the hunting season, with a grand mean of 3.8 miles $(6.1 \mathrm{~km})$. The mean seasonal standard diameters for all animals increased throughout the field season from 2.0 miles (3.2) for the calving season to 3.8 miles $(6.1 \mathrm{~km})$ for the hunting season.

Total and seasonal geographic centers of activity again demonstrate the relatively low use of the CSA during 1980 as well as the difference in use by the two groups. Of 68 seasonal centers of activity, 10 fell within the CSA, eight of these were for Grace's Landing animals. A11 three of the total centers of activity that fell within the CSA were for Grace's Landing animals.

Topographic factors. The study area ranges in elevation from 3800 to 6800 feet $(1160-2070 \mathrm{~m})$. Within this elevation range, the majority of elk locations were between 4500-5600 feet (1370-1700 m) (Table 20). Elevations between 3800 and 4400 feet $(1160-1340 \mathrm{~m})$ were used significantly less than availability during the calving, summer, and hunting seasons as well as for all seasons combined. In the next elevation interval (4500-5000 feet; 1370-1520 m), use was proportional to availability throughout all seasons except summer, in which use significantly exceeded availability. Within the 5100-5600 feet (1550$1700 \mathrm{~m}$ ) interval, use significantly exceeded availability during the calving and hunting seasons and for all seasons combined. Elevations between 5700 feet $(1740 \mathrm{~m})$ and 6800 feet $(2070 \mathrm{~m})$ were used according to availability during each season and for all seasons combined. 

Table 20. Percentages of availability and elk use related to study area elevation, 1980 .

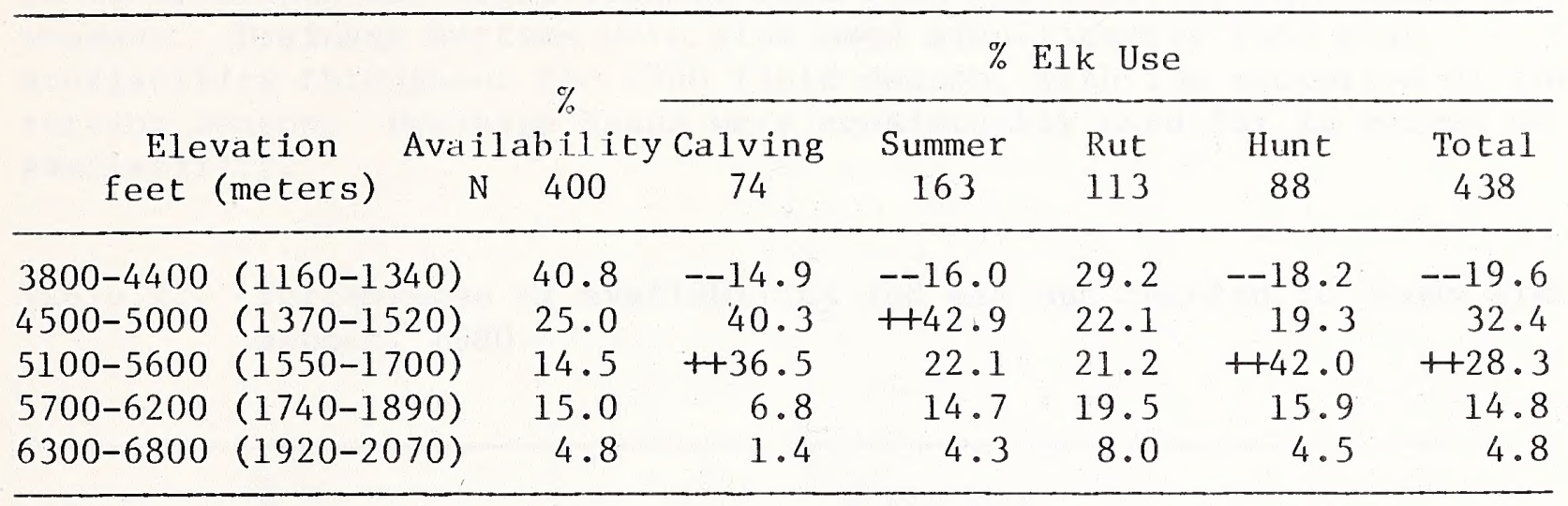

Slopes within the study area are primarily less than $16^{\circ}$. The majority of elk locations were on these gentle $\left(0-15^{\circ}\right)$ slopes (Table 21), with use being significantly greater than availability during the summer season and for all seasons combined. On slopes of moderate steepness $\left(16-30^{\circ}\right)$, use was proportional to availability except during the summer season and for all seasons combined in which use was significantly less than availability. Steep slopes. $\left(>30^{\circ}\right)$ were used less than availability for the calving and summer seasons, but conformed to availability for the remainder of the year.

Table 21. Percentages of availability and elk use related to study area slope, 1980 .

\begin{tabular}{lcccccc}
\hline & & \multicolumn{5}{c}{$\%$ Elk Use } \\
\cline { 2 - 7 } Slope & $\begin{array}{c}\text { Availability } \\
\text { N } 400\end{array}$ & $\begin{array}{c}\text { Calving } \\
74\end{array}$ & $\begin{array}{c}\text { Summer } \\
162\end{array}$ & $\begin{array}{r}\text { Rut } \\
113\end{array}$ & $\begin{array}{c}\text { Hunt } \\
88\end{array}$ & $\begin{array}{r}\text { Total } \\
437\end{array}$ \\
\hline $0-15^{\circ}$ & 59.0 & 68.9 & +75.3 & 69.0 & 68.2 & ++71.2 \\
$16-30^{\circ}$ & 34.0 & 29.7 & -23.5 & 25.7 & 25.0 & -25.4 \\
$>30^{\circ}$ & 7.0 & -1.4 & --1.2 & 5.3 & 6.8 & 3.4 \\
\hline
\end{tabular}

Aspects within the study area were in general used according to availability (Table 22). However, for all seasons combined, east aspects were used significantly more than what was available. Use on level sites was significantly less than availability for each season and for all seasons combined. 

Table 23 presents elk locations in respect to slope position. Ridge tops, upper slopes and mid-slopes were used according to availability, although a majority of the locations were within these categories. Use on lower slopes was significantly less than availability throughout all seasons. Drainage bottoms were also used significantly less than availability throughout the 1980 field season, with the exception of the rutting season. Drainage heads were consistently used far in excess of availability.

Table 22. Percentages of availability and elk use related to study area aspect, 1980 .

\begin{tabular}{|c|c|c|c|c|c|c|}
\hline \multirow[b]{2}{*}{ Aspect } & \multirow{2}{*}{$\begin{array}{c}\% \\
\text { Availa- } \\
\text { bility }\end{array}$} & \multicolumn{5}{|c|}{$\%$ E1k Use } \\
\hline & & $\begin{array}{c}\text { Calving } \\
74\end{array}$ & $\begin{array}{c}\text { Summer } \\
163\end{array}$ & $\begin{array}{l}\text { Rut } \\
113\end{array}$ & $\begin{array}{c}\text { Hunt } \\
88\end{array}$ & $\begin{array}{c}\text { Tota1 } \\
438\end{array}$ \\
\hline $\mathrm{N}$ & 16.8 & 10.8 & 11.0 & 13.3 & 13.6 & 12.1 \\
\hline $\mathrm{NE}$ & 9.5 & 17.6 & 10.4 & 16.8 & 11.4 & 13.5 \\
\hline $\mathrm{E}$ & 7.5 & 10.8 & 15.3 & 16.8 & 14.8 & +14.8 \\
\hline $\mathrm{SE}$ & 4.8 & 9.5 & 6.1 & 3.5 & 4.5 & 5.7 \\
\hline $\mathrm{S}$ & 2.8 & 4.1 & 6.1 & 3.5 & 3.4 & 4.6 \\
\hline SW & 9.8 & 5.4 & 9.8 & 5.3 & 6.8 & 7.3 \\
\hline$W$ & 13.5 & 16.2 & 21.5 & 9.7 & 13.6 & 16.0 \\
\hline NW & 15.8 & 20.3 & 14.7 & 23.9 & 27.3 & 20.5 \\
\hline Leve 1 & 19.8 & --5.4 & --4.9 & --7.1 & --4.5 & --5.5 \\
\hline
\end{tabular}

Table 23. Percentages of availability and elk use related to study area slope position, 1980 .

\begin{tabular}{|c|c|c|c|c|c|c|}
\hline \multirow{2}{*}{ Slope position } & \multirow{2}{*}{$\begin{array}{c}\% \\
\text { Availa- } \\
\text { bility }\end{array}$} & \multicolumn{5}{|c|}{$\%$ E1k Use } \\
\hline & & $\begin{array}{c}\text { Calving } \\
74\end{array}$ & Summer & Rut & $\begin{array}{c}\text { Hunt } \\
87\end{array}$ & $\begin{array}{c}\text { Total } \\
437\end{array}$ \\
\hline & 400 & & & & & \\
\hline Ridge top & 8.8 & 8.1 & 12.9 & 11.5 & 12.6 & 11.7 \\
\hline Upper slope & 25.0 & 35.1 & 20.8 & 33.6 & 23.0 & 27.0 \\
\hline Mid-slope & 21.8 & 28.4 & 25.1 & 15.0 & 26.4 & 23.3 \\
\hline Lower slope & 31.3 & --9.1 & --15.9 & $--13 \cdot 3$ & -17.2 & --14.4 \\
\hline Drainage bottom & 8.8 & --1.4 & --0.6 & 5.3 & --0.0 & --1.8 \\
\hline Drainage head & 4.5 & +17.6 & ++24.5 & ++21.1 & ++20.7 & +21.7 \\
\hline
\end{tabular}




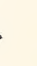


Horizontal configuration (Table 24) along the slope had little effect on elk use of the study area. Use of convex, concave and undulating configurations conformed to availability throughout all seasons and for all seasons combined. Straight slopes were used less than availability during the summer and hunting seasons as well as for all seasons combined.

Distance to water within the study area had little affect upon the distribution of elk (Table 25). The majority of locations fell within $50(45 \mathrm{~m})$ to 350 yards $(320 \mathrm{~m})$ of water. Areas closest to water $(0-50$ yards; $0-45 \mathrm{~m}$ ) received significantly less use than availability during the calving and summer seasons and for all seasons combined. The interval from 150 to 250 yards $(140-230 \mathrm{~m})$ also received significantly less use during the calving season. The only other significant variation from availability occurred for all seasons combined in the interval greater than 550 yards $(500 \mathrm{~m})$ from water. These areas experienced more use than availability.

Table 24. Percentages of availability and elk use related to horizontal configuration along the slope contour, 1980.

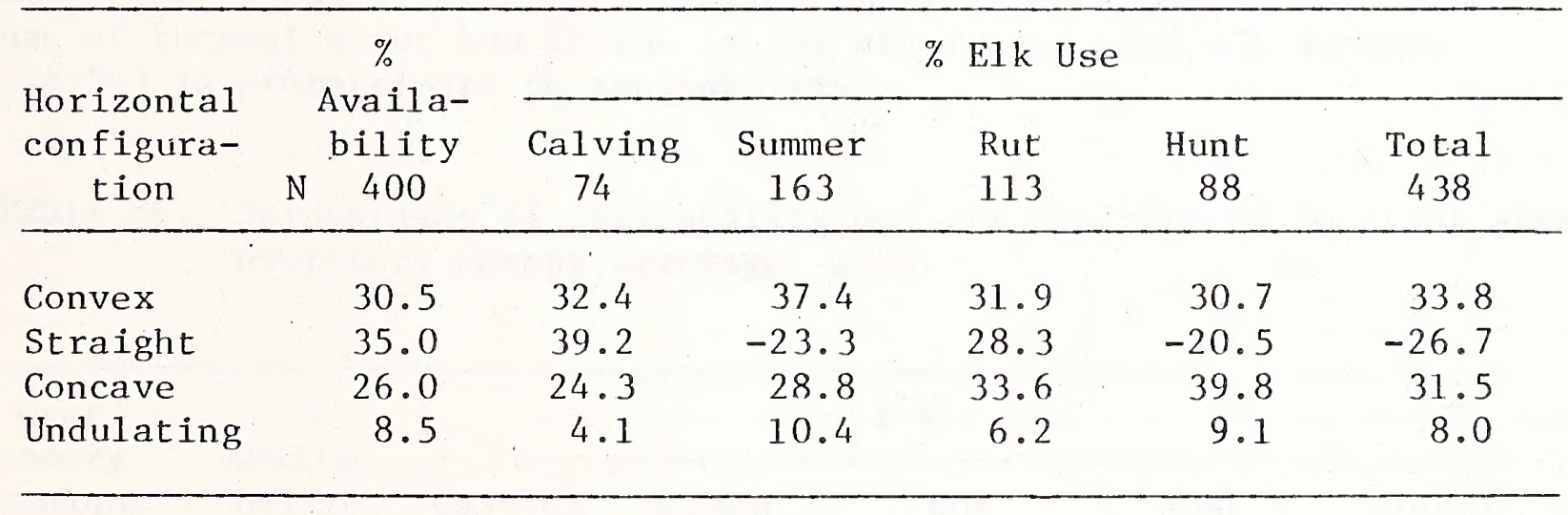

Table 25. Percentages of availability and elk use related to distance to water, 1980.

\begin{tabular}{lcrrrrr}
\hline & Availa- & \multicolumn{5}{c}{$\%$ Elk Use } \\
\cline { 5 - 7 } $\begin{array}{c}\text { Distance to water } \\
\text { yards (meters) }\end{array}$ & $\begin{array}{c}\text { bility } \\
\text { N } 400\end{array}$ & $\begin{array}{c}\text { Calving } \\
73\end{array}$ & $\begin{array}{c}\text { Summer } \\
163\end{array}$ & $\begin{array}{r}\text { Rut } \\
113\end{array}$ & $\begin{array}{c}\text { Hunt } \\
88\end{array}$ & \multicolumn{1}{c}{$\begin{array}{c}\text { Total } \\
437\end{array}$} \\
\hline $0-50(0-45)$ & 16.0 & --2.7 & --4.9 & 8.8 & 8.0 & --6.2 \\
$50-150(45-140)$ & 23.0 & 30.1 & 19.0 & 13.3 & 17.0 & 19.0 \\
$150-250(140-230)$ & 24.0 & -17.8 & 35.0 & 25.7 & 23.9 & 27.5 \\
$250-350(230-320)$ & 15.5 & 32.9 & 13.5 & 20.4 & 14.8 & 18.8 \\
$350-450(320-410)$ & 12.5 & 6.8 & 15.3 & 19.5 & 17.0 & 15.3 \\
$450-550(410-500)$ & 5.3 & 2.7 & 4.9 & 2.7 & 9.1 & 4.8 \\
$>550(>500)$ & 3.8 & 6.8 & 7.4 & 9.7 & 10.2 & +8.5 \\
\hline
\end{tabular}



Vegetative factors. Use of the study area related to percent overstory canopy coverage varied depending upon the season (Table 26). Use was proportional to availability for all classes during the calving season and for all seasons combined. During the summer season significantly less use was made of open sites and of sites in the 75-95\% class, but use significantly exceeded availability for non-open sites with less than $25 \%$ canopy coverage. Significantly greater use of the 75-95\% cover class occurred for both the rut and hunting seasons. The moderate class $(25-75 \%)$ was used significantly less than availability during the hunt. Given the relatively low incidence of western larch (Larix occidentalis) within most of the study area, it is assumed that any site containing $75 \%$ or greater cover provides adequate thermal cover. Therefore, thermal cover-forage ratios are easily obtained by combining the last two cover classes into the percent thermal cover. Since a measure of hiding cover for the study area is not available, these ratios cannot be directly related to those discussed by Thomas et al. (1979). Available hiding cover for the study area will be evaluated next field season. The study area on the whole has thermal cover-forage ratio of 40:60. During 1980, elk used less thermal cover than that available during the calving $(31: 69)$ and summer $(34: 66)$ seasons. However, during the rut $(61: 39)$ and hunt $(60: 40)$ these ratios are significantly different $(p<0.01)$, with more thermal cover being selected for. The use of thermal cover and forage in the study area over all seasons $(46: 54)$ is proportional to availability.

Table 26. Percentages of availability and elk use related to study area overstory canopy coverage, 1980 .

\begin{tabular}{|c|c|c|c|c|c|c|}
\hline \multirow{3}{*}{$\begin{array}{l}\text { Over- } \\
\text { story } \\
\text { canopy } \\
\text { cover }\end{array}$} & \multirow{2}{*}{$\begin{array}{c}\% \\
\text { Availa- } \\
\text { bility }\end{array}$} & \multicolumn{5}{|c|}{ \% Elk Use } \\
\hline & & Calving & Summer & Rut & Hunt & Total \\
\hline & $N \quad 300$ & 74 & 163 & 113 & 88 & 438 \\
\hline OPEN & 8.8 & 10.8 & -3.1 & 6.2 & 3.4 & 5.3 \\
\hline$<25 \%$ & 13.8 & 17.6 & +28.8 & 6.2 & 13.6 & 18.0 \\
\hline $25-75 \%$ & 37.4 & 40.5 & 34.4 & 26.5 & -22.7 & 31.1 \\
\hline $75-95 \%$ & 31.0 & 27.0 & -19.0 & ++54.0 & ++53.4 & 36.3 \\
\hline $95-100 \%$ & 9.1 & 4.1 & 14.7 & 7.1 & 6.8 & 9.4 \\
\hline
\end{tabular}

Table 27 gives percentages of availability and elk use of the study area categorized by stand composition, age and canopy coverage. The pole-young, mixed category and the mature-old, mixed category were not differentiated for the 1980 data. Therefore, for the purpose of this analysis, these categories are combined. The majority of elk locations for all seasons occur in the mixed species cover types. Use was significantly greater than availability for the light to moderate mixed 

species stands during the summer season and significantly less than availability during the hunting season. The densely stocked mixed species stands were used significantly more than availability during the rut and hunting seasons. All lodgepole stands were consistently used less than availability, but not significantly so. Use of the brush-seedling-sapling habitats varied with season. These areas received no use during the summer and rutting seasons. Use was greater than availability during the calving and hunting season (significantly so during the hunting season). The pasture-hayfield habitat was used significantly less than availability during each season and for all seasons combined. In general, use in other habitats approximated availability for all seasons.

E1k use by habitat type (Pfister et a1. 1977) is shown in Table 28. Use of individual habitat types varied from season to season, but the majority of the habitat types were not used significantly different from their availability within the study area. Pasture-hayfields were used significantly less than availability during all seasons. The PSME/bunchgrass types were used less than availability for a11 seasons (significantly less during the summer and rut) except during the hunt. PSME/VACA was consistently used less than availability for all seasons, with siginificant differences occurring for the calving season and for a11 seasons combined. The PSME/SYAL and ABLA/CACA habitat types were consistently used less than availability. Use of the PSME/PHMA, PSME/ VAGL, PSME/LIBO, PSME/CARU, ABLA/LIBO, and ABLA/XETE-VASC habitat types was generally greater than availability. Significantly greater use occurred during the summer and for all seasons combined within the PSME/CARU habitat type. Use significantly exceeded availability during the hunt and over al1 seasons for ABLA/LIBO and during the summer, hunt and all seasons combined within the ABLA/XETE-VASC habitat type. Use was significantly less than availability for ABLA/MEFE during the-summer and for ABLA/XETE-VAGL during the hunting season.

Disturbance relationships. Distance to the nearest site of active human disturbance was recorded for each elk location. Whenever possible, distances were measured from elk locations to specific sites of human activity, such as logging and road construction, as observed while tracking elk from the air. Otherwise, general areas of disturbance for discrete time periods were used. Logging occurred from mid-winter through hunting season in five units on the east ridge of the Chamberlain Creek drainage. Three of these units were BN logging contracts within the CSA. Much of the lower south and southeast aspects of Blacktail Mountain above main Chamberlain Creek was selectively logged from early June to mid-October. Between mid-May and mid-July, Champion selectively logged several hundred acres on the south and west aspects of Bata Mountain. In addition to these units, Champion selectively logged a unit above Bear Creek Flats from midJuly until just prior to the hunting closure. Several small units were logged in Pearson Creek, east of the study area from mid-February to early May. In addition to these logging activities, numerous small tracts were thinned on E Bar L Ranch land from Fish Creek north to the Blackfoot River 

Table 27. Percentages of availability and elk use related to habitat age, species composition and canopy coverage, 1980.

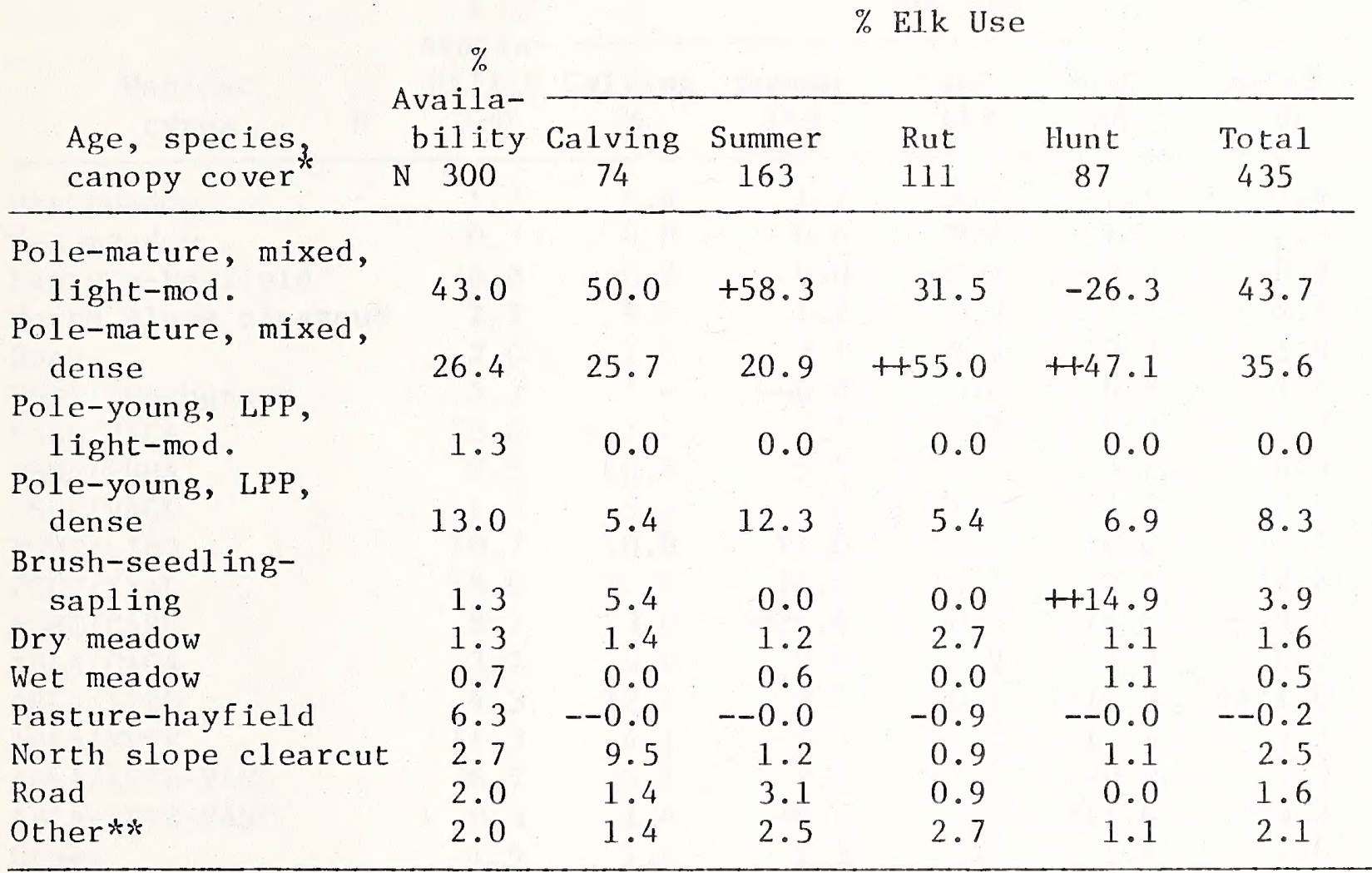

\footnotetext{
*Canopy cover: 1ight <25\%; moderate 25-75\%; dense $>75 \%$ ***

Other: brushy riparian, water, scree, rock
}

throughout the 1980 field season. In addition to the road construction within the CSA (mentioned in the pellet count results section) another spur road was constructed within the greater study area. During the first two weeks of October, Champion constructed a road towards the. Fish Creek drainage. This spur connects with the Sunset Hill road just north of Elk Creek.

Table 29 gives the distribution of elk locations in respect to nonroad disturbances. Analysis from previous years did not include the hunting season because all activities stopped during that period. Although this years analysis does include the hunting season it was not possible to spearate hunter pressure from other forms of disturbance. During the calving season, elk use was proportional to availability for all distance categories. The interval from 1.0 to 1.5 miles received the most elk use. During the summer season, use was significantly less than availability for areas less than 0.5 miles $(0.8 \mathrm{~km})$ from disturbance and significantly greater than availability for the interval from 1.0 to 1.5 miles $(1.6-2.4 \mathrm{~km})$. Results for the rutting season were similar to 

Table 28. Percentages of availability and elk use related to study area habitat types, 1980.

\begin{tabular}{|c|c|c|c|c|c|c|}
\hline \multirow[b]{2}{*}{$\begin{array}{c}\text { Habitat } \\
\text { types }\end{array}$} & \multirow{2}{*}{$\begin{array}{c}\% \\
\text { Availa- } \\
\text { bility } \\
300\end{array}$} & \multicolumn{5}{|c|}{$\%$ E1k Use } \\
\hline & & $\begin{array}{c}\text { Calving } \\
74\end{array}$ & $\begin{array}{c}\text { Summer } \\
163\end{array}$ & $\begin{array}{l}\text { Rut } \\
113\end{array}$ & $\begin{array}{c}\text { Hunt } \\
88\end{array}$ & $\begin{array}{c}\text { Total } \\
438\end{array}$ \\
\hline Dry meadow & 1.3 & 1.4 & 1.2 & 2.7 & 1.1 & 1.6 \\
\hline Wet meadow & 0.7 & 0.0 & 0.6 & 0.0 & 1.1 & 0.5 \\
\hline Pasture-hayfield & 6.3 & --0.0 & --0.0 & -0.9 & --0.0 & -0.2 \\
\hline North slope clearcut & 2.7 & 9.5 & 1.2 & 0.9 & 1.1 & 2.5 \\
\hline Road & 2.0 & 1.4 & 3.1 & 0.9 & 0.0 & 1.6 \\
\hline PSME/Bunchgrass & 5.7 & 1.4 & --0.0 & --0.0 & 6.8 & 1.6 \\
\hline PSEM/VACA & 13.0 & --1.4 & 7.4 & 6.2 & 6.8 & -5.9 \\
\hline PSMA/ PHMA & 2.3 & 10.8 & 5.5 & 5.3 & 5.7 & 6.4 \\
\hline PSME/VAGL & 1.3 & 5.5 & 0.6 & 2.7 & 2.3 & 2.3 \\
\hline PSME/LIBO & 10.7 & 10.8 & 11.0 & 12.4 & 6.8 & 10.5 \\
\hline PSME/SYAL & 18.0 & 12.2 & 14.1 & 14.2 & 9.1 & 12.8 \\
\hline PSME/CARU & 8.7 & 23.0 & +26.4 & 10.6 & 14.8 & $t+19.4$ \\
\hline ABLA/CACA & 2.7 & 0.0 & 0.0 & 0.9 & 2.3 & 0.7 \\
\hline ABLA/LIBO & 4.3 & 12.2 & 7.4 & 10.6 & +17.0 & +11.0 \\
\hline ABLA/MEFE & 11.3 & 4.1 & -3.7 & 11.5 & 12.5 & 7.5 \\
\hline ABLA/XETE-VAGL & 6.7 & 4.1 & 9.2 & 12.4 & --0.0 & 7.3 \\
\hline ABLA/XETE-VASC & 0.3 & 1.4 & +6.1 & 5.3 & +11.4 & +6.2 \\
\hline other & 1.9 & 1.4 & 2.5 & 2.7 & 1.1 & 2.0 \\
\hline
\end{tabular}

those of the summer season with use significantly less than availability for the 1.0 to 1.5 mile $(1.6-2.4 \mathrm{~km})$ interval. There was à shift to proportionally less use within the 0.5 to 1.0 mile $(0.8-1.6 \mathrm{~km})$ interval. Use during the hunting season was proportional to availability except for the last two intervals. The interval from 1.5 to 2.0 miles $(2.4-3.2 \mathrm{~km})$ received significantly less use than availability, the interval greater than 2.0 miles $(3.2 \mathrm{~km})$ received greater use.

Table 29. Percentages of availability and elk use related to logging and road building activities in the study area, 1980 .

\begin{tabular}{|c|c|c|c|c|c|c|c|c|}
\hline \multirow{2}{*}{$\begin{array}{l}\text { Distance } \\
\text { to } \\
\text { activity } \\
\text { in miles }\end{array}$} & \multicolumn{2}{|c|}{ Calving } & \multicolumn{2}{|c|}{ Summer } & \multicolumn{2}{|c|}{ Rut } & \multicolumn{2}{|c|}{ Hunt } \\
\hline & $\begin{array}{l}\text { Avail. } \\
\text { N } 300\end{array}$ & $\begin{array}{l}\text { Use } \\
74\end{array}$ & $\begin{array}{c}\text { Avail } \\
300\end{array}$ & $\begin{array}{l}\text { Use } \\
163\end{array}$ & $\begin{array}{c}\text { Avail } \\
300\end{array}$ & $\begin{array}{l}\text { Use } \\
113\end{array}$ & $\begin{array}{c}\text { Avail } \\
300\end{array}$ & $\begin{array}{r}\text { Use } \\
88\end{array}$ \\
\hline $0.0-0.5$ & 13.8 & 17.6 & 27.9 & --13.5 & 24.4 & -12.4 & 11.0 & 14.8 \\
\hline $0.5-1.0$ & 20.7 & 14.9 & 24.6 & 25.8 & 29.8 & 22.1 & 21.9 & 18.2 \\
\hline $1.0-1.5$ & 29.2 & 35.1 & 25.9 & +38.0 & 23.4 & +34.5 & 25.2 & 21.6 \\
\hline $1.5-2.0$ & 22.6 & 13.5 & 11.3 & 14.7 & 12.4 & 23.9 & 23.6 & --9.1 \\
\hline$>2.0$ & 13.8 & 18.9 & 10.3 & 8.0 & 10.0 & 7.1 & 18.3 & ++36.4 \\
\hline
\end{tabular}


. 
Distance to new roads in the CSA was also measured for each location. Locations that were on the opposite side of a major ridge from the new roads within the CSA were removed from this analysis. This method places greater emphasis upon elk locations within the main ridge system surrounding the CSA in respect to new roads. A11 locations were then analyzed in respect to their position within or outside this ridge system. In respect to the latter analysis, $44 \%$ of the study area is available within this major ridge system. Use was proportional to availability for the calving and hunting seasons. However, use outside the ridge system was significantly greater than availability for summer ( $(+)$, rut $(+)$ and for all seasons combined ( + ). Locations within the major ridge system are shown in Table 30. During the calving season, use was significantly less than availability for the intervals from $0-150$ yards $(0-140 \mathrm{~m})$ and $550-950$ yards $(500-870 \mathrm{~m})$ and significantly greater than availability for areas greater than 1350 yards $(1230 \mathrm{~m})$ from a new road. During the summer seasons, all areas less than 950 yards $(870 \mathrm{~m})$ from a new road were used significantly less than availability. The areas greater than 1350 yards $(1230 \mathrm{~m})$ were used significantly more than available. For the rutting season, use was again significantly greater than availability for the areas farthest from new roads and less than availability for the 550-950 yard (500-870 m) interval. During the hunting season, use was proportional to availability for all categories except the interval from 150 to 550 yards $(140-500 \mathrm{~m})$ in which use significantly exceeded availability. For all seasons combined, use was significantly less than availability for the intervals from 0 to 150 yards $(0-140 \mathrm{~m})$ and 550 to 950 yards $(500-870 \mathrm{~m})$ and significantly greater than availability for the areas more than 1350 yards $(1230 \mathrm{~m})$ from a new road.

Table 30. Percentages of availability and elk use related to distance to new roads in the CSA, 1980.

\begin{tabular}{|c|c|c|c|c|c|c|}
\hline \multirow{2}{*}{$\begin{array}{c}\text { Distance to } \\
\text { new road } \\
\text { in yards (meters) }\end{array}$} & \multirow{2}{*}{$\begin{array}{c}\% \\
\text { Availa- } \\
\text { bility } \\
\text { N } 132\end{array}$} & \multicolumn{5}{|c|}{$\%$ Elk Use } \\
\hline & & $\begin{array}{c}\text { Calving } \\
32\end{array}$ & $\begin{array}{c}\text { Summer } \\
53\end{array}$ & $\begin{array}{c}\text { Rut } \\
30\end{array}$ & $\begin{array}{c}\text { Hunt } \\
34\end{array}$ & $\begin{array}{c}\text { Total } \\
149\end{array}$ \\
\hline $0-150(0-14$ & 15 & - & -- & & 8 & -- \\
\hline $150-550(140-500)$ & 21.2 & 21.9 & --3.8 & 23.3 & +47.1 & 21.5 \\
\hline $550-950(500-870)$ & 47.7 & --15.6 & --5.7 & --3.3 & 26.5 & --12.1 \\
\hline $950-1350(870-1230)$ & 13.6 & 15.6 & 22.6 & 13.3 & 5.9 & 15.4 \\
\hline$>1350 \quad(>1230)$ & 15.0 & ++46.9 & ++66.0 & ++53.3 & 11.8 & +47.0 \\
\hline
\end{tabular}

Vehicular use on the majority of the open roads within the study area was light (less than 1 vehicle trip/day) during 1980. However, several roads associated with the logging and road construction activities mentioned previously received heavy (5-9 vehicle trips/day) traffic. The East Fork of Chemberlain Creek received heavy traffic throughout the year. The first half mile of the West Fork of Chamberlain Creek road received heavy traffic from calving to the start of hunting season. The main Chamberlain Creek road within the CSA received heavy use from the 

middle of July through hunting season. On the west side of the study area, the Fish Creek haul road received heavy use from calving season up to hunting season. In addition to these roads, the main haul road connecting Bear Creek with the Fish Creek haul road was heavily used from mid-summer to hunting season. Table 31 shows the distribution of elk locations with respect to open roads. During all seasons, areas within 150 yards $(140 \mathrm{~m})$ of open roads are used significantly less than their availability. The reverse is true for areas greater than 1350 yards $(1230 \mathrm{~m})$ from open roads for all seasons. During the summer season, use also significantly exceeded availability for areas between 950 yards $(870 \mathrm{~m})$ and 1350 yards $(1230 \mathrm{~m})$.

Table 31. Percentages of availability and elk use related to distance to open roads, 1980 .

\begin{tabular}{|c|c|c|c|c|c|c|c|c|}
\hline \multirow{2}{*}{$\begin{array}{l}\text { Distance } \\
\text { to open } \\
\text { roads } \\
\text { in yards } \\
\text { (meters) } \mathrm{N}\end{array}$} & \multicolumn{2}{|c|}{ Calving } & \multicolumn{2}{|c|}{ Summer } & \multicolumn{2}{|c|}{ Rut } & \multicolumn{2}{|c|}{ Hunt } \\
\hline & $\begin{array}{c}\text { Avail. } \\
300\end{array}$ & $\begin{array}{l}\text { Use } \\
74\end{array}$ & $\begin{array}{c}\text { Avail. } \\
300\end{array}$ & $\begin{array}{l}\text { Use } \\
163\end{array}$ & $\begin{array}{c}\text { Avail } \\
300\end{array}$ & $\begin{array}{l}\text { Use } \\
113\end{array}$ & $\begin{array}{c}\text { Avail } \\
300\end{array}$ & $\begin{array}{r}\text { Use } \\
87\end{array}$ \\
\hline \multicolumn{9}{|l|}{$0-150$} \\
\hline $\begin{array}{c}(0-140) \\
150-550\end{array}$ & 41.1 & --14.9 & 54.6 & --20.2 & 54.6 & $--13 \cdot 3$ & 27.6 & -3.4 \\
\hline $\begin{array}{c}(140-500) \\
550-950\end{array}$ & 37.6 & 32.4 & 32.0 & 40.5 & 32.0 & 23.0 & 29.3 & 19.5 \\
\hline $\begin{array}{c}(500-870) \\
950-1350\end{array}$ & 12.0 & 12.2 & 8.9 & 14.1 & 8.9 & 8.0 & 27.7 & 21.8 \\
\hline $\begin{aligned} & (870-1230) \\
> & 1350\end{aligned}$ & 7.0 & 6.8 & 3.4 & +17.8 & 3.4 & 9.7 & 14.5 & 10.3 \\
\hline$(>1230)$ & 2.3 & +33.8 & 1.1 & +7.4 & 1.1 & +46.0 & 1.4 & $H 44.8$ \\
\hline
\end{tabular}

Elk use of the study area as related to logging history is presented in Table 32. The majority of locations except during the calving season occurred in areas that are unlogged or logged more than 30 years ago.

However, these values approximated availability except during the hunting season in which significantly more use was made of unlogged areas. Non-forested areas were consistently used significantly less than availability. The only other significantly different use pattern occurred during the calving season, during which elk made more use of areas cut in the last decade. 

Table 32. Percentages of availability and elk use related to logged areas, 1980.

\begin{tabular}{|c|c|c|c|c|c|c|}
\hline \multirow{3}{*}{$\begin{array}{l}\text { Time of } \\
\text { logging }\end{array}$} & \multirow{2}{*}{$\begin{array}{c}\% \\
\text { Availa- } \\
\text { bility }\end{array}$} & \multicolumn{5}{|c|}{$\%$ E1k Use } \\
\hline & & Calving & Summer & Rut & Hunt & Total \\
\hline & $\mathrm{N} \quad 300$ & 74 & 162 & 113 & 88 & 437 \\
\hline $1970-1980$ & 14.0 & ++28.4 & 20.4 & 12.4 & 13.6 & 18.3 \\
\hline $1960-1969$ & 8.7 & 23.0 & 9.3 & 7.1 & 3.4 & 9.8 \\
\hline 1950-1959 & 6.0 & 4.1 & 3.1 & 9.7 & 6.8 & 5.7 \\
\hline Pre-1949 & 34.4 & 24.3 & 40.7 & 35.4 & 27.3 & 33.9 \\
\hline Unlogged & 27.3 & 18.9 & 26.5 & 34.5 & ++46.6 & 31.4 \\
\hline Non-forested & 9.7 & --1.4 & --0.0 & --0.9 & --2.3 & --0.9 \\
\hline
\end{tabular}

Relative Hunter Use and Elk Harvest

The study area is in Hunting District 292. It is also largely within the Blackfoot Special Management Area (BSMA), where roads are closed to public vehicular access from 1 September through 1 December. Either sex archery hunting for $\mathrm{elk}$ was allowed in the area from 6 September through 12 October 1981. Also, there was a general hunting season for antler males and for either sex by permit only from 19 october through 30 November. The number of either sex permits remained at 75 in 1980 , and they were valid only in the eastern part of H.D. 292.

The total number of hunters checked at the Bonner check station increased 25\%, from 4879 in 1979 and 4876 in 1978, to 6012 in 1980 (Hartkorn 1980). This check station serves a much wider area than H.D. 292, but results from the station show the hunting trends for the general area. The known number of elk harvested in and near the BSMA increased 50\% from 50 animals per year in 1978 and 1979, to 75 in 1980. Forty-three of the elk taken during 1980 were killed within the BSMA, and 32 were from nearby surrounding areas. Only one elk, a female, was taken during the archery season. Forty-three (58\%) of the elk harvested in 1980, were males ( 21 spikes and 22 branch-antlered), 25 (33\%) were females, and 7 (9\%) were calves.

\section{DISCUSSION}

Five years of pellet count data on all transects in the core study area (CSA) have now been acquired. Even though the levels of human disturbance in the CSA have increased since 1978, many of our early results and conclusions based on pre-disturbance data ( Scott 1978, and Marcum et al. 1979) are still valid after including the 1980 data. A 

combination of weather and vegetative composition, structure, and phenology are still the primary factors influencing habitat use patterns by elk in the CSA, as well as total use of the CSA. Though not necessarily a cause and effect relationship, we continue to show a very high correlation between precipitation and elk use of the CSA. None of the habitat components have been preferred throughout all years and seasons, but elk continue to make almost universal use of the available habitats in the CSA. However, elk use has been consistently less than availability on areas greater than 450 yards $(410 \mathrm{~m})$ from water, small diameter lodgepole pine stands (pole-sapling successional stage), and primary upper slopes and ridgetops. Except during the fall and the spring of wet years (1978 and 1980), elk use of steep slopes $\left(>30^{\circ}\right)$ has also been less than availability.

Fall elk use in the CSA has been evaluated since 1978 by using the ovo pellet count from the following spring. E1k use during fall 1979 was over twice the fall 1978 use. Fall 1979 was unusually warm and dry. In normal years elk are more attracted to relatively xeric sites, largely outside the CSA, by late September or early October. Though the level of use changed, the patterns of elk use of the CSA during fall months of 1978 and 1979 were similar and not highly selective. Use was greatest at elevations of 5700-6200 feet (1740-1890 m), on gentle $\left(0-15^{\circ}\right)$ mid-slopes or secondary upper slopes and ridges, and on westerly aspects. Use during both falls was significantly greater than availability for bunchgrass understories, and significantly less than availability for understories dominated by grouse wortleberry. However, the use of dense tree stands and old successional stages was greater during fall 1979 than during fall 1978. Generally, it appears that elk may be less vulnerable to hunters during years when the fall months are warmer and drier than normal.

During the springs of 1980 and 1978, which were relatively wet, elk preferred northern subunits at lower elevations ( $<5700$ feet, $1740 \mathrm{~m}$ ), moderate to steep slopes $\left(16-38^{\circ}\right)$, and old stands of large Douglas-fir in Douglas-fir habitat types with more xeric understory species. Conversely, during the very dry spring of 1977 , southern CSA subunits at higher elevations (>5700 feet, $1740 \mathrm{~m}$ ), gentle slopes $\left(0-15^{\circ}\right.$ ), and young stands of medium to large lodgepole pine in subalpine fir habitat types with mesic understory species were preferred by elk. Spring 1979 was slightly dry, and the amount and patterns of habitat use by elk in the CSA were intermediate to those of 1977 as compared to 1978 and 1980. A1so, habitat use patterns by elk in spring months are more selective during wet years than dry ones. Although influenced by sample size, spring elk use was significantly different from availability for 26 habitat components in 1978 and 34 in 1980, as compared to 10 and 16 for the dry years of 1979 and 1977 respectively. Spring habitat use by $e 1 k$ in the CSA was similar during all 4 years considered for some habitat components. Use was always greater than availability on areas with less than $25 \%$ overstory canopy cover, including clearings; sight 

distances of greater than 100 yards $(91 \mathrm{~m})$; and old successional stages. Use was always less than availability for areas greater than 450 yards $(410 \mathrm{~m})$ from water and areas with the understory dominated by grouse whortleberry.

The summer 1980 pellet count data support the results and conclusions presented previously (Scott 1978, Marcum et al. 1979 and 1980). From spring to summer, elk use tends to increase in more mesic habitats at higher elevations. However, habitat use in the CSA during moist summers may be similar to use during wet springs, except for the increased summer use of areas with greater overstory canopy coverage. During years when precipitation was greater than normal such as 1976, 1978 and 1980, and even somewhat drier than normal as during 1979, there was relatively less selectivity of the various habitat components in summer. During these years, the number of cases that summer use of habitat components by elk in the CSA differed significantly from availability ranged from on $1 y$ 8 to 12 . In contrast, during the drought year of 1977 , 46 significant differences were recorded in summer. Also, this differs from the spring results, discussed above, in that spring habitat selectivity by Chamberlain Creek elk is greater during wet years.

In many ways, the patterns of summer habitat use by elk in the CSA have been similar for all years. This is especially true for categories of elevation, slope, aspect, topography, and distance to water. But, it is also true for many of the vegetative habitat categories. The greatest variations in summer use of the CSA were in the total amount of use, and in the relative selectivity of mesic plant communites. In dry years elk move to wet areas in the CSA earlier, and stay longer. This was especially evident during the very dry summer of 1977 . Summer elk use of the CSA in 1977 was approximately 3 times greater than summer use during the wettest years of 1976 and 1980. Precipitation during 1978 and 1979 was intermediate to these extremes. Summer 1978 and 1979 elk use was similarly intermediate to use during the wetter and drier years. Elk in the CSA have demonstrated great adaptability in their use of available habitat to yearly changes in environmental conditions. However, during very dry years their options are much reduced, so they are then more vulnerable to disturbance.

There were no road building or logging activities in the CSA during the 1976 and 1977 seasons, only low levels of intermittent road building during 1978 and 1979, and moderate levels of activity, both roading and logging, during 1980. Last year we reported that pellet count results indicated that $\mathrm{elk}$ avoided areas within 150 yards $(140 \mathrm{~m})$ of new roads in the CSA during all three seasons (Marcum and Lehmkuh1 1980). Although disturbance in the area increased, we did not detect avoidance of areas near new roads by elk this year using the pellet count technique. Since pellet deposition is relatively constant and disturbance is relatively intermittent, this does not mean that the animals are not avoiding the actual disturbance. Telemetry results for 1981 indicate that areas within 150 yards $(140 \mathrm{~m})$ of new roads were avoided. Future results will clarify this relationship. Though areas near roads may be avoided by elk, we have detected no avoidance of 

the subunits where most of roading and logging activity has occurred. In fact, except for summer 1980 , elk use has been significantly greater than availability in the most disturbed subunit (8) during all seasons for the last two years. Elk use of the entire CSA during summer 1980 was somewhat less than we would expect, using precipitation-elk use regression model from last year. However, we did not detect any avoidance by elk of areas where road building and logging activities were greatest, and the correlation between precipitation and elk use was still high after adding the 1980 data. Thus, it does not now appear, that given these levels of roading and logging activities, elk avoided the CSA during 1980 because of human disturbance. As in past years, apparent avoidance of old logged areas and roads by elk could be attributed to other factors of habitat selection, and no distinct patterns of elk distribution with respect to planned logging areas or roads were observed.

As noted previously, the correlation between precipitation and elk use remains high after adding the 1980 pellet count data. We have hypothesized that this relationship is a result of direct weather effects; and indirect effects of weather on forage quality and quantity, both inside and outside the CSA (Marcum et al. 1979). Regardless of the cause-and-effect relationship though, this remains our most valuable tool for evaluation the influence of disturbance on total elk use of the CSA.

Telemetry results for the 1977,1978 and 1979 field seasons were discussed in previous annual reports and by Lehmkuh1 (1981). Use of the CSA by radio-collared elk was relatively less in 1980 than during previous years. However, this pattern of low use was predicted on the basis of annual precipitation (Marcum et al. 1980). The 1980 field season was the wettest season for which telemetry data were recorded. The CSA, which contains a large portion of the high elevation mesic sites within the study area, experiences increasing use with decreasing annual precipitation. Use of the CSA was not significantly different than its availability during the wet 1980 field season. Use of the CSA was significantly greater $(p<0.01)$ than availability for the preceeding years. Use increased from a moderate level during 1978, a moist year, to a very high level during 1977, an extremely dry year. This trend was most evident during the calving and summer seasons in which a large portion of the precipitation fell. Use during 1980 was the lowest for all four field seasons during these two seasons. Precipitation during the rutting and hunting seasons was approximately normal, with use adjusting accordingly. For the rutting season, use of the CSA was the lowest in 1978, followed by 1980 and 1977. Only during the rut of 1979 did the use of the CSA significantly exceed availability $(0.01<\mathrm{p}<0.05)$. Use during the hunting season followed a similar pattern, with 1978 as lowest followed by 1977 and 1980. Use was highest during the dry year of 1979 but significantly exceeded availability $(p<0.01)$ for both 1979 and 1980. As the CSA contains the most continuous, heavy cover and is best insulated against hunter access, this increase in use is probably explained by hunter pressure. 

Values for seasonal distribution and movement statistics varied from year to year. Values for mean and maximum distances between successive locations for the 1980 calving season were intermediate to high values for 1979 and low values for 1978. Home range area during the 1980 calving season was the highest value for the four years with 1978 being the lowest. The 1980 summer movement and area statistics were all intermediate between high values in 1978 and low values in 1977 and except for home range area, were larger than the 1979 values. The mean distance moved between successive locations during the 1980 rut was the highest value of all four years. The maximum movement for this season was the smallest of all four years compared to the high in 1977. The home range area for the 1980 rut was intermediate between a low in 1979 and a high in 1977. A11 home range and movement statistics for the 1980 hunting season were the highest observed throughout the four years. The lowest home range value for this season occurred in 1978. Maximum distance moved during the hunt was lowest for 1977, and mean distances were lowest for 1977 and 1978. When considering al1 locations from May to December for the four years, al1 movement and home range statistics were highest during 1977 and lowest during 1980.

Yearly differences in home range and movement statistics are probably a function of weather, forage availability, disturbance and hunter pressure. For the calving, rut and all seasons combined, the pattern may best be explained on the basis of differences in yearly precipitation. In general, home ranges and movements were largest in the dry year of 1977 . These dry conditions probably affected plant communities, causing them to mature earlier. This would affect forage availability and hence require elk to range further. A reversal of this trend occurred during the summer season of 1977, for which the lowest home range and movements were recorded. A large majority of locations (79.9\%) for that period were above 5700 feet in elevation, an area which comprises on 1 y $19.9 \%$ of the study area. The majority of preferred forage probably fell within these higher elevation areas, and hence limited animal movements. The trend for hunting seasons has been one of general increase of home range and movement statistics over the four years of study. Hunting pressure in this area has followed a similar trend. This trend alone probably accounts for this pattern. However, during the 1980 hunting season, two units were being logged on the east side of Chamberlain drainage and road construction was underway on the west side of the drainage. A combination of factors including hunter pressure, hunter camps, disturbance and elk habituating to safety zones probably accounted for the 1980 home range and movement statistics during the hunting season being much larger than previous values.

The 1980 season again reaffirms the disproportionate use of the CSA by the two trap-site groups. For all four years, the Grace's Landing group consistently used the CSA more than the Lindbergh-Potter group. Excluding one location, very little overlap occurred between the two composite home range groups. Future logging activities within the CSA 

will probably impact the Grace's Landing animals to a greater extent than the Lindbergh-Potter animals.

Individual and composite home ranges and movement statistics for elk vary for different study areas. The composite May to December home range $q^{f}$ all Chamberlain elk has been between 70-100 miles $\left(182-260 \mathrm{~km}^{2}\right)$ over the past four years. Since this area includes the winter range used by the study animals, it may be considered a yearround home range. Lonner (1980) reported a ${ }_{2}$ year-round composite home range for 36 animals of 685 miles $^{2}\left(1781 \mathrm{~km}^{2}\right)$. A composite year-rqund home range for $9 \mathrm{elk}$ in the Madison Valley was 568 miles $\left(1471 \mathrm{~km}^{2}\right.$ ) (Cada 1978). Seasonal averages of home range, movement statistics and standard diameters reported by Lonner were consistent1y larger than those found in this study. Craighead et al. (1973) reported average home ranges for $11 \mathrm{e} 1 \mathrm{k}$ in Yellowstone National Park that were smaller year-round but seasonally larger for spring and summer-fall than for Chamberlain elk. These authors also report a general increase in seasonal home ranges from spring to fall as was found in this study. Pedersen et a1.(1980) report a mean composite home range of 21.5 miles $^{2}$ $\left(28 \mathrm{~km}^{2}\right.$ ) for adult female elk on a summer range in the Blue Mountains of Oregon. Considering the difference in composite home ranges for Lindbergh-Potter and Grace's Landing animals of this study, the differences between the Chamberlain Creek study and the last two cited are relatively small. The large discrepancies in composite home ranges is best explained by the migratory tradition of the elk in the other studies (i.e., Lonner and Cada) (Knight 1980). Differences in average home ranges and movements of individual elk is probably a function of differences in habitat from one study area to another.

Habitat utilization by radio-collared elk from May to December was quite variable from 1977 through 1980. However, a number of patterns are apparent with respect to some variables. Radio-collared elk consistently avoided (use significantly less than availability) the lower elevations between 3800 and 4400 feet $(1160-1340 \mathrm{~m})$. The majority of locations for the four years fell between 4500 and 6200 feet (1370$1890 \mathrm{~m})$. During 1977, 1978, and 1979, elevations between 5700 and 6200 feet $(1740-1890 \mathrm{~m})$ were used in excess of availability $(p<0.01)$. The next lower elevations (5100-5600 feet; 1550-1700 m) were used in excess of availability $(\mathrm{p}<0.01)$ for the 1978, 1979, and 1980 field seasons. Use of slope positions was quite variable. This may be partly due to the subjective nature of position classification, especially with respect to what constitutes a drainage head. Analyses from previous years considered the drainage head classification to be more limited than did the analysis for this year. However, ridge tops and mid to upper slopes account for the majority of locations. Lower slopes were consistently used less than availability $(p<0.01)$. In respect to steepness of sloge, the majority of locations as well as availability were between $0-15^{\circ}$, but use was significantly different from availability only twice during the four years. During the 1979 and 1980 field seasons, slopes of less than $15^{\circ}$ were used in excess of 

availability $(\mathrm{p}<0.01)$. The apparent discrepancy between elk preference for gentle slopes and avoidance of level aspects is explained by the fact that the majority of level sites are low elevation pasturehayfields. Topographic configuration varied from year to year. Use was significantly less than availability on straight topography during 1977, 1978, and 1980. Use was significantly greater than availability on concave slopes for two years: 1977 and 1978. Use of convex and undulating slopes generally approximated availability. Distance from water generally had little effect on elk distribution. Areas greater than 550 yards $(550 \mathrm{~m})$ from water were used significantly in excess of availability except during the drought year of 1977. Areas less than 150 yards $(140 \mathrm{~m})$ from water were generally used less than their availability. Significantly less use occurred for the $0-50$ yard $(0-45 \mathrm{~m})$ interval in 1980 and for the $50-150$ yard $(45-140 \mathrm{~m})$ interval during 1977 and 1979. These topographic factors suggest that from May to December, elk tend to prefer higher elevations, particularly ridge tops, mid- and upper-slopes. Except during drought years, close proximity to water does not appear to be a major factor for Chamberlain elk, probably due to general mesic conditions of the study area.

Distribution of radio-collared elk with respect to vegetative factors showed a few patterns for the May to December period. Use was less than availability $(p<0.05)$ in open sites during 1978 and 1979. Otherwise, elk use by overstory canopy coverage class did not vary significantly from availability. Habitat age and composition showed some general trends. Mixed species stands from pole to mature size were consistently used in excess of availability but not significantly. Dense lodgepole stands were consistently used less than availability. The pasture-hayfield habitat classification was avoided by elk $(\mathrm{p}<0.01)$ for all four years. In respect to Montana Forest habitat types, the following patterns were noted. PSME/Bunchgrass types were consistently used less than availability. PSME/VACA and PSME/SYAL types were also used consistent1y less than availability, the former significantly so during 1977,1979 , and 1980 , and the latter during 1977 and 1979. PSME/CARU, ABLA/LIBO and ABLA/XETEVAGL types were always used in excess of availability. With respect to vegetative factors year-round, Chamberlain elk seem to prefer the higher elevation mesic sites with a very general preference for mixed species stands of greater than $25 \%$ canopy coverage.

Habitat utilization by radio elk on a seasonal basis is also highly variable from year to year, but some patterns emerge. Seasonal. elk use of the study area in respect to elevation shows strong patterns. During the calving and all other seasons except the rut, areas between 3800 feet $(1160 \mathrm{~m})$ and 4400 feet $(1340 \mathrm{~m})$ are used less than availability $(p<0.01)$. During calving season, there is a strong preference $(p<0.01)$ for mid-elevations (5100-5600 feet; $1550-1700 \mathrm{~m})$ for all years. This preference shifts to the 5700-6200 feet $(1740-1890 \mathrm{~m})$ interval during the summer season for all years except 1980 , which showed significantly greater use in the 4500-5000 feet $(1370-1520 \mathrm{~m}$ ) 

interval. No pattern for elevation use is evident during the rut, except for use of higher elevations during the warm dry fall of 1979. A general preference for mid- to higher-elevations during the hunting season is apparent. Neither steepness of slope nor aspect show any seasonal pattern throughout the study. Slope position showed a couple of general patterns which were expressed in the May to December analysis. Lower slopes were consistently avoided $(p<0.01)$ during all seasons. Mid- and upper-slopes and ridge tops consistently received the majority of use throughout all seasons, with a general trend from mid-slopes to upper slopes and ridgetops as the seasons progress. Seasonally, distance to water showed no apparent trend. In respect to topographic factors on a seasonal basis, elevation and slope position showed the strongest pattern. With the exception of the rutting season, elk use in general shifts from mid-elevations to higher elevations from calving to hunting season. During the rutting seasons elk were more widely distributed with respect to elevation. Slope position is highly dependent upon elevation and therefore showed a similar trend. The exceptions to this trend occurred during the wet 1980 field season in which slightly lower elevational preference was shown and during the rutting season in which elk were found on a variety of slope positions.

E1k use of vegetative factors from season to season were also quite variable. Habitat use with respect to overstory canopy coverage varied substantially during the calving and summer seasons. During the rut, a general preference was shown for moderate to dense stands with open stands consistently receiving less use than availability. Elk use during the hunting season showed a general shift from moderate to more dense stands from 1977 through 1980. In general, habitat age and species composition trends were described in the May to December analysis with a strong avoidance $(p<0.01)$ of pasture-hayfields throughout all seasons and the majority of use occurring in mixed species stands of pole to mature age. A more specific trend was noted during the hunting season in which elk use in dense mixed species stands accounted for the majority of the locations. Habitat utilization as determined by habitat types varied seasonally from year to year. General patterns were evident, but elk use was not significantly different than availability for any habitat type more than once within a particular season with three exceptions. The consistent avoidance of pasture-hayfields has been previously mentioned. Use of PSME/Bunchgrass types was less than availability during the calving season for all years, significantly so during 1977 and 1979. Except for the 1978 rut, PSME/VACA was consistently used less than availability, with significant differences occurring during the 1979 and 1980 calving seasons, and during the summer and hunting seasons of 1977 and 1979. Additional trends generally appear to be related to yearly precipitation patterns. During the drought year of 1977, the more mesic higher elevation habitat types were generally selected throughout that field season. A general shift to higher elevations andwetter habitat types occurred from calving to summer for all years. During the rut for all years, use approximated availability for most habitat types with the majority of locations 

occurring in Abies lasiocarpa series. Use during the hunting seasons again demonstrated a general preference for higher elevation habitat types. Seasonal use of vegetative factors were difficult to separate from topographic factors, especially elevation, but three patterns were evident. One, more mesic sites were selected for during dry conditions, more xeric sites were not preferred during wet seasons. Two, little habitat preference occurred with respect to vegetative factors during the rut and three, there appeared to be a preference for more dense stands during the hunting season.

Habitat use as related to disturbance showed several seasonal patterns. Distance to non-road disturbances showed a dual pattern. First, as evidenced by availability values, non-road disturbances have become more prominent within the study area from 1978 to 1980 . The 1978 disturbances had little effect on the distribution of elk; use approximated availability for all distance intervals for all seasons. Non-road disturbances during the calving season for all three years showed only one significant value; use less than availability during 1979. These results were probably a function of the distribution of the non-road disturbances which were generally located in areas seldom used by Chamberlain elk during that season. The second pattern was one of general avoidance of non-road disturbances during the summer and rutting seasons of 1979 and 1980. Use was significantly less than availability for areas less than 0.5 miles from a disturbance. In addition, areas more than 2 miles from disturbances were used significantly greater than availability during 1979 and areas between 1.0 and 1.5 miles received more use than availability $(\mathrm{p}<0.05)$ during 1980 .

Due to changes in analysis procedures in 1980, distances to new roads within the CSA cannot be directly compared to previous years until those data are reworked. However, two trends are evident. One, the majority of locations were generally greater than 1350 yards $(1230 \mathrm{~m})$ from a new road and two, few locations occurred within the first 150 yards $(140 \mathrm{~m})$ of a new road.

Distances to open roads generally had little effect on Chamberlain elk during the calving and summer seasons. This primarily is a function of road usage. During 1977, 1978, and 1979 the majority of roads received light (less than one vehicle trip/day) to moderate (1-4 vehicle trips/day) use. This situation changed in 1980 as a result of the widespread logging and road construction within the study area. Use during the 1980 calving and summer seasons was less than availability $(p<0.01)$ for areas less than 150 yards $(140 \mathrm{~m})$ from an open road and significantly greater than availability for areas further than 1350 yards $(1230 \mathrm{~m})$ from an open road. During the rut and hunting seasons, areas closest to open roads were consistently avoided $(p<0.01)$ and areas greater than 1350 yards $(1230 \mathrm{~m})$ consistently received more use $(\mathrm{p}<0.01)$.

Elk use related to logging history followed a general pattern irrespective of season. Non-forested areas were consistently used significantly less than availability throughout all years and seasons. 

Uncut areas generally received more use than availability. These values are significantly greater than availability during the summers of 1977 , 1978, and 1979, during the rut of 1977 and 1979 and during the hunting season of 1978, 1979, and 1980. A third trend is one of avoidance of areas cut prior to 1949 , significantly so during the summers of 1977 and 1978, and during the hunting season of 1977, 1978, and 1979. This avoidance is primarily a function of those areas generally being at lower elevations, which are not used much during summer months and which are relatively near to hunter access points.

The Blackfoot Management Area (BSMA) continues to be a popular hunting area, and use still seems to be increasing. Some cooperators have expressed concern over problems which would arise if hunter use continues to increase in the future. However, no irreconcilable problems have arisen yet. Since the harvest of females was limited, the substantial one year increase in the elk harvest in 1980 was probably not detrimental to the population. 

Cada, J. D. 1978. Gallatin big game studies. Mont. Dept. Fish and Game, Helena, MT. Proj. No.W-130-R-8, Job No. I-3.1. 64 pp.

Craighead, J. J., F. C. Craighead, Jr., R. L. Ruff, and B. W. O'Gara. 1973. Home ranges and activity patterns of nonmigratory elk of the Madison Drainage herd as determined by biotelemetry. Wildl. Monogr. 33. $50 \mathrm{pp}$.

Harrison, J. L. 1958. iange of movement of some Malayan rats. J. Mamma1. 38(3):190-206.

Hartkorn, F. 1980.. Personal communications concerning hunters and elk harvest through the Bonner check station.

Knight, R. R. 1970. The Sun River elk herd. Wildl. Monogr. 23. 66 pp.

Lehmkuhl, J. F. 1981. Distribution and habitat selection of elk in the north Garnet Mountains of western Montana. M.S. Thesis. Univ. of Mont., Missoula. In press.

Lonner, T. N. 1976. Job II-B, Long Tom Creek Study. Pages 15-56 in Ann. Prog. Rpt. of Mont. Coop. Elk-Logging Study.

- 1980. Job II-B, Long Tom Creek Study. Pages 4-38 in

Ann. Prog. Rpt. of Mont. Coop. Elk-Logging Study.

Lyon, L. J. 1973a. Job II-A, Proc. B-1, Conduct annual pellet count surveys to describe elk distribution patterns within the Burdette Creek-Deer Creek area. Pages 26-45 in Ann. Prog. Rpt. of Mont. Coop. Elk-Logging Study.

- 1973b. Job II-A, Proc. A-1, Burdette Creek-Deer Creek vegetation analysis. Pages 7-25 in Ann. Prog. Rpt. of Mont. Coop. Elk-Logging Study.

Marcum, C. L. 1975. Summer-fall habitat selection and use by a western Montana elk herd. Ph.D. dissertation, Univ. of Mont., Missoula. $188 \mathrm{pp}$.

, J. F. Lehmkuhl, and M. D. Scott. 1979. Job II-D, Chamberlain Creek Study. Pages 38-108 in Ann. Prog. Rpt. of Mont. Coop. Elk-Logging Study.

, and J. F. Lehmkuhl . 1980. Job II-D, Chamberlain Creek Study. Pages 39-84 in Ann. Prog. Rpt. of Mont. Coop. Elk-Logging Study.

and D. O. Loftsgaarden. 1980. J. Wild1. Manage. 44(4):963- 

Nie, N. H., C. H. Hull, J. G. Jenkens, K. Steinbrenner, and D. H. Bent. 1975. SPSS:Statistical package for the social sciences. Second edition. McGraw-Hill, Inc., New York. 675 pp.

Pedersen, R. J., A. W. Adams, J. M. Skovlin. 1980. Elk habitat uses in an unlogged and logged forest environment. Wild1. Res.

Rpt. No. 9. Oregon Dept. of Fish and Wildlife. Portland, OR. $121 \mathrm{pp}$.

Pfister, R. D., B. L. Kovalchik, S. F. Arno, and R. C. Presby. 1977. Forest habitat types of Montana. Intermountain For. and Rge. Expt. Sta. and U.S.D.A. Forest Service. Gen. Tech. Rpt. INT-34. May 1977. 174 pp.

Scott, M. D. 1978. Elk habitat selection and use on an undisturbed summer range in western Montana. M.S. Thesis. Univ. of Mont., Missoula. $98 \mathrm{pp}$.

Snedecor, G. W., and W. G. Cochran. 1967. Statistical methods:sixth edition. The Iowa St. Univ. Press, Ames. 593 pp.

Steele, R. W. 1981. Weather data summary 1957 through 1980, Lubrecht Experimental Forest, Greenough, MT. Mont. For. and Cons. Expt. Sta. Misc. Paper No. 13. School of Forestry, Univ. of Montana, Missoula.

Thomas, J. W., H. Black, Jr., R. J. Scheizinger, and R. J. Pedersen. 1979. Deer and elk. p. 104-127 in J. W. Thomas (ed.) Wildlife habitats in managed forest. U.S.D.A. Agr. Hdbk. No. 553.512 pp.

Submitted by: C. Les Marcum

W. Daniel Edge 



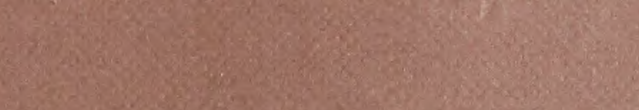

a.t.

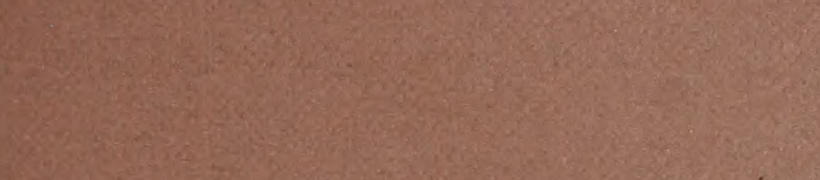

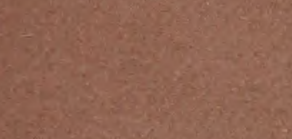

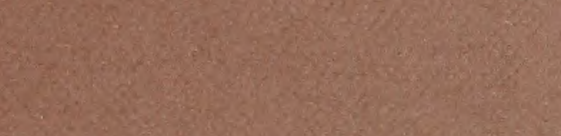


